\title{
Heart failure in nursing home residents
}

\author{
Citation for published version (APA):
}

van der Velden - Daamen, M. (2016). Heart failure in nursing home residents: Prevalence, diagnosis and treatment. [Doctoral Thesis, Maastricht University]. Datawyse / Universitaire Pers Maastricht. https://doi.org/10.26481/dis.20161012mv

Document status and date:

Published: 01/01/2016

DOI:

10.26481/dis.20161012mv

Document Version:

Publisher's PDF, also known as Version of record

\section{Please check the document version of this publication:}

- A submitted manuscript is the version of the article upon submission and before peer-review. There can be important differences between the submitted version and the official published version of record.

People interested in the research are advised to contact the author for the final version of the publication, or visit the DOI to the publisher's website.

- The final author version and the galley proof are versions of the publication after peer review.

- The final published version features the final layout of the paper including the volume, issue and page numbers.

Link to publication

\footnotetext{
General rights rights.

- You may freely distribute the URL identifying the publication in the public portal. please follow below link for the End User Agreement:

www.umlib.nl/taverne-license

Take down policy

If you believe that this document breaches copyright please contact us at:

repository@maastrichtuniversity.nl

providing details and we will investigate your claim.
}

Copyright and moral rights for the publications made accessible in the public portal are retained by the authors and/or other copyright owners and it is a condition of accessing publications that users recognise and abide by the legal requirements associated with these

- Users may download and print one copy of any publication from the public portal for the purpose of private study or research.

- You may not further distribute the material or use it for any profit-making activity or commercial gain

If the publication is distributed under the terms of Article $25 \mathrm{fa}$ of the Dutch Copyright Act, indicated by the "Taverne" license above, 
Heart failure in nursing home residents

Prevalence, diagnosis and treatment 
The research presented in this dissertation was conducted at the School for Public Health and Primary Care (CAPHRI), department of Health Services Research, Maastricht University. CAPHRI is part of the Netherlands School of Primary Care Research (Care), which was been acknowledged by the Royal Netherlands Academy of Science (KNAW).

This work was supported by a grant from the Dutch Organization for Health Research and Development (ZonMw grant number 60-61900-98-303).

ISBN: 9789461595966

(c) Copyright Mariëlle Daamen, Maastricht 2016

Cover: Daan Halters www.grizzlie.nl

Layout and printing: Datawyse / Universitaire Pers Maastricht 


\title{
Heart failure in nursing home residents
}

\section{Prevalence, diagnosis and treatment}

\author{
Proefschrift
}

\begin{abstract}
ter verkrijging van de graad van doctor aan de Universiteit Maastricht, op gezag van de Rector Magnificus, Prof. dr. Rianne M. Letschert, volgens het besluit van het College van Decanen, in het openbaar te verdedigen op woensdag 12 oktober 2016 om 16.00
\end{abstract}

door Anna Maria Johanna Daamen 


\section{Promotores}

Prof. dr. JMGA Schols

Prof. dr. JPH Hamers

Prof. dr. HP Brunner-la Rocca

\section{Beoordelingscommissie}

Prof. dr. MGA oude Egbrink (voorzitter)

Prof. dr. J Gussekloo (Leids University Medical Center)

Prof. dr. CMPM Hertogh (VU University Medical Center, Amsterdam)

Dr. BL Kietselaer

Dr. SMG Zwakhalen 


\section{Contents}

Chapter 1 General introduction

7

Chapter 2 Prevalence of Heart Failure in Nursing Homes: a Systematic

Literature Review

Published in Scandinavian Journal of Caring Sciences. 2010;24:202-8.

Chapter 3 Study protocol The prevalence and management of heart failure in

Dutch nursing homes; design of a multi-centre cross-sectional study

Published in BMC Geriatrics. 2012;12:29.

Chapter 4 Heart failure in nursing home residents; a cross-sectional study to determine the prevalence and clinical characteristics

Published in BMC geriatrics. 2015;15:167

Chapter 5 Diagnosis of heart failure in nursing home residents: Do we need a cardiologist?

Submitted for publication

Chapter 6 Treatment of heart failure in nursing home residents

Published in Journal of Geriatric Cardiology. 2016;13:44-50

Chapter 7 General discussion

Summary

109

Samenvatting

Valorization Addendum

Dankwoord

About the author

Publications 



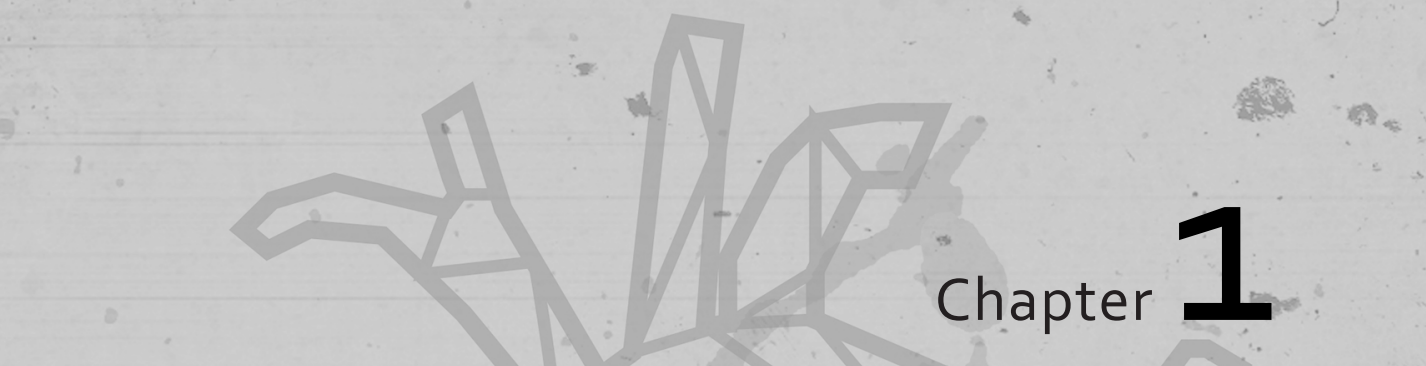

General introduction 



\section{INTRODUCTION}

This thesis focuses on heart failure (HF) in nursing home residents. HF is a clinical syndrome which arises because of the inability of the heart to pump a sufficient amount of blood in the circulation in relation to the body's need. Signs and symptoms may arise directly or indirectly from reduced function of the heart and include amongst others shortness of breath on exertion, fatigue and reduced exercise tolerance. These cause limitations in patients daily activities and lead to reduced quality of life.(1) Quality of life is a very important issue for nursing home residents. The perceived quality of life of nursing home residents is mainly determined by the physical health status, functional disabilities and altered social contacts.(2) HF has a negative influence on all of these domains. $(3,4)$

The prevalence of HF increases with age. In the general population the prevalence is estimated to be $3-13 \%$ for those over 65 years.(5) Both improved survival of patients with coronary heart disease and an ageing population contribute to an increasing elderly population with HF.(6) As nursing home residents are specifically characterized by high age, associated with considerable morbidity, it is expected that HF is prevalent in this target group.

The focus of nursing home care itself lies on improvement of symptoms and quality of life. Therefore, knowledge regarding HF is particularly relevant in nursing home residents, which is unfortunately up until now, largely lacking. This thesis reports on the prevalence, diagnosis and treatment of HF in nursing home residents. Within this first chapter relevant background information is provided about HF in general and more specifically about nursing home residents and nursing home care. Finally the outline and research questions of the thesis are presented.

\section{HEART FAILURE}

Heart failure (HF) is defined as a clinical syndrome with typical symptoms (e.g. breathlessness, ankle swelling, and fatigue) and signs (e.g. elevated jugular venous pressure, pulmonary crackles). It can be caused by any structural or functional cardiac or noncardiac disorder that impairs the ability of the heart to respond to physiological demands for increased cardiac output. $(7,8)$ The main causes of HF are: coronary artery disease (usually myocardial infarction), hypertension, valvular heart disease (mostly mitral regurgitation and aortic stenosis), cardiomyopathies and arrhythmias, mainly atrial fibrillation.(9) Various factors such as old age, hypertension, diabetes mellitus, obesity and coronary disease have been described as risk factors for developing HF. $(10,11)$ The latest guidelines of the European Society of Cardiology $(2012)$ and the American College of Cardiology/American Heart Association (2013) present recommendations about how HF should be diagnosed and treated. $(7,8)$ To diagnose HF, a 
structured diagnostic workup including history, physical examination, electrocardiography (ECG), assessment of cardiac markers (natriuretic peptides) and an echocardiography is recommended for each patient. In addition, there are two different types of HF: HF with reduced left ventricular systolic function (HFrEF) and HF with preserved left ventricular systolic function (HFpEF). The systolic function of the left ventricle can be considered as its ability to generate pressure and produce the stroke volume.(12) In HFpEF filling of the left ventricle is reduced resulting in inability of the heart to provide the necessary cardiac output to support normal body functions.(13) Patients with HFpEF are usually older, more likely to be women and more likely to have premorbid hypertension.(14) HF with preserved ejection fraction is present in more than half of all HF patients. (15) HFrEF is considered as reduced cardiac output by impaired contractility of the left ventricle, mostly due to myocardial damage. It is characterized by increased left ventricular volumes to compensate for the reduced ejection fraction.(12)

HF can be treated pharmacologically and non-pharmacologically. Evidence based pharmacological treatment is only available for HF with reduced ejection fraction (HFrEF) and compromises the use of an angiotensin converting enzyme (ACE)inhibitor or angiotensin-receptor antagonist if not tolerated, a beta blocker and a mineralocorticoid-receptor antagonist. A diuretic should be used to control fluid overload. Available studies of evidence based treatment of HF mostly concerned effects on mortality and hospital admissions.(16) Additionally, there is also an effect on relieving symptoms and improvement of quality of life.(17) For HF with preserved ejection fraction (HFpEF) however, no specific treatment is established.(18) Apart from treating fluid overload by using diuretic therapy, adequate treatment of underlying diseases such as hypertension, arrhythmias or coronary ischaemia and non-cardiac diseases that may contribute to symptoms is recommended. Non-pharmacological interventions consist of life style changes such as fluid- and sodium restriction, daily weighing, adjustment of activity, smoking cessation, limitation of the amount of alcohol ingested and besides that vaccination against influenza. They are applicable for all HF patients.(19) Importantly, non-pharmacological treatment can have a positive impact on symptoms, functional capacity, well-being, morbidity and even prognosis as explored in symptomatic HF patients with a reduced LVEF.(20)

\section{OLDER PEOPLE AND NURSING HOME CARE}

Currently there are 16.8 million inhabitants in the Netherlands of which $17 \%$ are above the age of 65 and $4 \%$ older than 80 years. (21) Of the people above 65 years, about $3 \%$ live in nursing homes.(22) This thesis specifically focuses on nursing home residents. 
Nursing homes offer complex long-term care to very frail older persons who have physical diseases and/or cognitive disorders that negatively affect the self-care abilities with respect to activities of daily living.(23)

Dutch nursing home care is organized differently as compared to other Western countries. The care is provided by teams of registered nurses, nurse assistants, paramedical professionals and specifically acknowledged and registered nursing home physicians, all employed by the nursing homes themselves. Nursing home care can be characterized as continuing, long-term, systematic and multidisciplinary care (CLSM), provided via an integrated care plan after a thorough and integral assessment of the resident's problems. Most nursing homes have separate wards for residents who mainly have physical diseases including among others stroke, Parkinson's disease etc. (somatic wards) and residents with cognitive impairments, mainly dementia (psychogeriatric care). About $65 \%$ of the beds available are for residents in need of psychogeriatric care and $35 \%$ for residents needing somatic care. The nursing home physician is responsible for the medical care and initiates the different therapeutic interventions.(24) These physicians have completed a three-year post graduate specialisttraining programme to become a qualified nursing home physician (NHP).

\section{HEART FAILURE IN NURSING HOME RESIDENTS}

Several issues should be addressed related to HF in nursing home residents. The prevalence of HF in nursing home residents is expected to be very high because, as mentioned earlier, HF is a disease of older persons. Considering the possible impact of HF on the daily activities and lifestyle of frail nursing home residents, it is essential to understand the extent of the problem. However reliable prevalence data about HF in nursing home residents are lacking because nursing home residents are often excluded from clinical and epidemiological studies.

Different physicians may be involved in diagnosing HF. If older patients are still able to visit a medical specialist, the diagnosis is made mostly by the cardiologist and based on history, physical examination, ECG, cardiac marker and imaging usually echocardiography. However, depending on the living conditions of the older person and their physical limitations referral to a specialist for additional investigation such as echocardiography may be more difficult or even impossible. The general practitioner (GP) may diagnose HF in older people still living in their own homes while a NHP may diagnose HF in older people living in the nursing home. Diagnosing HF by a GP or NHP has several constraints. First, the diagnostic tools of the GP and the NHP to diagnose HF are limited, because they mostly have no direct access to echocardiography. Second, diagnosing HF is complex in older persons and even more so in nursing home residents because basic symptoms of HF may be absent or atypical.(25) Typical signs such as dyspnoea and fatigue may be difficult to recognize or to interpret due to an 
already pre-existing reduction in mobility and comorbidities such as chronic obstructive pulmonary disease or renal dysfunction that may cause these symptoms too.(26) A recent study in the UK showed that the diagnosis of HF made by GPs was only confirmed in 34\% after the use of echocardiography and reviewing all available clinical information.(27)

To the best of our knowledge, it is not known how reliable the diagnosis of HF made by the NHP can be without the use of echocardiography. In addition, it is also not known whether signs and symptoms of possible HF will be recognized by the nursing staff who provide daily care or by the NHPs. It may be expected that in particular the NHP, because of his/her unique position regarding medical care in Dutch nursing homes, has more specific knowledge about chronic diseases such as HF. As a result misdiagnosis might be somewhat lower but uncertainty and faulty diagnosis may still be significant.

Regarding the treatment of HF, it can be expected that the NHP in the nursing home will mainly take care of treatment in nursing home residents. The pharmacotherapy protocol which is most commonly used in nursing homes, is usually drafted within the nursing home itself, but closely derived from available evidence based guidelines, in this case the guidelines of the European Society of Cardiology (2012) and the available national guideline, Multidisciplinary guidelines of heart failure 2010, based on the dated guidelines of the European Society of Cardiology (ESC) of 2008.(7, 28, 29)

The ESC-guidelines are not specifically adapted for frail older persons, as the limited evidence, mainly based on sub-group analyses, does not suggest a significant influence of age on treatment response. Therefore, it is assumed that all heart failure patients should be treated the same.

However, Heckman et al (2004) showed that in Canadian long-term care facilities the pharmacological treatment of HF did not follow the guidelines.(30) Reasons for this could be the greater risk of adverse drug reactions due to the often existing polypharmacy and the other comorbidities in nursing home residents.(31) Furthermore, adequate treatment of HF according to the guidelines may be hampered because the underlying type of HF may not be known. For distinguishing between HFrEF and HFpEF, echocardiography is needed and this is often omitted in nursing home residents.

Although non-pharmacological interventions can have a positive impact on symptoms of HF and functional capacity, it is also not known to what extent they are applied in nursing home residents.

Therefore, as early diagnosis and treatment may prevent the progression of HF and lead to an improvement of the symptoms and quality of life (32), it is of great importance to gain insights into the reliability of diagnosing HF by the NHP and the treatment of HF in nursing home residents. 


\section{AIMS AND OUTLINES OF THE THESIS}

Therefore, the main objective of our study is to gain more insight into the prevalence, diagnosis and treatment of HF in nursing home residents.

The specific aims of the thesis are:

1. To determine the prevalence of HF and the clinical characteristics of nursing home residents with HF.

2. To investigate to what extent it is possible to diagnose HF by the NHP in the nursing home setting without the use of echocardiography.

3. To investigate how HF is currently treated pharmacologically and nonpharmacologically in nursing home residents.

\section{OUTLINE OF THE THESIS}

This thesis comprises seven chapters. The current chapter presents the general introduction which provides background information and the outline of the thesis.

Chapter 2 presents a systematic review of the literature on the prevalence of HF in nursing home residents prior to this project. Chapter 3 describes the study protocol of our study on HF in nursing home residents. Chapter 4 presents the results related to the prevalence of heart failure and the clinical characteristics of nursing home residents with HF (aim 1). Chapter 5 reports about the accuracy of diagnosing HF by nursing home physicians compared to an expert team (aim 2). Chapter 6 shows the current pharmacological and non-pharmacological treatment of nursing home residents with HF (aim 3). Chapter 7 puts the main findings of this thesis into perspective and discusses the main limitations. It concludes with recommendations for clinical practice in nursing homes and future research. 


\section{REFERENCES}

1. Luttik ML, Lesman-Leegte I, Jaarsma T. Quality of Life and Depressive Symptoms in Heart Failure Patients and Their Partners: The Impact of Role and Gender. Journal of Cardiac Failure. 2009 9//;15(7):580-5.

2. Nispen van RMA, Beek van A, Wagner C. Verantwoorde zorg en kwaliteit van leven bij cliënten in verpleeg- en verzorgingshuizen: een kwalitatief onderzoek Nivel, 2005.

3. Iqbal J, Francis L, Reid J, Murray S, Denvir M. Quality of life in patients with chronic heart failure and their carers: a 3-year follow-up study assessing hospitalization and mortality. Eur J Heart Fail. Sep;12(9):1002-8.

4. Hobbs FD, Kenkre JE, Roalfe AK, Davis RC, Hare R, Davies MK. Impact of heart failure and left ventricular systolic dysfunction on quality of life: a cross-sectional study comparing common chronic cardiac and medical disorders and a representative adult population. Eur Heart J. 2002 Dec;23(23):1867-76.

5. Mosterd A, Hoes AW, de Bruyne MC, Deckers JW, Linker DT, Hofman A, et al. Prevalence of heart failure and left ventricular dysfunction in the general population; The Rotterdam Study. Eur Heart J. 1999 Mar;20(6):447-55.

6. Cowie MR, Fox KF, Wood DA, Metcalfe C, Thompson SG, Coats AJ, et al. Hospitalization of patients with heart failure: a population-based study. Eur Heart J. 2002 Jun;23(11):877-85.

7. McMurray JJ, Adamopoulos S, Anker SD, Auricchio A, Bohm M, Dickstein K, et al. ESC Guidelines for the diagnosis and treatment of acute and chronic heart failure 2012: The Task Force for the Diagnosis and Treatment of Acute and Chronic Heart Failure 2012 of the European Society of Cardiology. Developed in collaboration with the Heart Failure Association (HFA) of the ESC. Eur Heart J. 2012 Jul;33(14):1787-847.

8. Yancy CW, Jessup M, Bozkurt B, Butler J, Casey DE, Jr., Drazner MH, et al. 2013 ACCF/AHA guideline for the management of heart failure: executive summary: a report of the American College of Cardiology Foundation/American Heart Association Task Force on practice guidelines. Circulation. 2013 Oct 15;128(16):1810-52.

9. Roger VL, Go AS, Lloyd-Jones DM, Adams RJ, Berry JD, Brown TM, et al. Heart Disease and Stroke Statistics-2011 Update: A Report From the American Heart Association. Circulation. 2011 February 1, 2011;123(4):e18-e209.

10. Lam CS, Donal E, Kraigher-Krainer E, Vasan RS. Epidemiology and clinical course of heart failure with preserved ejection fraction. Eur J Heart Fail. 2011 Jan;13(1):18-28.

11. Kaila K, Haykowsky MJ, Thompson RB, Paterson DI. Heart failure with preserved ejection fraction in the elderly: scope of the problem. Heart Fail Rev. 2012 Sep;17(4-5):555-62.

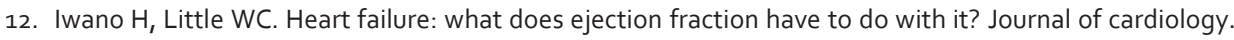
$2013 \mathrm{Jul} ; 62(1): 1-3$.

13. Cohen-Solal A. Diastolic heart failure: myth or reality? European Journal of Heart Failure. 2002;4(4):395-400.

14. Fonarow GC, Stough WG, Abraham WT, Albert NM, Gheorghiade M, Greenberg BH, et al. Characteristics, Treatments, and Outcomes of Patients With Preserved Systolic Function Hospitalized for Heart Failure: A Report From the OPTIMIZE-HF Registry. Journal of the American College of Cardiology. 2007 8/21/;50(8):768-77.

15. Owan TE, Hodge DO, Herges RM, Jacobsen SJ, Roger VL, Redfield MM. Trends in prevalence and outcome of heart failure with preserved ejection fraction. N Engl J Med. 2006 Jul 20;355(3):251-9.

16. Fonarow GC. Heart failure: recent advances in prevention and treatment. Reviews in cardiovascular medicine. 2000 Summer;1(1):25-33, 54.

17. Ekman I, Swedberg K. Patients' persistence of evidence-based treatment of chronic heart failure: a treatment paradox. Circulation. 2007 Aug 14;116(7):693-5.

18. Butler J, Fonarow GC, Zile MR, Lam CS, Roessig L, Schelbert EB, et al. Developing therapies for heart failure with preserved ejection fraction: current state and future directions. JACC Heart failure. 2014 Apr;2(2):97-112. 
19. Coats AJ. Advances in the non-drug, non-surgical, non-device management of chronic heart failure. Int J Cardiol. 2005 Apr 8;100(1):1-4.

20. van der Wal MH, van Veldhuisen DJ, Veeger NJ, Rutten FH, Jaarsma T. Compliance with nonpharmacological recommendations and outcome in heart failure patients. Eur Heart J. 2010 Jun;31(12):1486-93.

21. Giesbers H VA, Beer J de Bevolking: Wat is de huidige situatie? In: Volksgezondheid Toekomst Verkenning. Bilthoven: Nationaal Kompas Volksgezondheid. RIVM, 2014.

22. Hoek JF, Ribbe MW, Hertogh CMPM, van der Vleuten CPM. The Specialist Training Program for Nursing Home Physicians: A New Professional Challenge. Journal of the American Medical Directors Association.2(6):326-30.

23. Schols JM, van der Schriek-van Meel C. Day care for demented elderly in a dairy farm setting: positive first impressions. J Am Med Dir Assoc. 2006 Sep;7(7):456-9.

24. Schols JM, Crebolder HF, van Weel C. Nursing home and nursing home physician: the Dutch experience. J Am Med Dir Assoc. 2004 May-Jun;5(3):207-12.

25. Tresch DD. Clinical manifestations, diagnostic assessment, and etiology of heart failure in elderly patients. Clin Geriatr Med. 2000 Aug;16(3):445-56.

26. Caruana L, Petrie MC, Davie AP, McMurray JJ. Do patients with suspected heart failure and preserved left ventricular systolic function suffer from "diastolic heart failure" or from misdiagnosis? A prospective descriptive study. BMJ. $2000 \mathrm{Jul}$ 22;321(7255):215-8.

27. Hobbs FD. Unmet need for diagnosis of heart failure: the view from primary care. Heart. 2002 Oct;88 Suppl 2:iig-11.

28. Hoes AW WE, Rutten FH, Twickler TB, Rohling R, Jansen RWMM, Jaarsma T, Feenstra TL, Bouvy ML, Buskens E, De Graaff M (tot 1 september 2008), De Kok IHM, Dijkgraaf R (tot 1 september 2008), Duin M, Fischer E, Flikweert S † (tot 26 augustus 2008), Hammelburg R, Honig A, Hulzebos E, In den Bosch HJH (tot 1 juli 2008), Janssen-Boyne J, Koers H, Kortrijk M, Ninaber PA, Poot E (vanaf 1 juli 2008), Post PN, Rosenbrand CJGM, Schiffer AAJJ, Van Dijk JL, Van Dijk P, Van Erp J, Van Erven L (vanaf 1 september 2008), Van Leen M, Van Lieshout J, Van Veldhuisen DJ (tot 1 juli 2008), Weerts M (vanaf 1 september 2008), Voors AA. Multidisciplinaire richtlijn Hartfalen 2010. 2010.

29. Dickstein K, Cohen-Solal A, Filippatos G, McMurray JJ, Ponikowski P, Poole-Wilson PA, et al. ESC Guidelines for the diagnosis and treatment of acute and chronic heart failure 2008: the Task Force for the Diagnosis and Treatment of Acute and Chronic Heart Failure 2008 of the European Society of Cardiology. Developed in collaboration with the Heart Failure Association of the ESC (HFA) and endorsed by the European Society of Intensive Care Medicine (ESICM). Eur Heart J. 2008 Oct;29(19):2388-442.

30. Heckman GA, Misiaszek B, Merali F, Turpie ID, Patterson CJ, Flett N, et al. Management of heart failure in Canadian long-term care facilities. Can J Cardiol. 2004 Aug;20(10):963-9.

31. Michalik C, Matusik P, Nowak J, Chmielowska K, Tomaszewski KA, Parnicka A, et al. Heart failure, comorbidities, and polypharmacy among elderly nursing home residents. Polskie Archiwum Medycyny Wewnetrznej. 2013;123(4):170-5.

32. Gaulden L. Diagnosis and management of heart failure in the long-term care setting. Director. 2003 Fall;11(4):177-81. 



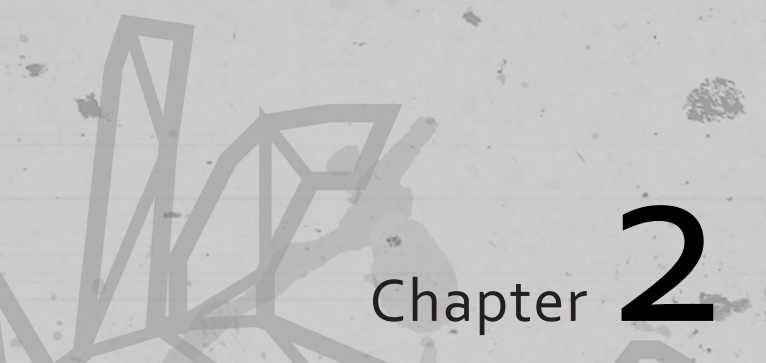

Prevalence of Heart Failure in Nursing Homes: a Systematic Literature Review

Mariëlle AMJ. Daamen, Jos MGA. Schols, Tiny Jaarsma, Jan PH Hamers

Published in Scandinavian Journal of Caring Sciences. 2010;24:202-8. 


\section{ABSTRACT}

Introduction: Heart failure is an important problem in western countries. In nursing home residents heart failure is expected to be highly prevalent. However, accurate diagnosis of heart failure in these patients is often hampered due to atypical findings and concomitant comorbidity. In order to deliver adequate nursing care and medical treatment, it is important to get insight into the prevalence of heart failure in this target group of patients.

Objectives: To assess the prevalence of heart failure as well as the comorbidity interfering with heart failure in nursing home residents.

Methods and results: A systematic literature review was conducted in Medline, Embase, Cinahl and the Cochrane Library. Ten studies were ultimately included. Findings indicate that the mean prevalence of heart failure is $20 \%$ (range $15-45 \%$ ) and that there is a significant level of comorbidity (dementia, diabetes mellitus and COPD) in nursing home residents with heart failure.

Conclusion: The reported prevalence of heart failure in nursing home residents is higher than in the general population and is associated with considerably comorbidity. However there are also indications that the prevalence of heart failure in nursing home residents is underestimated, negatively affecting quality of life and quality of care. Therefore, prospective prevalence studies and studies aiming to improve the care for nursing home residents with heart failure are warranted. 


\section{INTRODUCTION}

Heart failure (HF) is particularly a disease of the elderly and an increasing clinical problem in western countries.(1) Its prevalence and incidence are expected to increase in the future, mainly as a result of reduced mortality from coronary heart disease and stroke. In western countries the prevalence of HF in the general population ranges from $3-13 \%$ for those over 65 years (2): in the Netherlands the prevalence is estimated at $13 \%$ in persons of 75 or older (3) and patients are treated both by cardiologists and general practitioners.(4) The mean age of the HF population is currently 74 years and incidence and prevalence increase with age. $(5,6)$ Frail elderly persons living in nursing homes represent a specific patient group, with high levels of care dependency due to their disabilities, resulting from disease.(7) HF is expected to be particularly prevalent in this population, but reliable data are lacking because nursing home residents are often excluded from clinical and epidemiological studies.

$\mathrm{HF}$ is a clinical syndrome that in general is diagnosed by way of symptoms and physical findings. Many definitions of heart failure exist, but in recent years, most definitions of HF have emphasized the need for both the presence of symptoms of HF and physical signs of fluid retention.(5) However, diagnosis of HF in elderly patients, including nursing home residents, is often delayed due to an atypical presentation of clinical findings.(8) Accurate diagnosis of the presence and etiology of HF in older patients is even more difficult and hampered by the often concomitant comorbidity. Frequent concomitant diseases in older patients with HF are hypertension (38\%), obstructive lung disease (25\%), diabetes (29\%) and stroke (26\%).(9) These diseases often show characteristic signs and symptoms similar to those of HF (e.g. breathlessness, ankle swelling and fatigue) and thus may be difficult to interpret.

Early diagnosis and treatment may therefore prevent progression of HF and lead to improvement of symptoms and quality of life.(10) Results of clinical trials have established that adequate pharmacologic therapy reduces morbidity and mortality in HF patients. $(5,10,11,12)$ Improvement of symptoms and quality of life are especially important in the care for nursing home residents. Up until now, however, knowledge regarding diagnosis and treatment of $\mathrm{HF}$ in this growing and vulnerable population is lacking. It must be emphasized especially that early diagnosis and subsequent tailor made therapy may lead to improvement of quality of life in this specific group of patients. Therefore more knowledge about HF in this specific group is necessary. We performed a literature review on HF in nursing home residents, using the following research questions:

1. What is the prevalence of HF in nursing homes?

2. Which comorbidity interferes mostly with the diagnosis of HF in elderly nursing home residents? 


\section{Chapter 2}

\section{METHODS}

\section{Design}

We conducted a systematic literature review using the following computer databases: Medline, Embase, Cinahl and the Cochrane Library. In addition Evidence-Based Cardiovascular Medicine as a secondary journal as well as research and trial registers were searched. References and citations in selected journals were screened.

\section{Selection criteria}

Selected keywords were used in several combinations; these were, heart failure, congestive heart failure, left ventricular dysfunction, diastolic heart failure, cardiac failure, elderly, older patients, ageing population, aged, geriatrics, nursing home residents, long term care residents, chronic care, prevalence, diagnosis, comorbidity, symptoms and diagnostic interfering. The search was not limited to a specific period but articles (written in English, Dutch, German and Italian) should have been published before January 2008.

\section{Methodological quality}

To evaluate the quality of the included studies, we adapted criteria from existing scales for assessing the quality of other designs $(13,14)$ into an assessment scale for descriptive studies. To assess face validity, the scale was judged by two experts on research methodology and systematic reviews affiliated with Maastricht University.

The items included in the scale were divided into: aim and research question, design, sample, data collection, data-analysis and conclusion. In total there were 13 items to answer.

The theoretical score on the assessment scale ranges from o (very poor quality) to 26 (excellent quality). Criteria could be related as no, doubt or yes. For no the score was ' 0 ' for doubt ' 1 'and for yes ' 2 '. Two reviewers (reviewers' names on request) have assessed the quality of the selected articles. The empirical scores ranged from 7-24. Studies that scored less than 10 were considered to be of poor quality, and excluded from the review. 


\section{RESULTS}

\section{Inclusion and quality assessment of studies}

The first selection was performed by one reviewer screening all hits on title and/or abstract. After including all abstracts containing "heart failure and the elderly patient" or "heart failure and nursing home/ long-term care" 40 abstracts remained. Of these 18 were excluded because they did not meet specific inclusion criteria (prevalence, diagnosis, symptoms, comorbidity and clinical characteristics) as judged by two reviewers or because they were not written in English, Dutch, German or Italian. The full text of the remaining 22 was screened by two reviewers to judge their relevance to the research questions. Finally, 12 articles were included in the review.(15-26) Though there was no specific time period, the most dated publication was from 1995.

There was complete consensus between the reviewers on quality assessment for seven articles, three turned up minor disagreement and two $(20,24)$ required further discussion due to pronounced disagreement. For a final reliability check two articles were assessed by a third reviewer. This assessment resulted in complete consensus between the reviewers.

Subsequently, two studies $(20,22)$ were excluded for having scored $<10$ on the quality assessment scale, due to limitations in the data collection and analysis.

Ultimately leaving 10 studies which met the inclusion criteria and were of sufficient methodological quality.

\section{Clinical characteristics}

The studies described the clinical and functional characteristics of residents in longterm care, nursing homes or geriatric centres (summarised in Table 1). The number of patients in the studies included varied from 80 patients (24) to 86,094.(23) More women participated than men and the mean age ranged from 79 to 89 years. Three studies used a cross- sectional approach $(16,24,25)$, while the others used retrospective design. 
Chapter 2

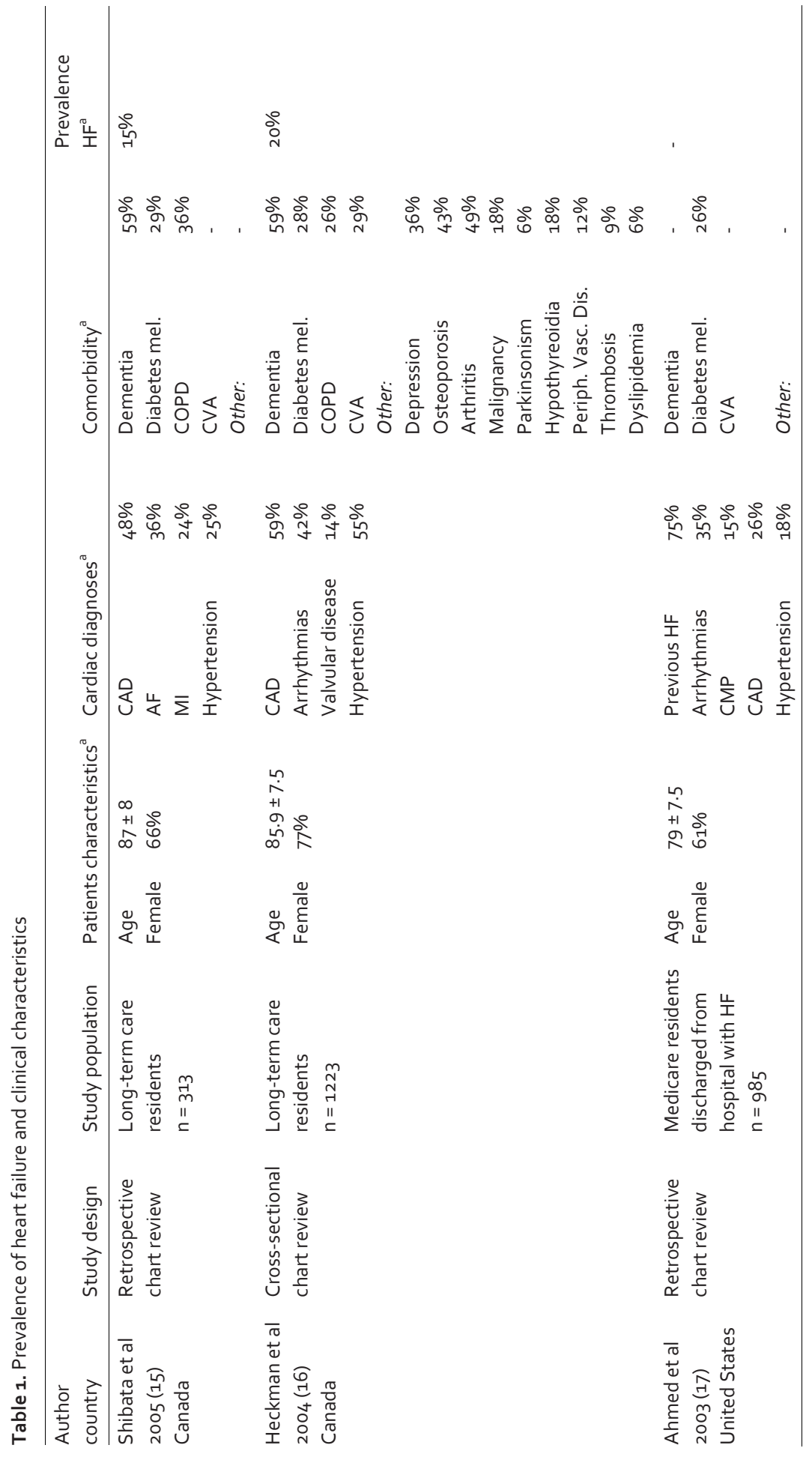


Prevalence of Heart Failure in Nursing Homes: a Systematic Literature Review

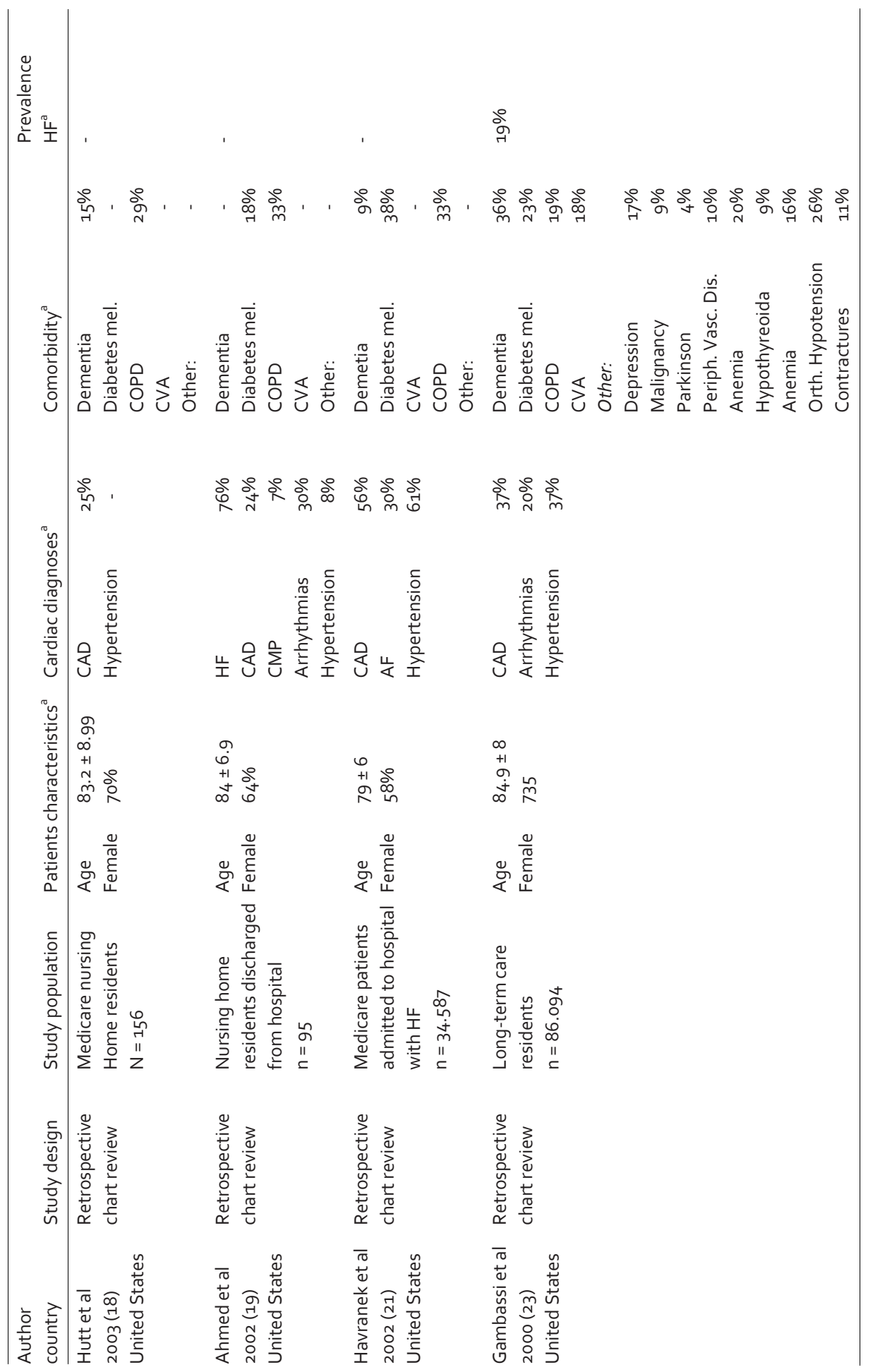


Chapter 2

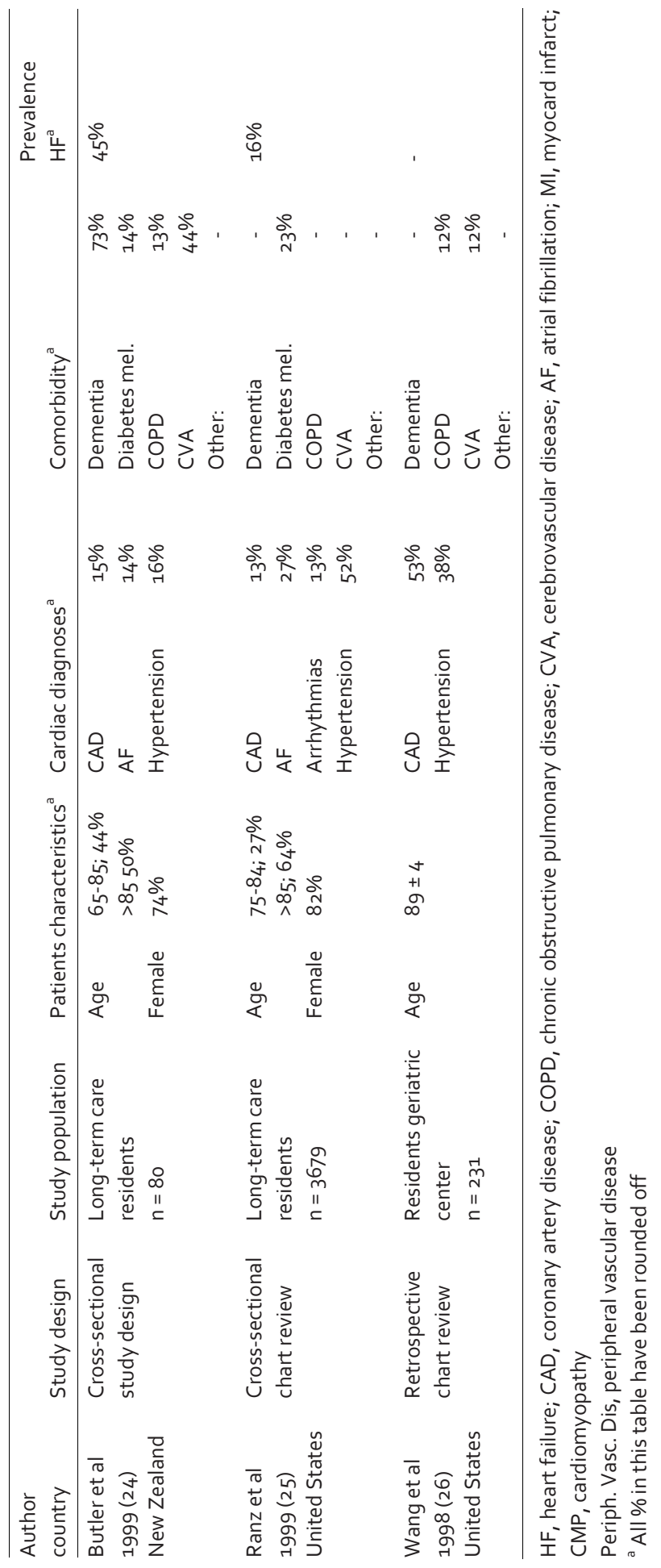




\section{The prevalence of heart failure}

The prevalence of HF in nursing homes was determined in five studies. $(15,16,23,24,25)$ In four studies its prevalence in long-term care settings varied from $15-20 \%$ with one exceptional prevalence rate of $45 \%$ in the fifth study.(24) In this study by Butler, HF was diagnosed in every patient after concrete examination by a geriatrician, while in the other four, information from medical records was used to confirm the diagnosis of HF.

Table 2. Diagnosis of heart failure

\begin{tabular}{|c|c|}
\hline Study & Criteria used to verify the diagnosis of heart failure \\
\hline Shibata 2005 (15) & $\begin{array}{l}\text { Presence of heart failure was defined as documentation by a physician in the } \\
\text { pharmacy database or health record }\end{array}$ \\
\hline Heckman 2004 (16) & $\begin{array}{l}\text { Diagnosis heart failure if pulmonary edema or symptomatic left ventricular } \\
\text { dysfunction was record in the chart. The adequacy of information supporting the } \\
\text { diagnosis of heart failure was gauged against the boston criteria }\end{array}$ \\
\hline Ahmed 2003 (17) & $\begin{array}{l}\text { Identification was done using the ICD-9 CM codes } 428 \text { and } 402.91 \text {. The diagnosis of } \\
\text { heart failure was verified }\end{array}$ \\
\hline Hutt 2003 (18) & $\begin{array}{l}\text { Presence of either documented pulmonary edema on chest X-ray in the nursing } \\
\text { home or a hospital discharge diagnosis of heart failure and two or more of the } \\
\text { following clinical signs/ symptoms; increased dyspnea on exertion, paroxysmal } \\
\text { nocturnal dyspnea, orthopnea, massive edema or altered sensorium }\end{array}$ \\
\hline Ahmed 2002 (19) & $\begin{array}{l}\text { Identification was done using the International Classification of Disease } 9^{\text {th }} \text { revision, } \\
\text { clinical Modification modes } 428 \text { (heart failure) and } 402.91 \text { (Hypertensive Heart } \\
\text { Disease with congestive heart failure) and the DRG code } 127 \text { ( Heart failure) } \\
\text { Modified Framingham heart failure diagnostic criteria based on the available data } \\
\text { were used to confirm the diagnosis heart failure }\end{array}$ \\
\hline Havranek 2002 (21) & $\begin{array}{l}\text { Discharge diagnosis was identified by any of the following ICD-9 codes } 402.01 \text {, } \\
402.11,402.91,404.01,404.11,404.91 \text { or } 428 x\end{array}$ \\
\hline Gambassi 2000 (23) & $\begin{array}{l}\text { Staff physician coded a diagnosis of heart failure using information obtained from } \\
\text { the medical record, including the physical examination of the resident, medication } \\
\text { and other treatment orders and hospital discharge documentation ( available for } \\
78 \% \text { ) Interrater trials, kappa coefficient for the diagnosis of chronic heart failure } \\
\text { was }>80\end{array}$ \\
\hline Butler 1999 (24) & $\begin{array}{l}\text { Examination by a consultant geriatrician. Blood tests were completed if they had } \\
\text { not been performed in the previous year. Diagnosis reviewed with hospital records } \\
\text { where possible }\end{array}$ \\
\hline Ranz 1999 (25) & $\begin{array}{l}\text { Using the pharmacy databases to identify a similar diagnosis in patients' medical } \\
\text { records in the facilities }\end{array}$ \\
\hline Wang $1998(26)$ & $\begin{array}{l}\text { Congestive heart failure defined as with symptoms and signs of chronic heart } \\
\text { failure and chest radiograph showing pulmonary congestion }\end{array}$ \\
\hline
\end{tabular}




\section{Diagnosis of heart failure}

The criteria for verifying the diagnosis of HF were based on different criteria in each study (see Table 2 ). Three studies $(17,19,21)$ used the international classification of diseases codes (ICD), two $(15,25)$ were based on pharmaceutical data, four $(16,18,23,25)$ on clinical and radiological signs and in the final study a staff physician coded the diagnosis. In two studies $(16,19)$ the diagnosis was confirmed, one used the 'Boston criteria' (27) and the other used the modified Framingham criteria. (28)

\section{Cardiac diseases and comorbidity}

Coronary artery disease (CAD) and arrhythmias (most frequent atrial fibrillation) were the most common primary cardiac diagnoses underlying HF. Non-cardiovascular comorbidities also were very common, especially diabetes mellitus (11-38\%), chronic obstructive pulmonary disease (COPD) (12-36\%), dementia (9-73\%) and hypertension (8-55\%).

\section{DISCUSSION}

This is the first systematic literature review of the prevalence of HF in nursing home residents and its associated comorbidity. Though the number of studies included is low, they show that, HF in nursing homes is indeed prevalent and that COPD, dementia and diabetes mellitus are frequently associated with its diagnosis.

The studies indicate that about 20\% (range 15-45\%) of nursing home residents suffer from HF. This figure is higher than in the general population (3-13\%) and can be explained by the fact that prevalence increases with age; the mean age of the study populations ranged between $79-89$ years.

As shown in the results, there was one exceptional prevalence value of $\mathrm{HF}(45 \%)$. In this study (24) HF was diagnosed after concrete examination by a geriatrician. It may be possible, that in studies using only medical records the prevalence of $\mathrm{HF}$ is underestimated. The study of Barents 2008 (29) concluded that both undetected and incorrect diagnoses of chronic HF in nursing home residents were common.

Concomitant comorbidity may also interfere with HF diagnosing in nursing home residents. Our results show that nursing home residents indeed experience considerable comorbidity. However, this is to be expected given the fact that nursing home admission usually takes place when there is high care dependency due to restrictions and disabilities caused by several diseases.(7) Dementia, diabetes mellitus and especially COPD are frequently associated with HF as is shown in the studies reviewed. However, Rutten 2005 (30) showed that unrecognised HF was present in about $21 \%$ of elderly in the general COPD population. It can be assumed that this also concerns 
nursing home residents. This means that a characteristic symptom of HF such as breathlessness often may be misinterpreted.

In addition dementia is very common in the nursing home population. A careful and thorough history - essential in the diagnostic process of HF - may be impossible in demented residents given their cognitive impairment. Probably for this reason HF is often not recognized adequately in this group of patients. Other diagnoses, such as anaemia, depression and malignancy, could have symptoms consistent with HF as well. It is probably for this reason that HF not seldom goes unrecognised and underestimated in this population. Only two of the reviewed studies $(16,23)$ explored concomitant comorbidity extensively.

With respect to the limitations of our study, it ought to be noted, that the reported figures of HF prevalence represent data from different countries, though long-term care facilities across borders show considerable differences in for example care services and extent of medical care.(31)

In summary HF occurs frequently in nursing home residents but limited research has been performed as to its real prevalence in this group. Therefore, recognising and diagnosing HF sufficiently early remains a challenge in face of the comorbidity, that often is present in this population. Moreover, it may be assumed that inadequate diagnosis of HF and its treatment will affect quality of life and quality of care. Further research is necessary. We recommend to perform a cross-sectional study design to determine the prevalence of HF in nursing homes and comparing the results of concrete patient examinations, with information from medical records. This will foster not only adequate diagnosis of HF but also the collection of information about comorbidity and secondary functional status in nursing home residents. It may also result in improvement of the diagnostic process and subsequently improve the current medical and nursing practice for HF in this target group of patients.

Recognising, diagnosing and treating HF early and adequately remains a real challenge. Early diagnosis and treatment may prevent progression of the disease and lead to the improvement of disabling symptoms, ultimately resulting in an overall improvement in quality of life. Nursing home residents should not be excluded from optimal HF management. 


\section{REFERENCES}

1. Stewart S, Maclntyre K, Capewell S, McMurray JJV. Heart failure and the aging population: an increasing burden in the $21^{\text {st }}$ century. Heart 2003;89:49-53.

2. Cowie MR, Mosterd A, Wood DA Deckers JW, Poole-Wilson PA, Sutton GC, Grobbee DE. Epidemiology of heart failure. Eur Heart J 1997;18: 208-25.

3. Mosterd A, Hoes AW. Prevalence of heart failure and left ventricular dysfunction in the general population. The Rotterdam study. Eur Heart J 1999;20:447-55.

4. Jaarsma T, Haaijer-Ruskamp FM, Sturm H, Van Veldhuisen DJ. Management of heart failure in The Netherlands. Eur J Heart Fail 2005;7:371-5.

5. The Task Force for the Diagnosis and Treatment of Acute and Chronic Heart Failure, European Society of Cardiology. Guidelines for the diagnosis and treatment of acute and chronic heart failure. Eur Heart $J$ 2008;29:2388-442.

6. Cowie MR, Wood DA, Coats AJS, Thompson SG, Poole-Wilson PA, Suresh V, Sutton GC. Incidence and aetiology of heartfailure. Eur Heart J 1999:20:421-28.

7. Schols JMGA, Crebolder HFJM, Weel C van. Nursing Home and Nursing Home Physician: The Dutch Experience. J Am Med Dir Assoc 2004;5:207-12.

8. Tresch DD. Clinical manifestations, diagnostic assessment, and etiology of heart failure in elderly patients. Clin Geriatr Med 2000;16:445-56.

9. Wel MC van der, Jansen RWMM, Bakx JC, Bor HHJ, Olderikkert MG, Weel C van. Non-cardiovascular comorbidity in elderly patients with heart failure outnumbers cardiovascular co-morbidity. Eur $J$ Heart Failure 2007;9:709-15.

10. Gaulden L. Diagnosis and management of heart failure in the long term care setting, Director 2003;11:177-81.

11. Hunt SA; American College of Cardiology; American Heart Association Task Force on Practice Guidelines. ACC/AHA 2005 Guideline Update for the Diagnosis and Management of Chronic Heart Failure in the Adult, J Am Coll Cardiol 2005 Sep 20;46(6):e1-82.

12. Flather MD, Shibata MC, Coats AJ, Van Veldhuisen DJ, Parkhomenko A, Borbola J, Cohen-Solal A, Dumitrascu D, Ferrari R, Lechat P, Soler-Soler J, Tavazzi L, Spinarova L, Toman J, Böhm M, Anker SD, Thompson SG, Poole-Wilson PA. FASTTRACK Randomized trial to determine the effect of nebivolol on mortality and cardiovascular hospital admission in elderly patients with heart failure (SENIORS). Eur Heart J $2005 ; 26: 215-25$.

13. Dutch Institute for Healthcare Improvement. Guideline assessment scale for qualitive research. April 2005 .

14. Verhagen AP, Vet HC de, Bie RA de, Kessels AG, Boers M, Bouter LM, Knipschild PG. The Delphi list: a criteria list for quality assessment of randomized clinical trials for conducting systematic reviews developed by delphi consensus. J Clin Epidemiol 1998;51:1235-41.

15. Shibata MC, Soneff CM, Tsuyuki RT.Utilization of evidence-based therapies for heart failure in the institutionalized elderly. Eur J Heart Fail 2005;7:1122-5.

16. Heckman GA, Misiszek B, Merali F, Turpie ID, Patterson CJ, Flett N, McKelvie RS. Management of heart failure in Canadian long-term care facilities. Can J Cardiol. 2004;20(10):963-9.

17. Ahmed A, Allman RM, Delong JF. Predictors of nursing home admission for older adults hospitialized with heart failure. Arch Gerontol Geriatr 2003;36:117-26.

18. Hutt E, Frederickson E, Ecord M, Kramer AM. Associations among processes and outcomes of care for medicare nursing home residents with acute heart failure. J Am Med Dir Assoc. 2003;4;220-1.

19. Ahmed A. Clinical characteristics of nursing home residents hospitalized with heart failure. J Am Med Dir Assoc. 2002;3:310-3.

20. Aronow WS, Ahn C, Gutstein H. Prevalence and incidence of cardiovascular disease in 1160 older men and 2464 older women in long-term health care facility. J Gerontol A Biol Sci Med Sci 2002;57:M45-6. 
21. Havranek EP, Msoudi FA, Westfall KA, Wolfe P, Ordin DL, Krumholz HM. Spectrum of heart failure in older patients: results from the National Heart Failure project. Am Heart J 2002;143:412-7.

22. Valle $R$, Chinellato $M$, Gallo G. Heart failure in the elderly living in long-term care facilities: Prevalence hospitalization, and adherence to guidelines recommendations. Ital Heart J Suppl 2001;2:772-4.

23. Gambassi G, Forman DE, Lapane KL, Mor V, Squadari A, Lipsitz LA, Bernabei R. Management of heart failure among very old persons living in longterm care: has the voice of trials spread? The SAGE Study Group. Am Heart J. 2000;139:85-93.

24. Butler R, Fonseka S, Barclay L, Sembhi S et al. The health of elderly residents in long term care institutions in New Zealand, et all, N Z Med J 1999;12:427-9.

25. Ranz TT, Blumenschein K, Clifton G.D. Prevalence and treatment of heart failure in elderly long-term care patients. Am J Health-Syst Pharm 1999;56:1334-8.

26. Wang R, Mouliswar M, Denman S, Kleban M. Mortality of the institutionalized old-old hospitalized with congestive heart failure. Arch Intern Med 1998;158:2464-8.

27. Carlson KJ, Lee DC, Goroll AH, Leahy M, Johnson RA. An analysis of physicians' reasons for prescribing long-term digitalis therapy in outpatients. J Chron Dis 1985;38:733-9.

28. McKee PA, Castelli WP, McNamara PM, Kannel WB. The natural history of congestive heart failure: the Framingham study. N Engl J Med 1971;285:1441-6.

29. Barents M, Horst ICC van der, Voors AA, Hillege JL, Muskiet FAJ, Jongste MJL de. Prevalence and misdiagnosis of chronic heart failure in nursing home residents: the role of B-type natriuretic peptides. Neth Heart J 2008;16:123-8.

30. Rutten FH, Cramer MJM, Grobbee DE, Sachs AP, Kirkels JH, Lammers JW, Hoes AW. Unrecognized heart failure in elderly patients with stable chronic obstructive pulmonary disease. Eur heart $J$ 2005;26:1887-1894.

31. Ribbe MW, Ljunggren G, Steel K, Topinkova E, Hawes C, Ikegami N, Henrard JC, Jónsson PV. Nursing homes in 10 nations: a comparison between countries and settings. Age Ageing 1997;26 Suppl 2:3-12. 



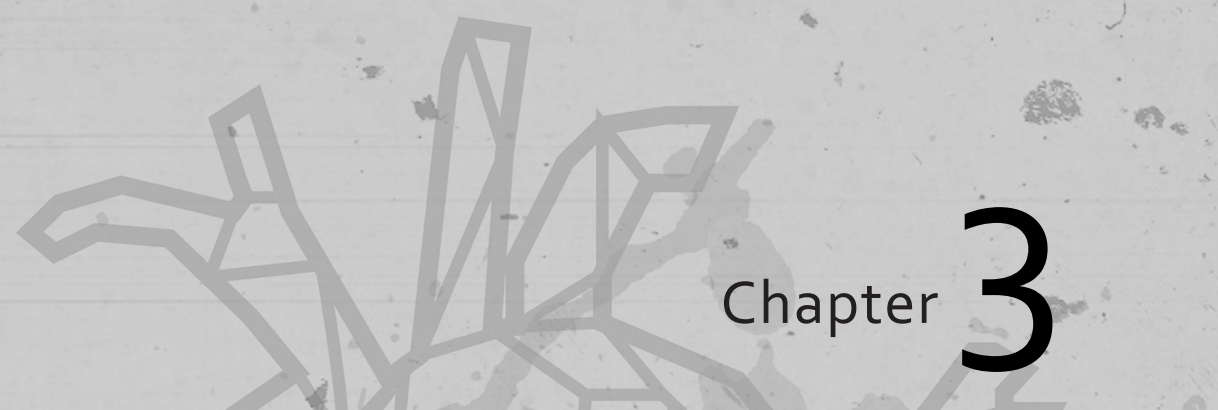

\section{Study protocol}

The prevalence and management of heart failure in Dutch nursing homes; design of a multi-centre cross-sectional

study

Mariëlle AMJ Daamen, Jan PH Hamers, Anton P Gorgels, Hans-Peter Brunner-la Rocca, Frans ES Tan, Marja P van Dieijen-Visser, Jos MGA Schols

Published in BMC Geriatrics. 2012;12:29. 


\section{Chapter 3}

\section{ABSTRACT}

Background: Heart failure is likely to be particularly prevalent in the nursing home population, but reliable data about the prevalence of heart failure in nursing homes are lacking. Therefore the aims of this study are to investigate (a) the prevalence and management of heart failure in nursing home residents and (b) the relation between heart failure and care dependency as well as heart failure and quality of life in nursing home residents.

Methods/design: Nursing home residents in the southern part of the Netherlands, aged over 65 years and receiving long-term somatic or psychogeriatric care will be included in the study. A panel of two cardiologists and a geriatrician will diagnose heart failure based on data collected from actual clinical examinations (including history, physical examination, ECG, cardiac markers and echocardiography), patient records and questionnaires. Care dependency will be measured using the Care Dependency Scale. To measure the quality of life of the participating residents, the Qualidem will be used for psychogeriatric residents and the SF-12 and VAS for somatic residents.

Conclusion: The study will provide an insight into the actual prevalence and management of heart failure in nursing home residents as well as their quality of life and care dependency. 


\section{BACKGROUND}

Heart failure (HF) is a highly prevalent chronic disease in older persons. Its prevalence increases with age reaching $15-20 \%$ in those aged over 80 years.(1) According to current guidelines, HF is stated as a clinical syndrome characterized by the presence of symptoms and typical signs of HF and objective evidence of a structural and/or functional abnormality of the heart, usually illustrated by echocardiography.(2) Accurate diagnosis of the presence and aetiology of HF is important given its crucial influence on therapy. However, signs and symptoms of HF in older persons are often obscured, due to physical limitations or the unreliability of clinical history due to dementia.(3) In addition, signs of $\mathrm{HF}$, such as fatigue or dyspnoea, are often attributed to the normal ageing process. Besides, symptoms are often non-specific and can be attributed to other common diseases in older persons such as venous insufficiency or obesity.(4) The diagnosis of HF is especially challenging if comorbidities are present that share common symptoms of HF such as chronic obstructive pulmonary disease (COPD) and venous insufficiency.(5)

This implicates that the diagnosis of HF is particularly difficult in older persons and nursing home residents. The latter represent a specific group, involving very frail and disabled elderly persons with chronic somatic diseases or progressive dementia, both often being complicated by comorbidities.(6) The prevalence of HF in nursing home residents is estimated to be $20-25 \% \cdot(3,7)$ Furthermore, HF in this specific group is likely to be underdiagnosed, due to the lack of knowledge regarding adequate diagnosis and treatment of HF in this population. This counts the more because nursing home residents are often excluded from clinical and epidemiological studies.

It is well known that $\mathrm{HF}$ is accompanied by a high patient and economic burden.(8) HF patients are often re-admitted to hospital, mainly due to periodic episodes of clinical deterioration.(9) In the Netherlands, as well as other Western countries cardiovascular diseases (including HF) account for the highest hospitalisation rate, resulting in high financial costs. $(10,11)$

Notwithstanding the fact that survival of HF has improved in recent decades, once hospitalised for heart failure, $33 \%$ of elderly patients die within the following year.(12) Women and older persons experience less improvement in survival, partly because they often suffer from HF with a preserved ejection fraction, but also because they are less likely to receive treatment with B-blockers and ACE-inhibitors. $(12,13)$

HF also leads to an impaired quality of life. $(14,15)$ The symptoms of HF such as fatigue and dyspnoea result in increased care dependency which is accompanied by a decline in health status and quality of life.(16) Therefore, early diagnosis and treatment of HF may prevent the progression of heart failure and lead to improvement in symptoms and quality of life.(17) Furthermore, it is known that older persons are less likely to receive evidence-based treatments for HF.(18) Although ACE- inhibitors have 


\section{Chapter 3}

been demonstrated to benefit HF patients, they remain underused for HF treatment in nursing home settings.(19)

The aim of this study is to gain an insight into the prevalence and management of $\mathrm{HF}$ in nursing home residents and to explore the association between $\mathrm{HF}$, care dependency and quality of life.

The following research questions will be addressed:

1. What is the prevalence of HF in Dutch nursing home residents?

2. How is HF currently treated in nursing home residents both pharmacologically and non-pharmacologically?

3. What is the association between HF and the care dependency and quality of life of nursing home residents?

This article describes the study protocol.

\section{METHODS/ DESIGN}

This multicentre study will follow a cross-sectional design.

\section{Setting}

Five healthcare organisations that provide institutional long-term care in the Southern part of the Netherlands will participate in the study. These healthcare organisations have various nursing home facilities for both chronic somatic and psychogeriatric care. Dutch nursing home care is provided by teams of registered nurses, nurse assistants, paramedical professionals and nursing home physicians, who are employed by the nursing homes themselves. The care can be characterised as continuing, long lasting, systematic and multidisciplinary care (CLSM) that is provided via an integrated care plan after a thorough and integral assessment of the resident's problems. Nursing homes also have a geriatric rehabilitation function for a substantial number of somatic residents. The nursing home physician is responsible for all medical care and initiates the different therapeutic interventions.(20)

\section{Study population and sample}

The study population will consist of nursing home residents who receive long term care on somatic or psychogeriatric wards. Both somatic and psychogeriatric residents will be eligible when over 65 years of age. Residents receiving palliative care or admitted for short-term rehabilitation (staying $<2$ months) will be excluded. The overall number of nursing home residents at the five participating healthcare organisations is 
about 4500. After excluding the places allocated for rehabilitation and terminal care about 3500 residents will be available for recruitment.

A total of 1000 nursing home residents will be included in the study, with 200 from each participating organisation. Based on the current segmentation of somatic residents $(35 \%)$ versus psychogeriatric $(65 \%)$ residents in Dutch nursing homes, we aim to include 70 somatic and 130 psychogeriatric residents from each organisation.

In a feasibility study on somatic wards, we found that about $50 \%$ of the approached residents were willing to participate. Reasons given for not participating included: they considered themselves too old, or believed that the investigations would be too burdensome. We also encountered difficulties, when asking legal representatives to make decisions regarding participation on behalf of residents. These preliminary findings were in line with a study conducted by Barnes et al, who also focused on the recruitment of older people in a HF study, in which only $30 \%$ of the initially identified participants agreed to participate.(21)

Therefore, it will probably be necessary to approach three times the number of residents per healthcare organisation in order to recruit 200 residents per site.

\section{Sample size calculation}

The calculation of sample size was based on an estimated prevalence of $\mathrm{HF}$ in nursing home residents of $\mathrm{p}=0.20$ with a standard deviation of 0.025 and a confidence level (\%) of $95 \%$. No power considerations are required, because there is no null hypothesis to be tested. Accordingly, 983 residents should be included in the study; therefore a sample of 1000 residents will be selected.

\section{Selection of participants}

For practical and logistic reasons, nursing home residents living in the facilities with the highest number of residents will be the first to be recruited per care home organisation. The residents and/or their legal representatives will receive a letter describing the purpose and content of the study. Informed consent will be obtained from the residents themselves or from their legal representatives in the case of psychogeriatric residents or residents with aphasia.

\section{Ethical considerations}

The study protocol complies with the Declaration of Helsinki and has been granted approval from the Medical Ethics Committee of Maastricht University/Academic Hospital Maastricht. (NL33281.068.10/MEC10-3-074)

The study is registered in the Dutch trial register (NTR2663) 


\section{Chapter 3}

\section{Study protocol}

\section{Training of nursing home physicians}

Nursing home physicians (NHP) at each healthcare organisation (four per site) will participate in the study. The physicians will receive a refresher course, from a cardiologist specialising in HF at the Maastricht University Medical Centre, regarding diagnosing HF and performing a structured physical examination. Training will consist of an introduction about signs and symptoms of HF followed by bed-side teaching (3 hours) and a session and lecture about electrocardiography (ECG) findings in relation to HF ( 2 hours). The NHP will subsequently visit the University Medical Centre's outpatient $\mathrm{HF}$ clinic to refresh their knowledge and practise diagnostic skills related to HF (3 hours).

\section{Assessment of heart failure}

After training the NHP will start assessing the participants. During the assessment, the study NHP will perform the anamnesis and the physical examination.To ensure that no prior probability of HF is taken into account during the history taking and physical examination, the NHP will not have access to pre-existing information about the residents, with the exception of their name and date of birth. Two research nurses and a NHP/researcher, who will be responsible for gathering data from the medical records and the questionnaires, will record the ECG and take blood samples for the measurement of the NT-pro BNP marker. The ECG will be interpreted by the same study NHP who executed the examination. A qualified (fellow) cardiologist will record the echocardiogram on site, using a mobile echo device with recording capabilities.

The entire assessment will be carried out on site in the participating nursing homes.

\section{Diagnosis of heart failure}

The final diagnosis of HF will be based on all the data collected and will be made by an expert team of two cardiologists and a geriatrician using the definition of HF from the guidelines of the European Society of Cardiology 2008.(2)

To diagnose $\mathrm{HF}$, data will be collected from actual clinical examinations (including history, physical examination, ECG, cardiac markers and echocardiogram) and from the patients' records (past medical history and medication).

At the end of the assessment all residents will be categorized in one of the following groups:

1. No HF

2. HF, no previous history

3. HF, already known (either overt HF with signs and symptoms or re-compensated $\mathrm{HF}$ ) 


\section{MEASUREMENTS}

The data required to answer the research questions are listed in Table 1.

\section{Demographic data and clinical characteristics}

Data regarding general and specific resident characteristics will be gathered for all participants. The variables age, gender, medication, diagnosis on admission and comorbidity will be retrieved from the medical records. The cognitive status of each resident will be measured using the Mini Mental State Examination (MMSE). This is a valid test of cognitive function including the areas of orientation, registration, attention and calculation, recall, language repetition and complex commands.(22) 
Chapter 3

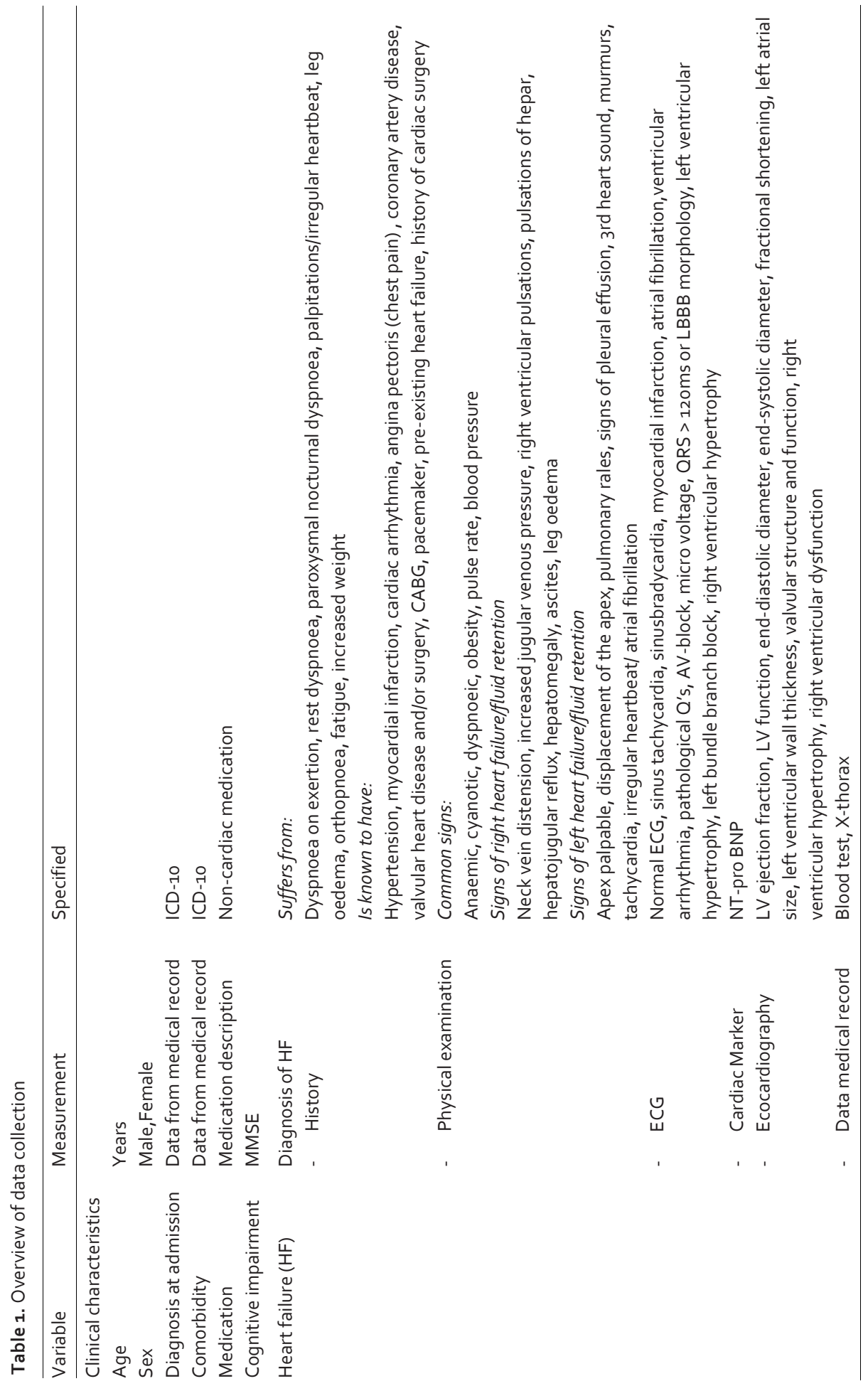


The prevalence and management of heart failure in Dutch nursing homes

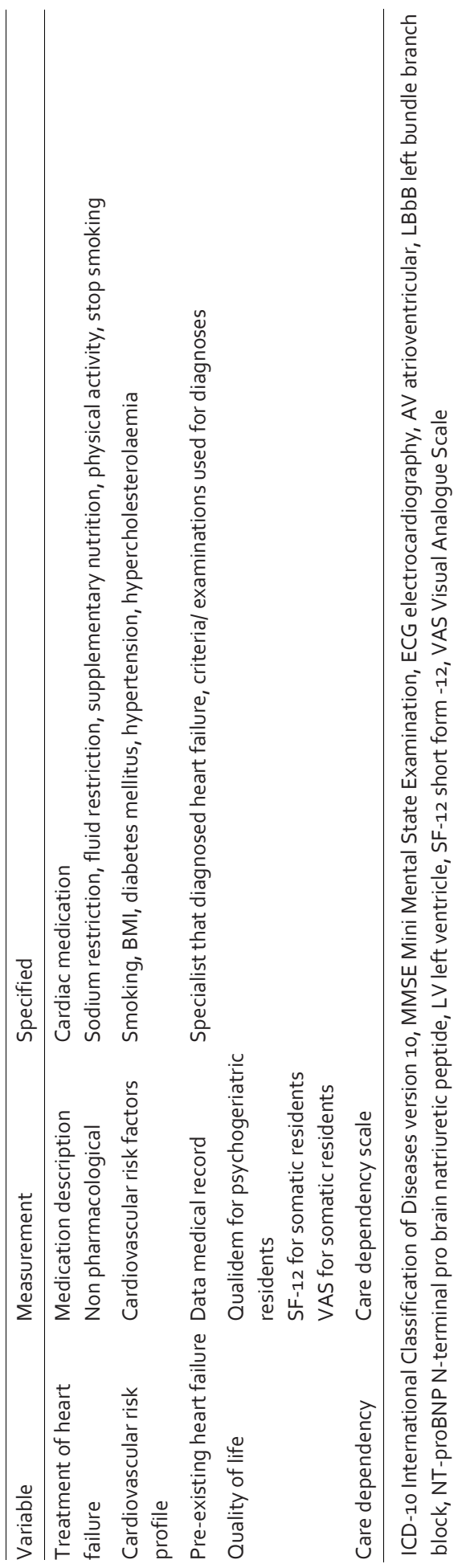




\section{Chapter 3}

\section{Heart failure}

\section{Physical examination and clinical history}

The actual history and physical examination will be recorded on a client record file developed for this study. In somatic residents the history-related questions will be answered by the residents themselves; in psychogeriatric residents these questions will be answered by the nurses responsible for their daily care and/or the family caregiver of the resident.

\section{Electrocardiogram (ECG)}

The clinical assessment will also include a standard 12-lead ECG, recorded by the research nurse. Abnormal ECG findings will be identified according to predefined criteria.

Measurement of N-terminal pro brain natriuretic peptide (NT-pro BNP)

A venous blood sample will be taken to determine the NT-pro BNP concentration. These samples will be analysed in the clinical chemistry laboratory of the Maastricht University Medical Centre on an Elecsys 2010 (Roche Diagnostics, Mannheim, Germany), using the NT-pro BNP assay. A normal concentration of NT- pro BNP <125pg/ml in an untreated patient has a high negative predictive value for HF.(23)

\section{Echocardiogram}

The echocardiogram will be recorded using a Philips $\mathrm{CX}_{50}$ CompactXtreme Ultrasound System. The echocardiogram will provide essential information about the aetiology and severity of HF.

\section{Complementary information from medical records}

Additional information will be obtained from the medical records such as main diagnosis on admission, comorbidity, results of recent blood tests or X-thorax (if available) and currently prescribed medication.

If HF has already been diagnosed, we will search for information in the medical record about who diagnosed HF and on which criteria the diagnosis was based.

\section{Current treatment of heart failure}

To study the current pharmacological treatment of HF in nursing homes data will be collected on cardiac medication prescriptions and data on non-pharmacological treatment will be extracted from the medical and nursing records. 


\section{Care dependency and quality of life}

Care dependency will be assessed using the Care Dependency Scale (CDS). The CDS consists of 15 items measuring human needs on a five-point Likert-type scale and the score ranges from 15 (completely dependent on care) to 75 (almost independent of care).(24, 25)

Quality of life will be measured using the Short-Form Health Survey 12 item (SF12) and the Visual Analogue Scale (VAS) for somatic residents. The SF-12 is a short form derived from the SF 36 . It has proven validity and it is appropriate for use in studies with a large sample size and studies focusing on patient-based assessments.(26) The visual analogue scale (VAS) subjectively measures the quality of life experienced on a scale from 0-10.

The Qualidem will be used to measure the quality of life in psychogeriatric residents. This scale contains 37 items divided into 9 subscales. It has sufficient validity to be used for research in residential care settings. $(27,28)$

\section{STATISTICAL ANALYSIS}

The data will be analysed using SPSS software PASW Statistics 17 and will include descriptive frequency distributions for all variables. Differences between groups will be tested using Student's T-test or analysis of variance (ANOVA) for continuous (dependent) variables and the Chi-square test (cross-table analysis) and/or multivariable logistic regression analyses for discrete (dependent) variables.

\section{DISCUSSION}

The study will provide insight into the actual prevalence and management of HF in nursing home residents as well as their quality of life and care dependency. In order to improve the care for HF in nursing home residents, first the accuracy to identify HF in nursing home residents has to be assessed. HF is likely to be highly prevalent in this specific given their advanced age and prevalence of cardiovascular diseases. Furthermore, $\mathrm{HF}$ is probably underdiagnosed in this group as symptoms are often not recognized or are misinterpreted. It is also known that $\mathrm{HF}$ is not always treated according to current guidelines (ESC-guidelines 2008, CBO 2010).(12,19) Nursing home residents are often excluded from epidemiological and clinical studies and therefore the benefits and adverse effects of medical treatment of HF in nursing home residents have not been properly examined. Eventually, the results of the study will lead to recommendations for improving the diagnostic process and management of HF in these 


\section{Chapter 3}

patients. Moreover the results of the study may contribute to a better quality of care for HF residents.

This study on the prevalence of HF differs from other studies by the type of approach used to diagnose HF. Of those studies, reviewed by Daamen and colleagues (3), most showed a prevalence of about $15-20 \%$, but were based on retrospective searches of medical records. Only one study revealed a prevalence of HF of $45 \%$ (29) and in that study HF was diagnosed after a focused clinical assessment by a geriatrician. This will be the approach used in our study. On the other hand this may also be a limitation, as refusal by eligible participants because they consider the examinations too burdensome may result in a low number of participants. 


\section{REFERENCES}

1. Bleumink GS, Knetsch AM, Sturkenboom MC, Straus SM, Hofman A, Deckers JW, Witteman JCM, Stricker BHCh . Quantifying the heart failure epidemic: prevalence, incidence rate, lifetime risk and prognosis of heart failure The Rotterdam Study. Eur Heart J. 2004, 25:1614-1619

2. Dickstein K, Cohen-Solal A, Filippatos G, McMurray JJ, Ponikowski P, Poole-Wilson PA, Strömberg A, Veldhuisen van DJ, Atar D, Hoes AW, Keren A, Mebazaa A, Nieminen M, Giulianu Priori G, Swedberg K. ESC Guidelines for the diagnosis and treatment of acute and chronic heart failure 2008: the Task Force for the Diagnosis and Treatment of Acute and Chronic Heart Failure 2008 of the European Society of Cardiology. Developed in collaboration with the Heart Failure Association of the ESC (HFA) and endorsed by the European Society of Intensive Care Medicine (ESICM). Eur Heart J 2008, 29:2388-2442

3. Daamen MA, Schols JM, Jaarsma T, Hamers JP. Prevalence of heart failure in nursing homes: a systematic literature review. Scand J Caring Sci 2010, 24:202-208

4. Tresch DD. Clinical manifestations, diagnostic assessment, and etiology of heart failure in elderly patients. Clin Geriatr Med 2000, 16:445-456

5. Rutten FH, Cramer MJ, Grobbee DE, Sachs AP, Kirkels JH, Lammers JW, Hoes AW. Unrecognized heart failure in elderly patients with stable chronic obstructive pulmonary disease. Eur Heart J 2005, 26:18871894

6. Schols JM, Crebolder HF, van Weel C. Nursing home and nursing home physician: the Dutch experience. J Am Med Dir Assoc 200, 5:207-212

7. Barents M, van der Horst IC, Voors AA, Hillege JL, Muskiet FA, de Jongste MJ. Prevalence and misdiagnosis of chronic heart failure in nursing home residents: the role of B-type natriuretic peptides. Neth Heart J 2008, 16:123-128

8. Zannad F, Agrinier N, Alla F. Heart failure burden and therapy. Europace 2009, 11 (Suppl 5):1-9

9. Stewart S, Maclntyre K, MacLeod MM, Bailey AE, Capewell S, McMurray JJ. Trends in hospitalization for heart failure in Scotland, 1990-1996. An epidemic that has reached its peak? Eur Heart J 2001, 22:209-217

10. Wieren S van, Poos MJJC. Voor welke ziekten en aandoeningen wordt ziekenhuiszorg veel gebruikt? In: Volksgezondheid Toekomst Verkenning, Nationaal Kompas Volksgezondheid. Bilthoven: RIVM, [http://www.nationaalkompas.nl> Nationaal Kompas Volksgezondheid|ZorglZiekenhuiszorg]

11. Braunschweig F, Cowie MR, Auricchio A. What are the costs of heart failure? Europace 2011, 13 (Suppl 2):ii13-17

12. Curtis LH, Greiner MA, Hammill BG, Kramer JM, Whellan DJ, Schulman KA, Hernandez AF. Early and long-term outcomes of heart failure in elderly persons, 2001-2005. Arch Intern Med 2008, 168:2481-2488

13. Roger VL, Weston SA, Redfield MM, Hellermann-Homan JP, Killian J, Yawn BP, Jacobsen SJ. Trends in heart failure incidence and survival in a community-based population. JAMA 2004, 292:344-350

14. Juenger J, Schellberg D, Kraemer S, Haunstetter A, Zugck C, Herzog W, Haass M. Health related quality of life in patients with congestive heart failure: comparison with other chronic diseases and relation to functional variables. Heart 2002, 87:235-241

15. Iqbal J, Francis L, Reid J, Murray S, Denvir M. Quality of life in patients with chronic heart failure and their carers: a 3-year follow-up study assessing hospitalization and mortality. Eur J Heart Fail 2010,12:1002-1008

16. Janssen DJ, Franssen FM, Wouters EF, Schols JM, Spruit MA. Impaired health status and care dependency in patients with advanced COPD or chronic heart failure. Qual Life Res 2010, 20:1679-1688

17. Gaulden L. Diagnosis and management of heart failure in the long-term care setting. Director 2003, 11:177-181

18. Pulignano G, Del Sindaco D, Tavazzi L, Lucci D, Gorini M, Leggio F, Porcu M, Scherillo M, Opasich C, Di Lenarda A, Senni M, Maggioni AP. Clinical features and outcomes of elderly outpatients with heart failure followed up in hospital cardiology units: Data from a large nationwide cardiology database (IN-CHF Registry). American heart Journal 2002, 143:45-55 


\section{Chapter 3}

19. Ruths S, Straand J, Nygaard HA, Hodneland F. Drug treatment of heart failure--do nursing-home residents deserve better? Scand J Prim Health Care 2000, 18:226-231.

20. Schols JM. Nursing home medicine in The Netherlands. Eur J Gen Pract 2005, 11:141-143

21. Barnes S, Gott M, Payne S, Parker C, Seamark D, Gariballa S, Small N. Recruiting older people into a large, community-based study of heart failure. Chronic Illn 2005, 1:321-329

22. Folstein MF, Folstein SE, McHugh PR. "Mini-mental state". A practical method for grading the cognitive state of patients for the clinician. J Psychiatr Res 1975, 12:189-198

23. Dutch institute for health Care improvement (CBO). Multidisciplinaire richtlijn hartfalen. 2010. [www.cbo.nl/Downloads/1081/rl_hartfalen_2010.pdf]

24. Dijkstra A, Tiesinga LJ, Plantinga L, Veltman G, Dassen TW. Diagnostic accuracy of the care dependency scale. J Adv Nurs 2005, 50:410-416

25. Dijkstra A, Tiesinga LJ, Goossen WT, Dassen TW. Further psychometric testing of the Dutch Care Dependency Scale on two different patient groups. Int J Nurs Pract 2002, 8:305-314

26. Ware J, Jr., Kosinski M, Keller SD. A 12-Item Short-Form Health Survey: construction of scales and preliminary tests of reliability and validity. Med Care 1996, 34:220-233

27. Ettema TP, Droes RM, de Lange J, Mellenbergh GJ, Ribbe MW. QUALIDEM: development and evaluation of a dementia specific quality of life instrument--validation. Int J Geriatr Psychiatry 2007, 22:424-430

28. Verbeek H, Zwakhalen SM, van Rossum E, Ambergen T, Kempen GI, Hamers JP. Dementia care redesigned: Effects of small-scale living facilities on residents, their family caregivers, and staff. J Am Med Dir Assoc 2010, 11:662-670

29. Butler R, Fonseka S, Barclay L, Sembhi S, Wells S. The health of elderly residents in long term care institutions in New Zealand. N Z Med J 1999, 112:427-429 


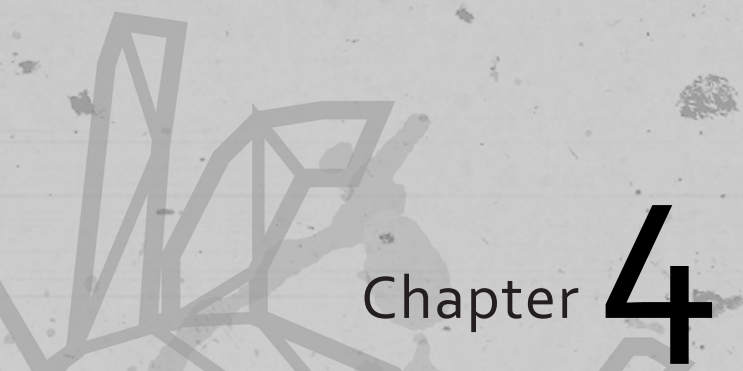

Heart failure in nursing home residents; a cross-sectional study to determine the prevalence and clinical characteristics

Mariëlle AMJ Daamen, Jan PH Hamers, Anton PM Gorgels, Hans-Peter Brunner-la Rocca, Frans ES Tan, Marja P van Dieijen-Visser, Jos MGA Schols

Published in BMC geriatrics. 2015;15:167 


\section{Chapter 4}

\section{ABSTRACT}

Background: Heart failure (HF) is expected to be highly prevalent in nursing home residents, but precise figures are scarce. The aim of this study was to determine the prevalence of HF in nursing home residents and to get insight in the clinical characteristics of residents with HF.

Methods: The study followed a multi-centre cross-sectional design.

Nursing home residents $(n=501)$ in the southern part of the Netherlands aged over 65 years and receiving long-term somatic or psychogeriatric care were included in the study. The diagnosis of HF and related characteristics were based on data collected from actual clinical examinations (including history, physical examination, ECG, cardiac markers and echocardiography), patient records and questionnaires. A panel of two cardiologists and a geriatrician ultimately judged the data to diagnose HF.

Results: The overall prevalence of HF in nursing residents was 33\%, of which $52 \%$ had HF with preserved ejection fraction. The symptoms dyspnoea and oedema and a cardiac history were more common in residents with HF. Diabetes mellitus, chronic obstructive pulmonary disease (COPD) were also more prevalent in those with HF. Residents with HF had a higher score on the Mini Mental State Examination. 54\% of those with HF where not known before, and in $31 \%$ with a history of HF, this diagnosis was not confirmed by the expert panel.

Conclusion: This study shows that HF is highly prevalent in nursing home residents with many unknown or falsely diagnosed with HF. Equal number of HF patients had reduced and preserved left-ventricular ejection fraction. 


\section{BACKGROUND}

In Western countries, heart failure (HF) is common in older people. The prevalence of $\mathrm{HF}$ increases up to $17.4 \%$ at the age of 85 years and more.(1) It is a growing problem as the population ages and survival rates after cardiovascular events increase.(2) In addition, there is a longer exposure to risk factors for HF and age-related changes.(3) Various factors such as older age, hypertension, diabetes mellitus (DM), obesity and coronary artery disease (CAD) have been described as risk factors for developing HF. $(4,5)$

Early diagnosis and treatment of HF may prevent progression and lead to improvement of symptoms and quality of life $(6,7)$, which are especially important in the care of nursing home residents. These residents can be described as old and considerably disabled persons, with either chronic somatic diseases or progressive dementia beyond the range of home care services.(8) The diagnosis of $\mathrm{HF}$ in nursing home residents is however challenging, due to atypical signs and symptoms, cognitive impairment, immobility, polypharmacy and misinterpretation of symptoms due to comorbidities. $(9,10)$ Importantly, these residents often do not undergo proper diagnostics as recommended by the guidelines.(11) As a consequence, the prevalence of HF in such residents may be significantly underestimated, but also overestimated due to misinterpretation of symptoms corresponding to comorbidities. A systematic review by Daamen et al. showed that the prevalence of $\mathrm{HF}$ in nursing home residents is estimated to be $15-25 \%$.(12) The diagnosis of HF was, however, based on information derived from medical records only in all but one study included. In this study by Butler et al., the diagnosis of HF was made after a clinical examination, resulting in an HF prevalence as high as $45 \%$.(13) However, the prevalence in UK long-term care facilities was recently reported to be much lower when also using echocardiography (i.e. 23\%).(14) Thus, there is significant uncertainty regarding the proper diagnosis of HF in nursing home residents. The aim of this study was, therefore, to determine the prevalence and clinical characteristics of HF in Dutch nursing home residents, based on an onsite comprehensive HF assessment, including not only medical history, medication and clinical assessment, but also ECG, echocardiography and biomarkers. The final diagnosis was made by an expert panel.

\section{METHODS}

This study followed a multi-centre cross-sectional design as previously published.(15) The study protocol complied with the declaration of Helsinki and has been granted approval from the Medical Ethics Committee of Maastricht University/Academic Hospital Maastricht (NL33281.068.10/MEC10-3-074). The study has been registered in the Netherlands National Trial Register (NTR2663). 


\section{Setting and participants}

In the southern parts of the Netherlands, long-term care is covered by five organizations providing nursing home care, with an overall number of approximately 4.500 nursing home residents. Nursing home care in the Netherlands is provided by teams of registered nurses, nurse assistants, paramedical professionals and nursing home physicians, who are employed by the nursing homes themselves.(16) The types of care offered by nursing homes include long-term care (somatic or psychogeriatric), rehabilitation, respite care, palliative (or hospice) care, consultation and advice and also crisis intervention.(8)

Nursing home residents of 28 locations allocated to these five long-term care organizations were asked to participate in the study $(n=1920)$. To complete the study within the specified time period (January 2011 to June 2013) and for practical and logistical reasons, nursing home residents living in the facilities with the highest number of residents were first recruited within each care home organization. The number of locations involved per organization differed from 3 to 8 . Residents were eligible if they received chronic somatic care or psychogeriatric care and were over 65 years of age. Residents who received palliative care or were admitted for short-term rehabilitation (staying less than 2 months) were excluded. Informed written consent was obtained from the residents themselves or from their legal representatives in the case of psychogeriatric disorder, or residents with aphasia.

Based on our systematic review, the expected prevalence of HF was $20 \%$ with a range of $15-45 \%$.(12) For the calculation of the required sample size, it seemed reasonable to assume that the estimated prevalence of HF in nursing home residents would be within the range $p=0.20$ to $p=0.40$ with a confidence interval width of $25 \%$ of the estimated prevalence. Accordingly, 368 (if $p=0.40$ ) to 983 residents (if $p=0.20$ ) should be included in the study for sufficient power as described.(15)

\section{Measurements and materials}

\section{Demographic data and clinical characteristics}

Data regarding general and clinical characteristics were gathered for all participating residents. These included age, gender and symptoms and signs of HF (dyspnoea, orthopnoea, palpitations, paroxysmal nocturnal dyspnoea (PND), fatigue, increased weight, pulse rate, blood pressure, increased jugular venous pressure, hepatojugular reflux, right ventricular pulsations, hepatic pulsations, hepatomegaly, oedema, palpable apex, displacement of the apex, third heart sound, murmur, pulmonary rales, pleural effusion). Moreover, information regarding cardiac history (hypertension, myocardial infarction, arrhythmia, CAD, valvular heart disease, coronary bypass graft, pacemaker, pre-existing heart failure), comorbidity, cardiovascular risk factors (Body Mass Index (BMI), hypercholesterolemia, DM and smoking) and medication (cardiac and 
non-cardiac medication) were collected. Patients underwent a Mini Mental State Examination (MMSE), blood sampling, a standard 12-lead electrocardiogram (ECG) and an echocardiogram. Doppler-echocardiography was performed according to current standards from parasternal, apical and epigastric views.(17)

\section{Study procedure of the heart failure assessment}

First, a nursing home physician (NHP) assessed medical history and performed physical examination. Before the start of the study, this NHP (3-4 per organization) had received a refresher course on diagnosing $\mathrm{HF}$ and performing a structured physical examination. The training included a review of signs and symptoms of HF followed by bedside teaching ( 3 hours), a lecture on ECG findings in relation to HF ( 2 hours) and a visit to the outpatient HF clinic of the Maastricht University Medical Centre (3 hours). Two research nurses and an NHP/researcher were responsible for recording the ECGs, collecting the blood samples, gathering data from the medical records and filling in the questionnaires. Qualified (fellow) cardiologists recorded an echocardiogram on site. The entire assessment was carried out on site in the participating nursing homes with a mean time span of four weeks to complete data collection per resident.

The actual history and physical examination were recorded on a client record file developed for this study. Somatic residents answered the history-related questions themselves and for psychogeriatric residents, the nurses responsible for their daily care or the main family caregiver of the resident answered these questions. $\mathrm{N}$ terminal of the prohormone brain natriuretic peptide (NT-pro BNP), haemoglobin and serum creatinine concentrations were analysed at the clinical chemistry laboratory of the Maastricht University Medical Centre on an Elecsys 2010 (Roche Diagnostics, Mannheim, Germany). A standard 12-lead ECG was made using the Cardiovit AT-10 plus (Schiller, Switzerland). The following (possibly HF-related) ECG findings were recorded: sinus tachycardia (heart rate $>100$ beats/min), sinus bradycardia (heart rate $<60$ beats/min), pathological Q-waves, atrial fibrillation, ventricular arrhythmia, different degrees of AV-block, low voltage of the QRS complexes $(<5 \mathrm{~mm}$ in the frontal plan), QRS widening (> $0.12 \mathrm{~ms}$ ) due to right bundle branch block, left bundle branch block or non-specific widening and left (LV) and/or right ventricular (RV) hypertrophy[18]. The echocardiogram was performed using a Philips CX 50 Compact Xtreme Ultrasound System (Philips, the Netherlands). The following parameters were measured using standard views (Lang); LV end-diastolic and end-systolic diameter, LV wall thickness, LV function indicators such as fractional shortening and LV ejection fraction, diastolic function variables such as E/A and E/E' ratio, left atrial size, valvular structure and function, tricuspid regurgitation velocity peak as an indicator of RV systolic pressure, RV dilatation and/or hypertrophy and dysfunction and vena cava inferior width and respiratory variation as a marker of venous overload. A LV ejection fraction of $\geq 50 \%$ was regarded as preserved ejection fraction.(19) 


\section{Chapter 4}

\section{Diagnosis of heart failure}

An expert team of two cardiologists and a geriatrician were responsible for the final diagnosis of HF using all data collected by the NHP, research nurse and (fellow) cardiologist, based on the current guidelines of the European Society of Cardiology (ESC).(20)

1. Signs and symptoms of HF

2. Presence of structural or functional cardiac abnormalities.

The members of the expert team judged all files independently. First the data were judged on the presence of signs and symptoms. Subsequently, the measurements of the echocardiography and the ECG were used to assess functional and/or structural cardiac abnormalities, compatible with the diagnosis of HF. In the absence of current signs and symptoms, medical history and medication provided important information to make the diagnosis of HF. In residents without an echocardiogram or in the case of uncertainty regarding the diagnosis, the NT-pro BNP value, ECG findings, medical history and medication (in that order) were considered for the final diagnosis.

When there was mutual agreement on the diagnosis, the file was closed. All files with disagreement were discussed in the presence of all three members of the expert team to reach a consensus on the final diagnosis.

\section{STATISTICAL ANALYSIS}

Statistical analyses were performed using IBM SPSS statistics software version 20 and included descriptive frequency distributions for all variables. Differences between groups were tested using Student's $t$-tests or analysis of variance (ANOVA) for continuous variables and Chi-square test (cross-table analysis) and multivariable logistic regression analysis for discrete variables, respectively, with a level of significance of $p<0.05$ for all variables. The selection of variables included in the multivariable logistic regression analysis was based on the literature and expert opinion. These variables were gender, CAD, BMI, DM, chronic obstructive pulmonary disease (COPD), haemoglobin, creatinine, heart rate, systolic blood pressure, pre-existing HF, arrhythmia, valvular heart disease. $(21,22)$ To avoid circular reasoning the variables dyspnoea, signals of right-sided HF and NT-pro BNP were not added to the model, because these were used to diagnose HF. 


\section{RESULTS}

\section{Study sample}

Of the residents fulfilling the inclusion criteria, $27 \%$ of those or their legal representatives agreed to participate. Main reasons for not participating included that residents considered themselves too old or believed that the investigations were too burdensome. The expert team eventually assessed 501 client record files and decided on the diagnosis of HF. HF assessment (medical history, physical examination, blood sampling, ECG and echo) was completed for $87 \%$ of the participating residents (see Figure 1 for further details). Missing blood samples occurred because of the inability to puncture the vein. Some ECG's could not be made due to resistance $(n=3)$ and extreme tremor in the limbs $(n=2)$. Missing outcomes of echocardiography were mainly caused by poor image quality due to e.g. obesity and in case of COPD. In a minority of cases $(n=10)$ psychogeriatric residents resisted against the echocardiography.

The demographic characteristics, age, gender and ward type showed no clinical significance differences for both participants and non-participants (see Table 1).

\section{The prevalence of heart failure}

The prevalence of $\mathrm{HF}$ in nursing home residents was $33 \%$ with a $95 \%$ confidence interval of $29 \%$ to $37 \%$, of which $54 \%$ were not previously known (figure 2). HF was more often diagnosed in the somatic group than in psychogeriatric residents. The prevalence was practically similar in men and women. Reduced LV ejection fraction was present in 64 and preserved ejection fraction in 70 cases. Asymptomatic systolic dysfunction of the left ventricle (LVEF < 50 without symptoms, stage B) was found in 27 residents (see also table 2).

$\mathrm{HF}$ was recorded in the medical history of 112 residents. The diagnosis of HF was rejected in $31 \%$ of those residents. Figure 2 shows an overview of the prevalence of HF compared with HF previously recorded in medical files. 


\section{Chapter 4}

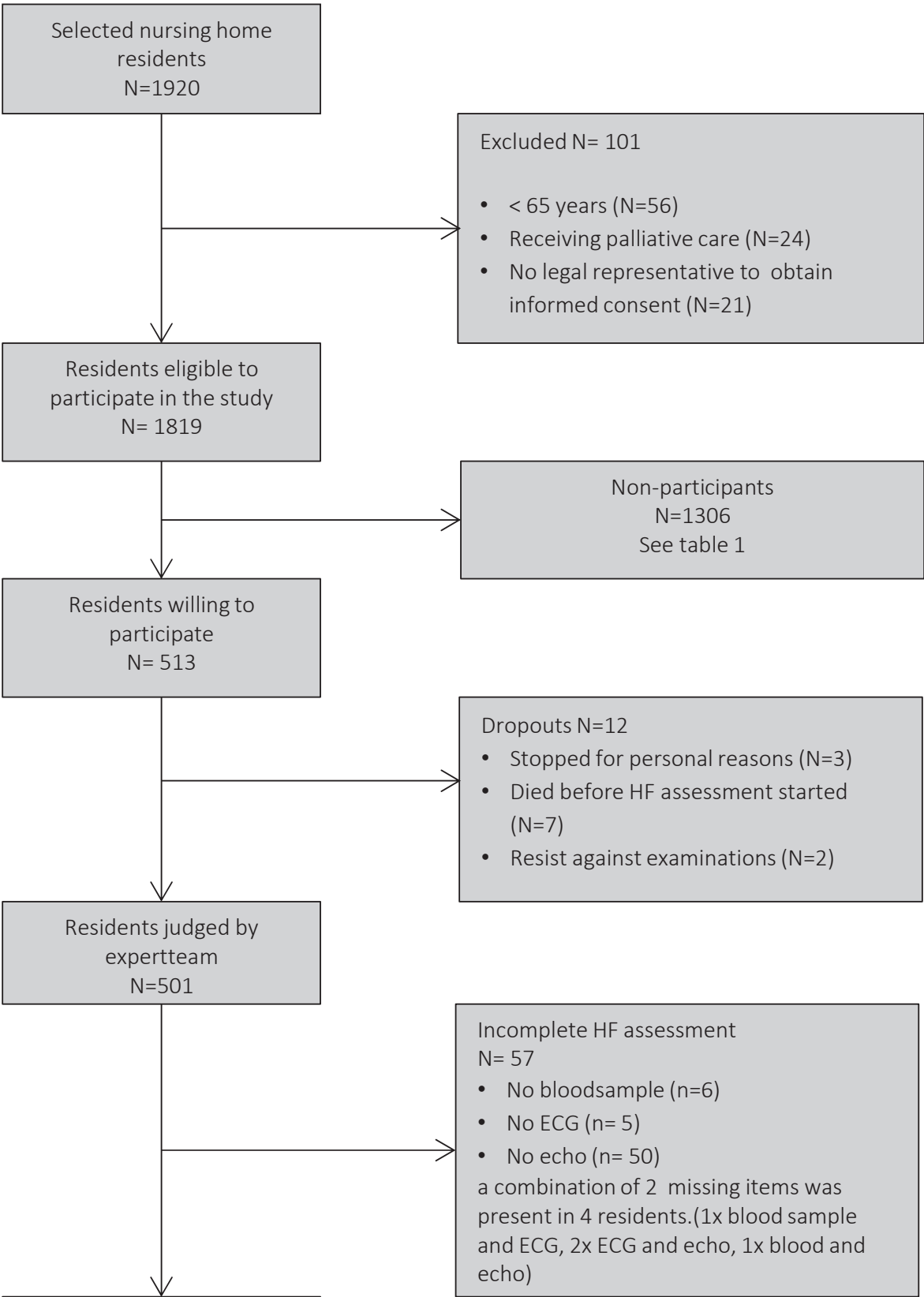

Residents with complete

HF-assessment $\mathrm{N}=444$

Figure 1. Flow chart of residents' participation 
Table 1. Basis characteristics of participants and non-participants

\begin{tabular}{llccc}
\hline Characteristics & & Participants $(\mathrm{n}=513)$ & $\begin{array}{c}\text { Non- participants } \\
(\mathrm{n}=1306) *\end{array}$ & p-value \\
\hline Age (years) & $65-74$ & $69(14 \%)$ & $116(11 \%)$ & \\
& $75-84$ & $238(46 \%)$ & $436(43 \%)$ & 0.113 \\
& $85^{+}$ & $206(40 \%)$ & $464(46 \%)$ & 0.005 \\
Gender & Mean (SD, range) & $82(7,65-100)$ & $83(7,65-108)$ & 0.04 \\
& Male & $184(36 \%)$ & $376(29 \%)$ & $930(71 \%)$ \\
Ward & Female & $329(64 \%)$ & $889(68 \%)$ & 0.224 \\
& Psychogeriatric care & $336(65 \%)$ & $417(32 \%)$ & \\
\hline
\end{tabular}

*Age available for $n=1016$ non-participants

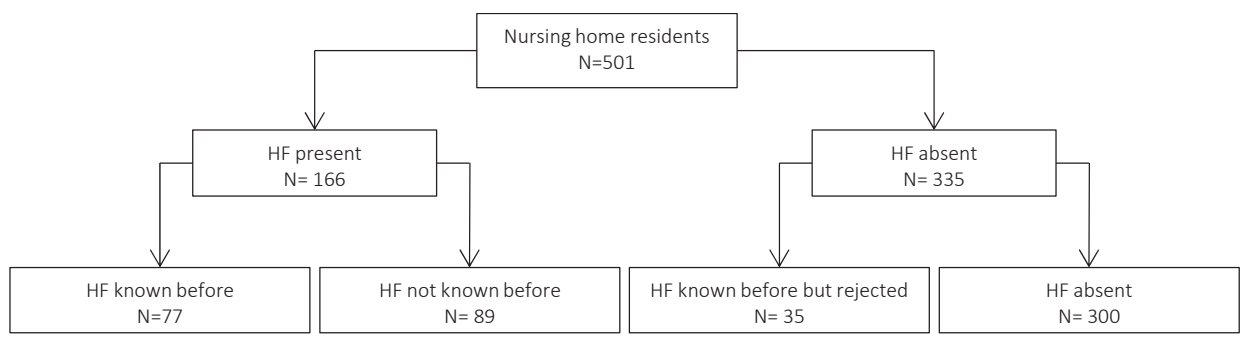

Figure 2. Prevalence of HF compared with HF previously recorded in medical files

Table 2. Presence of heart failure in nursing home residents

\begin{tabular}{llcccccc}
\hline Variabele & HF absent & HF present & $\begin{array}{c}(95 \%-C I) \\
\text { of perc. HF }\end{array}$ & HFrEF* & HFpEF* & $\begin{array}{c}\text { Asymptomatic } \\
\text { HF with rEF** }\end{array}$ \\
\hline Total & $335(67 \%)$ & $166(33 \%)$ & $(29 \%, 37 \%)$ & $64(48 \%)$ & $70(52 \%)$ & $27(10 \%)$ \\
Gender & Male & $118(66 \%)$ & $61(34 \%)$ & $(30 \%, 38 \%)$ & $29(58 \%)$ & $21(42 \%)$ & $12(44 \%)$ \\
& Female & $217(67 \%)$ & $105(33 \%)$ & $(29 \%, 37 \%)$ & $35(42 \%)$ & $49(58 \%)$ & $15(56 \%)$ \\
\multirow{2}{*}{ Ward } & $\begin{array}{l}\text { Psychogeriatric } \\
\text { care }\end{array}$ & $227(70 \%)$ & $99(30 \%)$ & $(26 \%, 34 \%)$ & $36(45 \%)$ & $44(55 \%)$ & $19(70 \%)$ \\
& & & & & & $8(30 \%)$ \\
\hline
\end{tabular}

HFrEF heart failure with reduced ejection fraction, HFpEF heart failure with preserved ejection fraction, rEF reduced ejection fraction

*Echo data about left ventricular ejection fraction (LVEF) available for 134 of the 166 residents with HF

** Echo data about LVEF available for 271 of the 335 residents without HF 


\section{Clinical characteristics}

As depicted in table 3, residents with HF were older, more likely to have complaints of orthopnoea and palpitations, more often had a cardiac history of myocardial ischemia, myocardial infarction and arrhythmia and more often displayed signs of an increased jugular venous pressure, pulsations of the right ventricle, oedema, murmurs and pulmonary rales. A higher number of nursing home residents with $\mathrm{HF}$ had diabetes mellitus, COPD and/or less cognitive disorders. However, none of these factors were sufficiently sensitive or specific for diagnosing or excluding heart failure. Regarding the cardiac risk factors (hypercholesterolemia, smoking and $\mathrm{BMI}$ ), there were no differences between the study groups with and without HF.

The independent predictors of prevalent HF entered in the multivariable logistic regression model are presented in Table 4 . The non-significant variables $(p>0.05)$ were removed stepwise using the backward procedure. The final model showed that the variables, CAD, arrhythmia, age, creatinine and HF in history being significant in univariate analysis were independent factors associated with the presence of HF.

Table 3. Demographic and clinical characteristics

\begin{tabular}{|c|c|c|c|c|}
\hline Variables & $\begin{array}{l}\text { Total } \\
\mathrm{N}=501\end{array}$ & $\begin{array}{c}\mathrm{HF}- \\
\mathrm{N}=335\end{array}$ & $\begin{array}{c}\mathrm{HF}+ \\
\mathrm{N}=166\end{array}$ & $\mathrm{p}$-value \\
\hline Age (years) mean (SD) & $82(7)$ & $81(7)$ & $84(6)$ & $<.001$ \\
\hline Gender, male n (\%) & $179(36)$ & $118(35)$ & $61(37)$ & 0.738 \\
\hline Psychogeriatric n (\%) & $326(65)$ & $227(68)$ & $99(60)$ & 0.073 \\
\hline \multicolumn{5}{|l|}{ Symptoms } \\
\hline \multicolumn{5}{|l|}{ NYHA class $n(\%) n=494$} \\
\hline 1 & $301(60)$ & $235(70)$ & $66(40)$ & $<.001$ \\
\hline 2 & $108(22)$ & $55(16)$ & $53(33)$ & $<.001$ \\
\hline 3 & $57(11)$ & $26(8)$ & $31(19)$ & 0.001 \\
\hline 4 & $28(6)$ & $15(5)$ & $13(8)$ & 0.203 \\
\hline Orthopnoea $n(\%) n=486$ & $62(12)$ & 29 (9) & $33(20)$ & 0.001 \\
\hline Palpitations $n(\%) n=484$ & $70(14)$ & $27(8)$ & $43(26)$ & $<.001$ \\
\hline PND $n(\%) n=486$ & $40(8)$ & $22(7)$ & $18(11)$ & 0.033 \\
\hline Fatigue $n(\%) n=492$ & $183(37)$ & $113(34)$ & $70(42)$ & 0.178 \\
\hline Weight gain $n(\%) n=480$ & $97(19)$ & $69(21)$ & $28(17)$ & 0.522 \\
\hline \multicolumn{5}{|l|}{ Physical examination } \\
\hline Anemic $n(\%) n=500$ & $28(6)$ & $17(5)$ & $11(7)$ & 0.609 \\
\hline Cyanotic $n(\%) n=500$ & $1(0,2)$ & $1(0,3)$ & $1(0,6)$ & 0.284 \\
\hline Dyspnoea $\mathrm{n}(\%) \mathrm{n}=497$ & $82(16)$ & $43(13)$ & $39(24)$ & 0.004 \\
\hline Pulse rate mean(SD) $n=500$ & $73(14)$ & $72(12)$ & $74(17)$ & 0.069 \\
\hline Systolic blood pressure mean (SD) $n=498$ & $139(26)$ & $141(26)$ & $136(25)$ & 0.030 \\
\hline Diastolic blood pressure mean (SD) $n=498$ & $75(14)$ & $75(13)$ & 74 15) & 0.219 \\
\hline
\end{tabular}




\begin{tabular}{|c|c|c|c|c|}
\hline Variables & $\begin{array}{l}\text { Total } \\
\mathrm{N}=501\end{array}$ & $\begin{array}{c}\mathrm{HF}- \\
\mathrm{N}=335\end{array}$ & $\begin{array}{c}\mathrm{HF}+ \\
\mathrm{N}=166\end{array}$ & p-value \\
\hline Increased VJ pressure $n(\%) n=481$ & $128(26)$ & $66(20)$ & $166(37)$ & $<.001$ \\
\hline HPR n (\%) n=468 & $26(5)$ & $16(5)$ & $10(6)$ & 0.570 \\
\hline Pulsations RV n (\%) & $61(12)$ & $30(9)$ & $31(19)$ & 0.002 \\
\hline Pulsations liver n (\%) & $18(4)$ & $11(3)$ & $7(4)$ & 0.597 \\
\hline Hepatomegaly $n(\%) n=484$ & $35(7)$ & $20(6)$ & $15(9)$ & 0.298 \\
\hline Oedema $n(\%) n=500$ & $275(55)$ & $166(50)$ & $109(66)$ & $<.001$ \\
\hline Ictus palpable $n(\%) n=494$ & $158(32)$ & $102(30)$ & $56(34)$ & 0.628 \\
\hline Third heart sound $n(\%) n=467$ & $17(3)$ & $10(3)$ & $7(4)$ & 0.746 \\
\hline Murmur $n(\%) n=473$ & $185(37)$ & $110(33)$ & $75(45)$ & 0.019 \\
\hline Irregular heartbeats n (\%) n=498 & $153(31)$ & $66(20)$ & $87(52)$ & $<.001$ \\
\hline Rales n (\%) n=459 & $151(30)$ & $75(22)$ & $76(46)$ & $<.001$ \\
\hline Pleural effusion $n(\%) n=412$ & $34(7)$ & $15(5)$ & $19(11)$ & 0.008 \\
\hline \multicolumn{5}{|l|}{ Cardiac history } \\
\hline Hypertension n (\%) & $236(47)$ & $146(44)$ & $90(54)$ & 0.025 \\
\hline Myocardial infarction $n(\%) n=490$ & $81(16)$ & $37(11)$ & $44(27)$ & $<.001$ \\
\hline Arrhythmia n (\%) n=476 & $132(28)$ & $54(17)$ & $78(50)$ & $<.001$ \\
\hline Coronary ischemia $n(\%) n=490$ & $113(23)$ & $57(17)$ & $56(34)$ & $<.001$ \\
\hline Valvular heart disease $n(\%) n=495$ & $38(8)$ & $13(4)$ & $25(15)$ & $<.001$ \\
\hline Coronary bypass graft n (\%) n=496 & $40(8)$ & $17(5)$ & $23(14)$ & 0.003 \\
\hline Pace maker $n(\%) n=493$ & $19(4)$ & $8(2,4)$ & $11(7)$ & 0.059 \\
\hline Heart failure in history n (\%) & $112(22)$ & $35(10)$ & $77(46)$ & $<.001$ \\
\hline \multicolumn{5}{|l|}{ Blood sample } \\
\hline NT- pro BNP mean(IQR) $\mathrm{n}=493 \mathrm{nmol} / \mathrm{L}$ & $138(3-4130)$ & $61(3-3427)$ & $292(13-4130)$ & $<.001$ \\
\hline Creatinine $\mu \mathrm{mol} / \mathrm{I}$ mean (SD) $\mathrm{n}=493$ & $88(51)$ & $82(44)$ & $99(61)$ & $<.001$ \\
\hline Haemoglobin $\mathrm{mmol} / \mathrm{l}$ mean (SD) $\mathrm{n}=467$ & $8,0(0,90)$ & $8,1(0,87)$ & $7,8(0,93)$ & 0.002 \\
\hline \multicolumn{5}{|l|}{ Comorbidity } \\
\hline Diabetes mellitus n (\%) & $107(21)$ & $63(19)$ & $4426)$ & 0.048 \\
\hline COPD n (\%) & $83(17)$ & $45(13)$ & $38(23)$ & 0.007 \\
\hline CVA n (\%) & $207(41)$ & $131(39)$ & $76(46)$ & 0.153 \\
\hline \multicolumn{5}{|l|}{ Cardiac risk factors } \\
\hline BMI mean $(S D) n=488$ & $25(5)$ & $25(5)$ & $26(5)$ & 0,224 \\
\hline Hypercholesterolemia n (\%) n=444 & $130(26)$ & $88(26)$ & $42(25)$ & 0.209 \\
\hline Smoking $n(\%) n=492$ & $68(14)$ & $46(14)$ & $2213)$ & $0.35^{8}$ \\
\hline \multicolumn{5}{|l|}{ Cognitive function } \\
\hline MMSE mean (SD) n=477 & 14 (9) & $13(9)$ & $16(8)$ & 0.011 \\
\hline
\end{tabular}

NYHA New York Heart Association, PND paroxysmal nocturnal dyspnea, HPR hepatojugular reflux, RV right ventricle, NT-proBNP N-terminal of prohomone brain natriuretic peptide, COPD chronic obstructive pulmonary disease, CVA cerebrovascular accidents, BMI body mass index, MMSE mini mental state examination. 


\section{Chapter 4}

Table 4. Multivariable Logistic Regression Analysis

\begin{tabular}{|c|c|c|c|c|c|c|c|c|}
\hline \multirow{3}{*}{$\frac{\text { Variable }}{\text { Gender }}$} & \multirow{3}{*}{$\begin{array}{l}\text { OR Ratio } \\
0.98\end{array}$} & \multirow{2}{*}{\multicolumn{2}{|c|}{$95 \%-\mathrm{Cl}$}} & \multirow[b]{2}{*}{$\mathrm{p}$-value } & \multicolumn{4}{|c|}{ Final model } \\
\hline & & & & & $\overline{O R}$ & $95 \%-C$ & & $p$-value \\
\hline & & 0.58 & 1.65 & 0.92 & & & & \\
\hline Coronary artery disease & 2.24 & 1.36 & 3.68 & 0.002 & 2.10 & 1.29 & 3.40 & 0.003 \\
\hline Body Mass Index $\left(\mathrm{kg} / \mathrm{m}^{2}\right)$ & 1.03 & 0.98 & 1.08 & 0.29 & & & & \\
\hline Diabetes mellitus & 1.09 & 0.62 & 1.91 & 0.77 & & & & \\
\hline COPD & 1.15 & 0.63 & 2.10 & 0.64 & & & & \\
\hline Haemoglobin $(\mathrm{mmol} / \mathrm{l})$ & 0.84 & 0.65 & 1.11 & 0.22 & & & & \\
\hline Arrhythmia & 3.80 & 2.32 & 6.23 & $<.001$ & 4.12 & 2.55 & 6.65 & $<.001$ \\
\hline Age (years) & 1.08 & 1.04 & 1.12 & $<.001$ & 1.07 & 1.04 & 1.11 & $<.001$ \\
\hline Creatinine $(\mu \mathrm{mol} / \mathrm{l})$ & 1.01 & 1.00 & 1.01 & 0.06 & 1.01 & 1.00 & 1.01 & 0.026 \\
\hline Heart failure in history & 5.46 & 3.23 & 9.24 & $<.001$ & 5.97 & 3.58 & 9.95 & $<.001$ \\
\hline Valvular heart disease & 0.92 & 0.72 & 1.18 & 0.52 & & & & \\
\hline Heart rate (beats/min) & 1.01 & 0.99 & 1.03 & 0.26 & & & & \\
\hline $\begin{array}{l}\text { Systolic blood pressure } \\
(\mathrm{mmHg})\end{array}$ & 1.00 & 0.99 & 1.01 & 0.43 & & & & \\
\hline
\end{tabular}

\section{DISCUSSION}

In this study, the prevalence of HF was $33 \%$ for all participating nursing home residents, of which more than half were previously undiagnosed and a previous diagnosis of HF was rejected in almost one third. HFpEF and HFrEF were equally prevalent. Therefore, the hypothesis that HF is highly prevalent in nursing home residents is confirmed, and the prevalence was clearly higher than among older persons in the general population.(1)

The prevalence of $45 \%$ found in a study by Butler et al.(13) in which HF was diagnosed in nursing home residents after physical examination by a geriatrician, is higher than in our study. However, the limitations of that study were the lack of a clear description of HF and the lack of further diagnostics such as an echocardiogram as recommended by the guidelines.(20) Therefore, the presence of HF may be overestimated, which follows from other studies of a similar population by Hancock et al.(14) and Barents et al.(23) where the prevalence of HF was much lower (i.e. 23\%). The HF assessment and definition of HF in these studies were similar to our study. The demographic and clinical characteristics of the residents were also comparable to our study. There is no obvious explanation as to why the prevalence rate in our study was somewhat higher. The difference between the studies of Hancock et al (14) and Barents et al (23) and our study is the confirmation of the diagnosis of HF by an expert team of two cardiologists and a geriatrician. In their studies, there were individual decisions by two cardiologists and no panel discussions. 
Residents with HF had less cognitive disorders; a result that is not in line with studies in the literature where patients with HF suffer more often from cognitive disorders .$(24,25)$ This might be explained by the fact that there is a difference in study sample. Our nursing home residents are a specific group of older persons, where a high number suffers from cognitive disorders as the primary diagnosis. However analysis of the MMSE score in the subgroup of somatic residents still shows a higher MMSE score in residents with HF.

In the study by Hanock et al (14) more patients (i.e. app. two-third) with HFpEF were observed as compared to our study. HFpEF was equally common as HFrEF in our study, and as expected, more prevalent in women.(14) In large cohorts of the general population, the frequency of HFrEF versus HFpEF was also the same with approximately half having reduced and half having preserved $\operatorname{LVEF}(26,27)$, although average age was lower than in our cohort of nursing home residents (i.e. app 75 years). Asymptomatic left ventricular systolic dysfunction was additionally found in $10 \%$ of the residents in our study. Taken together, there was a substantial number of residents with reduced LVEF, i.e. approximately one fourth of all residents investigated in this study. Compared with the study by Hancock et al (14), this is a higher percentage of residents with reduced LVEF and could explain the difference in the prevalence of HF. HFrEF is better defined than HFpEF and particularly asymptomatic diastolic dysfunction in such an elderly population is difficult to determine. Therefore, direct comparison of patients with reduced LVEF between different cohorts may be more reliable despite some inaccuracy in measurement of LVEF by echocardiography.(28) Nevertheless, it obviously remains to be determined how many of the patients with asymptomatic reduced LVEF will develop signs and symptoms of HF over time.

Multivariable analysis showed that factors such as arrhythmia, CAD, age, a history of pre-existing HF were associated with the presence of HF. Interestingly, there was no association found with gender, which may be a risk factor for the development of $\mathrm{HF}$ in the general population.(29) There were no other studies in nursing home residents that investigated risk factors for prevalent HF in a multivariable analysis. Thus, the specific pattern of risk factors in residents of nursing homes needs to be confirmed in future trial, in particular because they differ somewhat to what is described in other cohorts.

Furthermore, the diagnosis of HF was not known in more than half of those having $\mathrm{HF}$ and a previous diagnosis of HF was not confirmed by the expert team in one third of all cases. These findings indicate an important problem, as a significant number of residents obviously might not be treated correctly. This could be of significant impact to residents of nursing homes as it can be expected that symptoms are not adequately recognised and treated in a substantial number of patients. Although not prospectively investigated by randomised treatment trials in this population, this may have important impact on well-being and quality of life. Moreover, it implies a challenge to improve the diagnostic process of HF in nursing homes residents. The implementation 
of the structured procedure used by the expert team may improve the diagnostic process significantly. This includes echocardiography using mobile devices in residents suspected to suffer from HF. The clinical features identified in this study to be accompanied with increased risk of prevalent HF may help to detect such patients that should undergo such structured work-up.

The strength of the present study is the thorough method of data collection using an on-site integral examination of each resident. On the other hand, the participation rate was not as high as anticipated (27\%). A consideration here is that legal representatives often do not want to decide for participation on behalf of the residents, which explains the lower participation rate of psychogeriatric patients. Our findings are in line with a study conducted by Barnes et al.(30) on HF in the elderly, where only $30 \%$ of patients agreed to participate. Still, residents included did not differ in a clinical meaningful way from those that did not agree to participate. Therefore, it is likely that the results of this study are representative for our nursing home population in the South of the Netherlands. A 10\% missing echo values can be seen as a limitation in this study. This may result in misdiagnosis in some patients and importantly, lack of information on potential underlying causes of heart failure and left-ventricular ejection fraction. This may negatively affect the quality of treatment in these patients. However, in routine clinical care, echocardiography cannot be performed in all subjects due to exactly the same reasons also found in our cohort.

Moreover, we did not investigate to what extent treatment would have changed based on more accurate diagnosis and the impact on the patients' well-being is unknown. This is particularly true since the large treatment trials that are the basis for the treatment recommendations did not include the population of our study. Still, guideline recommendations are independent of patient's age. Therefore, the diagnostic approach we used would at least result in treatment, which is better following the current guidelines. Finally, we included residents in one region only and results might be different in other countries and may depend on the structure of health care in each country. Therefore, it is important to conduct such studies in different countries as results in this regard are still very limited.

\section{CONCLUSION}

$\mathrm{HF}$ is highly prevalent in nursing home residents with many unknown or falsely diagnosed with HF. Equal number of HF patients had reduced and preserved leftventricular ejection fraction. 


\section{REFERENCES}

1. Bleumink GS, Knetsch AM, Sturkenboom MC, Straus SM, Hofman A, Deckers JW, Witteman JC, Stricker $\mathrm{BH}$ : Quantifying the heart failure epidemic: prevalence, incidence rate, lifetime risk and prognosis of heart failure The Rotterdam Study. Eur Heart J 2004, 25(18):1614-1619.

2. Kannel WB: Incidence and epidemiology of heart failure. Heart Fail Rev 2000, 5(2):167-173.

3. Jugdutt BI: Prevention of heart failure in the elderly: when, where and how to begin? Heart Fail Rev 2012, 17(4-5):531-544.

4. Lam CS, Donal E, Kraigher-Krainer E, Vasan RS: Epidemiology and clinical course of heart failure with preserved ejection fraction. Eur J Heart Fail 2011, 13(1):18-28.

5. Kaila K, Haykowsky MJ, Thompson RB, Paterson DI: Heart failure with preserved ejection fraction in the elderly: scope of the problem. Heart Fail Rev 2012, 17(4-5):555-562.

6. Gaulden L: Diagnosis and management of heart failure in the long-term care setting. Director 2003, 11(4):177-181.

7. Ruths S, Straand J, Nygaard HA, Hodneland F: Drug treatment of heart failure--do nursing-home residents deserve better? Scand J Prim Health Care 2000, 18(4):226-231.

8. Schols JM, Crebolder HF, van Weel C: Nursing home and nursing home physician: the Dutch experience. J Am Med Dir Assoc 2004, 5(3):207-212.

9. Oudejans I, Mosterd A, Bloemen JA, Valk MJ, van Velzen E, Wielders JP, Zuithoff NP, Rutten FH, Hoes AW: Clinical evaluation of geriatric outpatients with suspected heart failure: value of symptoms, signs, and additional tests. Eur J Heart Fail, 13(5):518-527.

10. Rutten FH, Cramer MJ, Grobbee DE, Sachs AP, Kirkels JH, Lammers JW, Hoes AW: Unrecognized heart failure in elderly patients with stable chronic obstructive pulmonary disease. Eur Heart $J$ 2005, 26(18):1887-1894.

11. Iacoviello M, Antoncecchi V: Heart failure in elderly: progress in clinical evaluation and therapeutic approach. Journal of geriatric cardiology : JGC 2013, 10(2):165-177.

12. Daamen MA, Schols JM, Jaarsma T, Hamers JP: Prevalence of heart failure in nursing homes: a systematic literature review. Scand J Caring Sci 2010, 24(1):202-208.

13. Butler R, Fonseka S, Barclay L, Sembhi S, Wells S: The health of elderly residents in long term care institutions in New Zealand. N Z Med J 1999, 112(1099):427-429.

14. Hancock HC, Close H, Mason JM, Murphy JJ, Fuat A, Singh R, Wood E, de Belder M, Brennan G, Hussain $\mathrm{N}$ et al: High prevalence of undetected heart failure in long-term care residents: findings from the Heart Failure in Care Homes (HFinCH) study. Eur J Heart Fail 2013, 15(2):158-165.

15. Daamen MA, Hamers JP, Gorgels AP, Brunner-la Rocca HP, Tan FE, van Dieijen-Visser MP, Schols JM: The prevalence and management of heart failure in Dutch nursing homes; design of a multi-centre cross-sectional study. BMC Geriatr 2012, 12:29.

16. Schols JM: Nursing home medicine in The Netherlands. Eur J Gen Pract 2005, 11(3-4):141-143.

17. Lang RM, Bierig M, Devereux RB, Flachskampf FA, Foster E, Pellikka PA, Picard MH, Roman MJ, Seward J, Shanewise JS et al: Recommendations for chamber quantification: a report from the American Society of Echocardiography's Guidelines and Standards Committee and the Chamber Quantification Writing Group, developed in conjunction with the European Association of Echocardiography, a branch of the European Society of Cardiology. J Am Soc Echocardiogr 2005, 18(12):1440-1463.

18. O'Keefe Jr J., Hammill S., Freed M., Poqwizd S.: The ECG criteria book., 2nd edn. Sudbury: Jones and Bartlett Publishers; 2011.

19. Yancy CW, Jessup M, Bozkurt B, Butler J, Casey DE, Jr., Drazner MH, Fonarow GC, Geraci SA, Horwich T, Januzzi JL et al: 2013 ACCF/AHA guideline for the management of heart failure: executive summary: a report of the American College of Cardiology Foundation/American Heart Association Task Force on practice guidelines. Circulation 2013, 128(16):1810-1852. 


\section{Chapter 4}

20. McMurray JJ, Adamopoulos S, Anker SD, Auricchio A, Bohm M, Dickstein K, Falk V, Filippatos G, Fonseca C, Gomez-Sanchez MA et al: ESC Guidelines for the diagnosis and treatment of acute and chronic heart failure 2012: The Task Force for the Diagnosis and Treatment of Acute and Chronic Heart Failure 2012 of the European Society of Cardiology. Developed in collaboration with the Heart Failure Association (HFA) of the ESC. Eur Heart J 2012, 33(14):1787-1847.

21. Cowie MR, Mosterd A, Wood DA, Deckers JW, Poole-Wilson PA, Sutton GC, Grobbee DE: The epidemiology of heart failure. Eur Heart J 1997, 18(2):208-225.

22. Cowie MR, Wood DA, Coats AJ, Thompson SG, Poole-Wilson PA, Suresh V, Sutton GC: Incidence and aetiology of heart failure; a population-based study. Eur Heart J 1999, 20(6):421-428.

23. Barents $M$, van der Horst IC, Voors AA, Hillege $J L$, Muskiet FA, de Jongste MJ: Prevalence and misdiagnosis of chronic heart failure in nursing home residents: the role of B-type natriuretic peptides. Neth Heart J 2008, 16(4):123-128.

24. Pressler SJ, Subramanian U, Kareken D, Perkins SM, Gradus-Pizlo I, Sauve MJ, Ding Y, Kim J, Sloan R, Jaynes $\mathrm{H}$ et al: Cognitive deficits in chronic heart failure. Nurs Res 2010, 59(2):127-139.

25. Zuccala G, Pedone C, Cesari M, Onder G, Pahor M, Marzetti E, Lo Monaco MR, Cocchi A, Carbonin P, Bernabei R: The effects of cognitive impairment on mortality among hospitalized patients with heart failure. Am J Med 2003, 115(2):97-103.

26. Owan TE, Hodge DO, Herges RM, Jacobsen SJ, Roger VL, Redfield MM: Trends in prevalence and outcome of heart failure with preserved ejection fraction. N Engl J Med 2006, 355(3):251-259.

27. Tribouilloy C, Rusinaru D, Mahjoub H, Souliere V, Levy F, Peltier M, Slama M, Massy Z: Prognosis of heart failure with preserved ejection fraction: a 5 year prospective population-based study. Eur Heart $J$ 2008, 29(3):339-347.

28. Kaufmann BA, Min SY, Goetschalckx K, Bernheim AM, Buser PT, Pfisterer ME, Brunner-La Rocca HP: How reliable are left ventricular ejection fraction cut offs assessed by echocardiography for clinical decision making in patients with heart failure? Int J Cardiovasc Imaging 2013, 29(3):581-588.

29. Ammar KA, Jacobsen SJ, Mahoney DW, Kors JA, Redfield MM, Burnett JC, Jr., Rodeheffer RJ: Prevalence and prognostic significance of heart failure stages: application of the American College of Cardiology/American Heart Association heart failure staging criteria in the community. Circulation 2007, 115(12):1563-1570.

30. Barnes S, Gott M, Payne S, Parker C, Seamark D, Gariballa S, Small N: Recruiting older people into a large, community-based study of heart failure. Chronic Illn 2005, 1(4):321-329. 


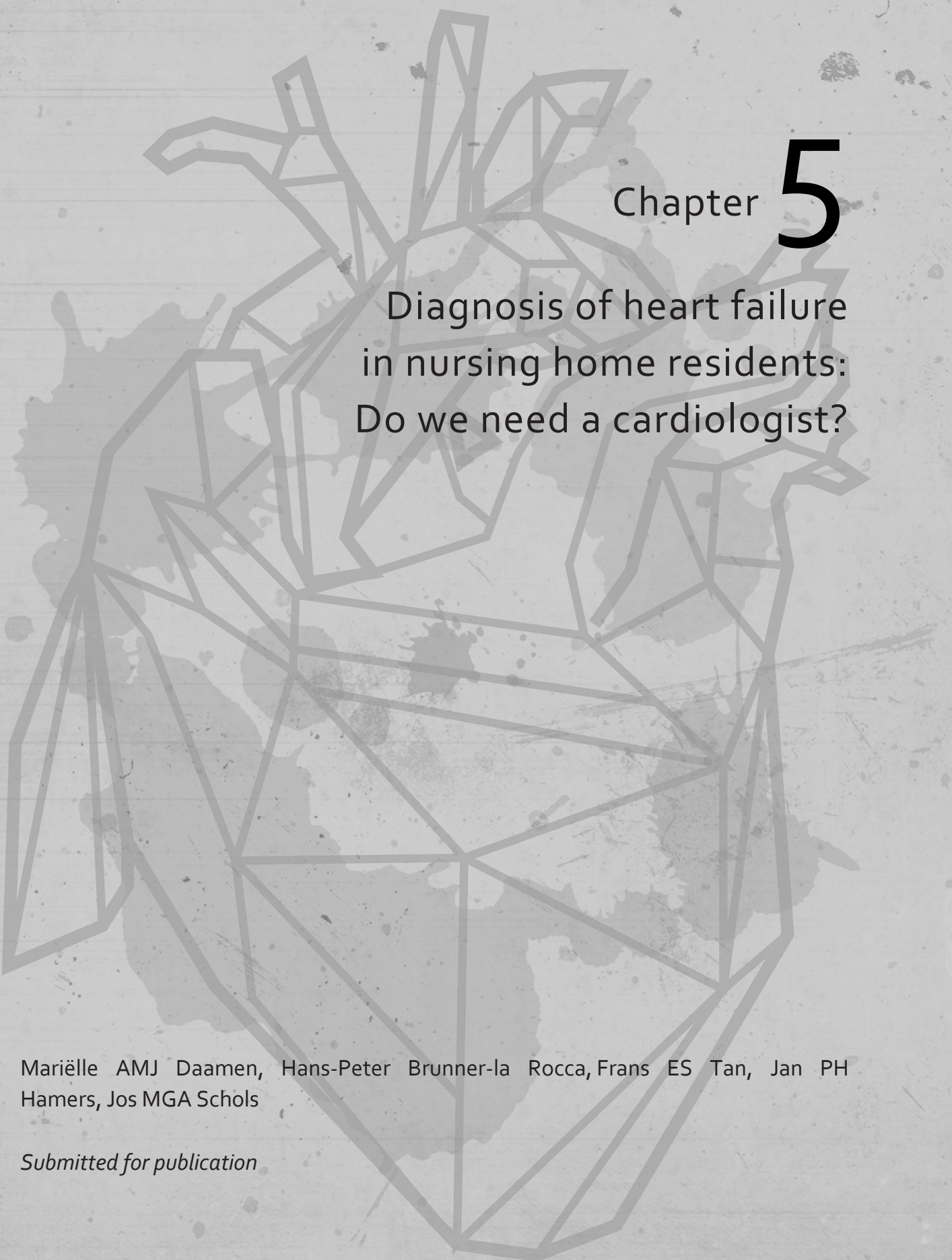


Objectives: Heart failure (HF) is highly prevalent in nursing home residents. Guidelines require the presence of typical signs and symptoms as well as structural or functional cardiac impairment to diagnose HF. Echocardiography is recommended to diagnose HF properly. In nursing homes, echocardiography is difficult to perform and $\mathrm{HF}$ is usually diagnosed by the nursing home physician (NHP) based on history, clinical examination, electrocardiography (ECG) and levels of B-type natriuretic peptide only, which is in contrast to a cardiologist who probably always will apply for an echocardiogram. In this study, we aimed 1) to investigate the agreement on the diagnosis of HF made by the NHP without echocardiography and 2) to determine the clinical characteristics which may contribute to the proper diagnosis of HF in nursing home residents.

Design: The study followed a cross-sectional design.

Setting and participants: Nursing home residents in the southern part of the Netherlands with a completed HF-assessment including anamnesis, physical examination, NT-proBNP levels, ECG and echocardiography, aged over 65 years and receiving longterm somatic or psychogeriatric care were included in the study.

Methods: The NHP decided (stepwise) on the diagnosis of HF, first after anamnesis and physical examination, second after additional information on NT-proBNP and ECG, and finally, on all available information, including medication and comorbidities, except echocardiography results. An expert team consisting of two cardiologists and one hospital geriatrician decided on the final diagnosis based on all available information.

Results: The NHP correctly identified 109 residents with HF compared to the expert team (sensitivity $75 \%$ ) and excluded HF correctly in 248 residents (specificity $83 \%$ ) with an overall agreement of $80.4 \%$ (kappa 0.57). The expert team diagnosed 145 residents with HF of which 36 cases remained undetected by the NHP (25\%). Characteristics with a high contribution in predicting HF were a history of HF, a high NTproBNP level, the presence of rales, arrhythmias and use of cardiac medication.

Conclusion: NHPs are fairly capable of diagnosing HF in nursing home residents without echocardiography. Echocardiography may be required if this will lead to adjustments in treatment. 


\section{INTRODUCTION}

Heart failure (HF) is a common chronic disease. Its prevalence increases with age and it is very frequent among nursing home residents. $(1,2)$ Nursing home residents are a specific group of very frail and considerably disabled patients, with high levels of care dependency due to chronic somatic diseases or progressive dementia. The care they need is beyond the range of regular home care services.(3)

Typical signs and symptoms of HF, such as dyspnoea and oedema, and a structural or functional cardiac impairment as assessed by cardiac imaging indicate the presence of HF.(4) In order to diagnose HF, a structured diagnostic workup including medical history, physical examination, electrocardiography (ECG), assessment of cardiac markers (natriuretic peptides) and echocardiography is recommended for proper diagnosis.(4) However with increasing age, diagnosis of HF becomes more complex, often complicated by geriatric syndromes including frailty, symptoms of comorbidities and psychogeriatric disorders, which may lead to misinterpretation.(5-7) Therefore, the diagnosis may be uncertain if solely based on signs and symptoms without echocardiography to seek underlying cardiac dysfunction.

Moreover, the distinction between HF with reduced and preserved left-ventricular ejection fraction as well as the detection of potentially correctable underlying causes of HF such as aortic stenosis may have important therapeutic consequences. $(8,9) \mathrm{A}$ false positive diagnosis of HF may lead to unnecessary treatment in a population that is already at high risk for adverse drug reactions and often receiving multiple other drugs, whereas unrecognized HF is associated with impaired quality of life and hospitalization. Since early diagnosis and treatment of HF may prevent progression and lead to improvement of quality of life, it is essential that HF is diagnosed adequately particularly in this population.(10) However, due to functional limitations or resistance against hospital referrals and unavailability of on-site echocardiography, it is difficult to perform echocardiography in nursing home residents suspected to have HF. Consequently, the physician attending nursing homes will diagnose HF instead of the cardiologist. In most Western countries, physicians attending nursing homes are general practitioners providing medical care to the residents. In the Netherlands, physicians have completed a specialist training programme to become a qualified nursing home physician (NHP).(11) NHPs may diagnose HF based on clinical signs and symptoms only, possibly supported by ECG and levels of B-type natriuretic peptide (BNP or N-terminal pro BNP [NT-proBNP]).

To the best of our knowledge, there are no studies in which the diagnostic accuracy for HF, diagnosed using the available tools without echocardiography, assessed by NHPs is described. Studies in primary health care with general practitioners having the same limited diagnostic tools, showed that the diagnosis of HF was only confirmed by echocardiography in about $30 \%$ of cases. $(12,13)$ Two recent studies in nursing home residents have reported that a previous diagnosis of HF could not be confirmed in $78 \%$ 


\section{Chapter 5}

and $62 \%$ of cases, respectively. However, in these studies it was not known who made the diagnosis of HF before and which diagnostic tools were used. $(2,14)$

This study investigated the accuracy of diagnosing HF by NHPs, based on clinical assessment (history, physical examination), diagnostic tests generally available in nursing homes (i.e. ECG and NT-proBNP), and additional information such as comorbidities, medication and additional blood testing, as compared to an expert team additionally using echocardiography (gold standard). Moreover, we determined the clinical characteristics which may contribute to a correct diagnosis of HF in those residents where there was doubt about the presence or absence of HF by the NHP.

\section{METHODS}

\section{Study design and sample}

This study followed a multi-center cross-sectional design and was carried out between January 2011 and June 2013 in five long-term care organizations in the southern parts of the Netherlands, with an overall number of about 4,500 nursing home residents. Within the specified time period, it was feasible to ask nursing home residents at 28 locations $(n=1920)$ allocated to these five long-term care organizations (3-8 per organization) to participate in the study. These residents received chronic somatic care or psychogeriatric care and were over 65 years of age. Residents who received palliative care or were admitted for short-term rehabilitation (staying $<2$ months) were excluded. Informed written consent was obtained from the residents themselves or from their legal representatives in the case of psychogeriatric residents or residents with aphasia.

The study protocol complied with the Declaration of Helsinki and was approved by the Medical Ethics Committee of Maastricht University/ Academic Hospital Maastricht (NL33281.068.10/MEC10-03-074).

\section{MEASUREMENTS AND MATERIALS}

\section{Demographic data and clinical characteristics}

Data regarding general and clinical characteristics were gathered for all participants, including age, gender, symptoms and signs of HF (dyspnoea, orthopnoea, palpitations, paroxysmal nocturnal dyspnoea, fatigue, weight gain, heart rate, blood pressure, increased jugular venous pressure, hepatojugular reflux, right ventricular pulsations, pulsations of liver, hepatomegaly, oedema, apex palpable, displacement of the apex, third heart sound, murmurs, pulmonary rales, pleural effusion), cardiac history (hypertension, myocardial infarction, arrhythmia, coronary artery disease, valvular 
heart disease, coronary bypass graft, pacemaker, pre-existing HF), comorbidities, cardiovascular risk factors (hypertension, hypercholesterolaemia, diabetes mellitus, smoking), medication (cardiac and non-cardiac), MMSE, blood sample (NT-proBNP, creatinine, haemoglobin), and ECG. Patients also underwent echocardiography, but these results were not made available to the NHP. Only residents in whom all this information was available were included in this study (Figure 1).

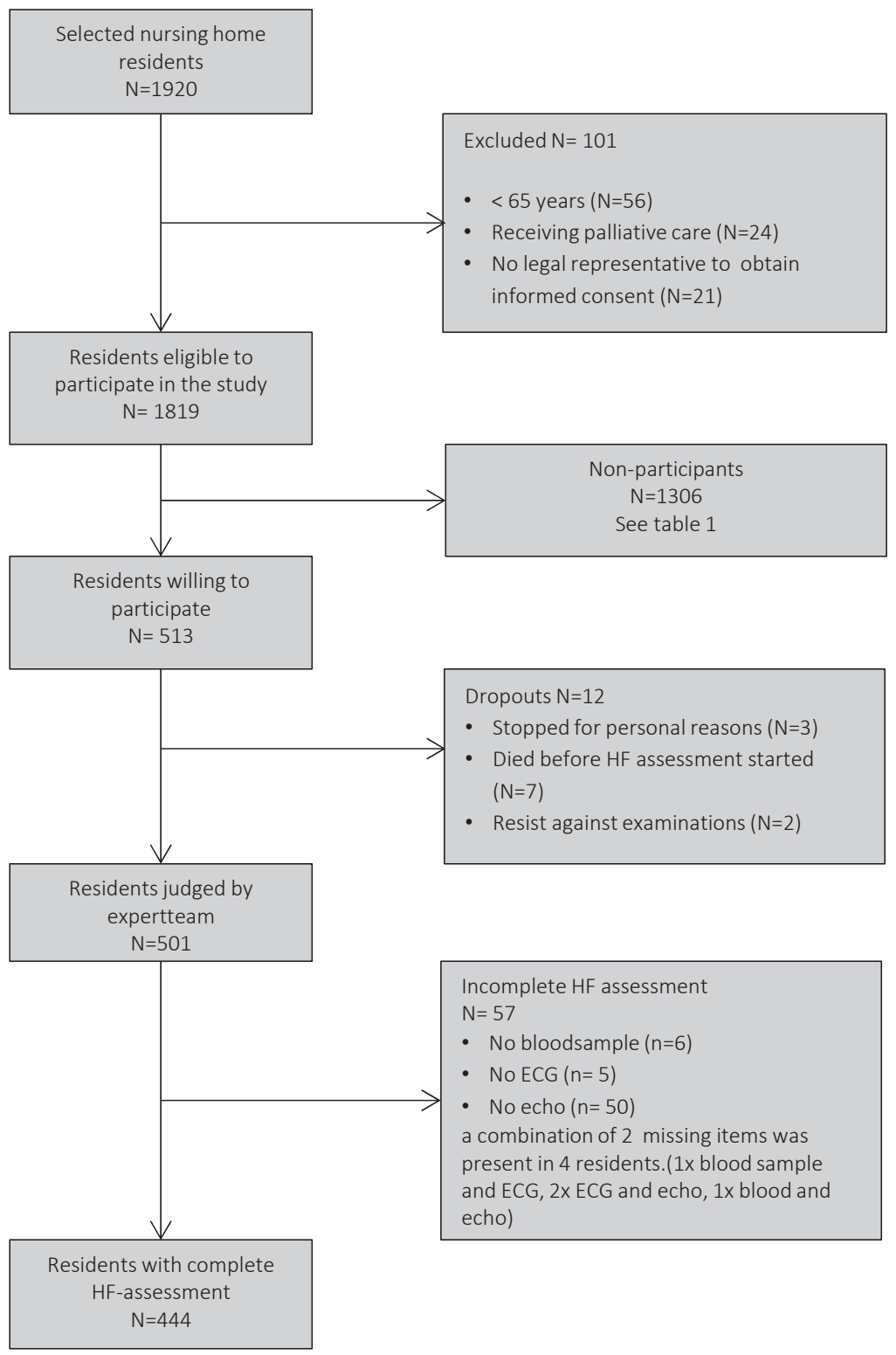

Figure 1. Flow chart of residents' participation 


\section{Study procedure of the heart failure assessment}

Before the start of the inclusion of participants, all participating NHPs (3-4 per organization) had received a refresher course regarding diagnosing HF and performing a structured physical examination by HF experts of the department of Cardiology at Maastricht University Medical Centre. The refresher course included a review of signs and symptoms of HF followed by bedside teaching ( 3 hours), a lecture on ECG findings in relation to HF ( 2 hours) and a visit to the outpatient HF clinic of the Maastricht University Medical Centre ( 3 hours). NHPs took the cardiac history, anamnesis and performed the physical examination. They were blinded to pre-existing information about the residents with the exception of their name and date of birth. The medical history and physical examination were recorded in a case record file (CRF) developed for this study. In residents having somatic disorders only the history-related questions were answered by the residents themselves; in psychogeriatric residents, these questions were answered by the nurses responsible for their daily care and/ or the main family caregiver of the resident.

Two research nurses and a NHP/researcher were responsible for recording the ECG, collecting a blood sample, gathering data from the medical records and filling in the questionnaires. Qualified (fellow) cardiologists recorded the echocardiogram onsite using a mobile echocardiography device (Philips $\mathrm{CX}_{50}$, Eindhoven NL).

To determine NT-proBNP levels, venous blood samples were analysed at the clinical chemistry laboratory at Maastricht University Medical Centre on an Elecsys 2010 (Roche Diagnostics, Mannheim, Germany). A standard 12-lead ECG was made using Cardiovit AT-10 plus (Schiller, Switzerland). The following ECG findings were recorded: heart rate, heart rhythm, QRS duration, arrhythmias, pathological Q's, conduction disturbances, and ST-deviations.

Standard echocardiography from parasternal, apical and subcostal view was performed and analyses were done according to the recommendation of the American Society of Echocardiography.(15) The following measurements were done by the echocardiographer: left ventricular (LV) ejection fraction, end-diastolic and end- systolic diameters of the LV, left atrial size, LV wall thickness, valvular structure and function, right ventricular hypertrophy and right ventricular dysfunction. If image quality did not allow quantitative measurements, qualitative assessment was used. Considering the image quality of echocardiography did not change results (data not shown).

\section{Diagnosis of heart failure by nursing home physician}

The NHP was asked to decide on the diagnosis of HF at three different stages. First, after medical history (including cardiac history) and physical examination, by answering absent, present, probably or possible. Second after the additional information on NT-proBNP and ECG, the NHP decided again, using the same four answer options. 
Finally, the NHP received additional information about medication, comorbidities and additional blood analysis and had to decide whether HF was present or absent.

\section{Diagnosis of heart failure by expert team}

An expert team of two cardiologists and a geriatrician was responsible for the final diagnosis of HF based on all the data collected as mentioned above, according to the current guidelines of the European Society of cardiology $(\mathrm{ESC})(4)$

1. Symptoms of HF;

2. Signs of HF unless treated with diuretics;

3. Presence of structural or functional cardiac abnormalities. For this, the results of the echocardiography were used.

The members of the expert team judged all files independently. When there was mutual agreement on the diagnosis, the file was closed. All files with some disagreement were discussed in the presence of all three members of the expert team to ultimately reach consensus and make a final diagnosis.

\section{STATISTICAL ANALYSIS}

Statistical analyses were performed using IBM SPSS statistics software version 22 . Descriptive frequency distributions for all variables were determined. Differences between groups were tested using Student's T tests or Mann-Whitney u-test (parametric and non-parametric testing) and Chi-square test (cross-table analysis). Pvalues of $<0.05$ were considered statistically significant.

The accuracy of the diagnosis of HF by the NHP versus the expert team was determined by the number of true and false positive diagnoses. The results are presented by sensitivity, specificity and positive and negative predictive values. To predict the presence or absence of HF in the group of residents where there was uncertainty about the diagnosis by the NHP (HF probably or possible), a statistical model was created using the statistical significant characteristics $(P$-value $<0.05)$ of the demographic and clinical characteristics based on the diagnosis of HF by the expert team. In order to reduce the number of variables included in the multivariable model, some characteristics were combined and recoded to a new variable. Dyspnoea is a combination of New York Heart Association classification, orthopnoea and paroxysmal nocturnal dyspnoea. Coronary artery disease included myocardial infarction, coronary bypass graft and coronary ischemia. Cardiac medication included the use of a diuretic, a beta-blocker or an angiotensin converting enzyme inhibitor. Arrhythmia was recoded in case of an irregular heartbeat, arrhythmia in the history, atrial fibrillation on the 


\section{Chapter 5}

ECG and presence of a pacemaker. Multivariable logistic regression analysis was performed and variables with a P-value $>0.05$ were subsequently excluded using the backward procedure. Multi-collinearity was tested with collinearity diagnostics; tolerance, VIF, eigenvalues and variance proportions. The probability values in each subject of the regression analysis were used as a test value for diagnostic accuracy in a ROC curve analysis. The cut-off point with the highest sum of sensitivity and specificity was used to determine the predictive value of the model.(16) The percentage of missing values for the logistic regression was $7.7 \%$. To prevent biased results, missing values were imputed prior to logistic regression using the multiple imputation procedure.

\section{RESULTS}

\section{Study sample}

After applying the exclusion criteria, $27 \%(n=513)$ of the approached residents or their legal representatives, agreed to participate in the study as depicted in Figure 1. Although there is no information available about exact numbers, the main reasons for not participating were that residents considered themselves too old or believed that the investigations were too burdensome. Compared to participants, in the non-participating residents group, there were more women (71\% versus $64 \%$ ) in which a few with very high age, resulting in a slightly higher mean age in this group (83 versus 82 ).

There were $n=444$ residents with a complete HF assessment (history, physical examination, ECG and echocardiography).

\section{Demographic and clinical characteristics}

An overview of demographic and clinical characteristics of the 444 residents with complete data is presented in Table 1. Residents with HF showed significantly more typical signs and symptoms of HF such as increased vena jugularis pressure and rales. Hypertension and oedema were highly prevalent in residents with and without HF.

\section{Diagnosis of heart failure by nursing home physician and expert team.}

The expert team diagnosed HF in 145 of the 444 nursing home residents (33\%). The decisions on HF by the NHPs at the three different stages in the HF- assessment are shown in Table 2. After anamnesis and physical examination, HF was diagnosed by the NHPs in only a minority of patients and no definite decision could be made in more than half. After the additional information about ECG and NT-proBNP, the uncertainty (HF possible or probably) only slightly diminished (from $51 \%$ to $48 \%$ ). Finally, after 
deciding on all the available information the NHP diagnosed more HF than the expert team. Concordance with the presence or absence of $\mathrm{HF}$ was reached in $80.4 \%$ of cases.

Table 1. Demographic and clinical characteristics of nursing home residents diagnosed with and without heart failure by the expert team

\begin{tabular}{|c|c|c|c|}
\hline \multirow[t]{2}{*}{ Variables } & \multicolumn{3}{|c|}{ Residents with and without HF diagnosed by the expert team } \\
\hline & No HF $n=299$ & HF present $n=145$ & p-value \\
\hline Age (years) mean (SD) & $81(7)$ & $84(6)$ & $<.001$ \\
\hline Gender, male & $105(35)$ & 57 (39) & 0.389 \\
\hline psychogeriatric & $199(67)$ & $85(59)$ & 0.102 \\
\hline \multicolumn{4}{|l|}{ Symptoms \% } \\
\hline NYHA 1 & $210(70)$ & $60(42)$ & $<.001$ \\
\hline 2 & $49(16)$ & $45(32)$ & \\
\hline 3 & $25(8)$ & $28(20)$ & \\
\hline 4 & $13(4)$ & $10(7)$ & \\
\hline Orthopnea & $26(9)$ & $29(20)$ & 0.003 \\
\hline Palpitation & $23(8)$ & $37(26)$ & $<.001$ \\
\hline PND & $17(6)$ & $17(12)$ & 0.041 \\
\hline Fatigue & $96(32)$ & $61(42)$ & 0.096 \\
\hline \multicolumn{4}{|l|}{ Physical examination } \\
\hline Heart rate (bpm) mean (SD) & $72(12)$ & $74(16)$ & 0.253 \\
\hline Systolic BP (mmHg) mean (SD) & $140(25)$ & $136(26)$ & 0.117 \\
\hline Diastolic BP (mmHg) mean (SD) & $75(13)$ & $74(15)$ & 0.179 \\
\hline Increased JV pressure & $63(21)$ & $52(36)$ & 0.002 \\
\hline Hepatomegaly & $16(5)$ & $13(9)$ & 0.229 \\
\hline Edema & $149(50)$ & $96(66)$ & 0.001 \\
\hline Murmurs & $98(33)$ & $65(45)$ & 0.015 \\
\hline Irregular heart beat & $41(14)$ & $63(43)$ & $<.001$ \\
\hline Rales & $68(23)$ & $67(46)$ & $<.001$ \\
\hline Pleural effusion & $14(5)$ & $18(12)$ & 0.005 \\
\hline \multicolumn{4}{|l|}{ Cardial history } \\
\hline Myocardial infarction & $31(10)$ & $36(25)$ & $<.001$ \\
\hline Arrhythmia & $33(11)$ & 57 (39) & $<.001$ \\
\hline Coronary ischemia & $49(16)$ & $46(32)$ & 0.001 \\
\hline Valvular heart disease & $11(4)$ & $21(15)$ & $<.001$ \\
\hline Coronary Bypass graft & $16(5)$ & $22(15)$ & 0.001 \\
\hline Pace maker & 8 (3) & $11(8)$ & 0.035 \\
\hline Heart failure in history & $32(11)$ & $68(47)$ & $<.001$ \\
\hline \multicolumn{4}{|l|}{ Comorbidity } \\
\hline Diabetes mellitus & $57(19)$ & $35(24)$ & 0.216 \\
\hline COPD & $42(14)$ & $31(21)$ & 0.051 \\
\hline CVA & $113(38)$ & $64(44)$ & 0.200 \\
\hline \multicolumn{4}{|l|}{ Cardiac risk factors } \\
\hline Hypertension & $126(42)$ & $78(54)$ & 0.021 \\
\hline Hypercholesterolemia & $79(26)$ & $35(24)$ & 0.65 \\
\hline Smoking & $42(14)$ & $17(12)$ & 0.113 \\
\hline
\end{tabular}




\begin{tabular}{|c|c|c|c|}
\hline \multirow[t]{2}{*}{ Variables } & \multicolumn{3}{|c|}{ Residents with and without HF diagnosed by the expert team } \\
\hline & No HF $n=299$ & HF present $n=145$ & p-value \\
\hline \multicolumn{4}{|l|}{ Cardiac medication } \\
\hline Diuretics & $88(29)$ & $87(60)$ & $<.001$ \\
\hline Beta-blocker & $65(22)$ & $72(50)$ & $<.001$ \\
\hline ACE -inhibitor & $44(15)$ & $38(26)$ & 0.003 \\
\hline ARB-antagonist & $30(10)$ & $15(10)$ & 0.919 \\
\hline \multicolumn{4}{|l|}{ Blood sample } \\
\hline NT-pro BNP pg/ml median (IQR) & $245(330)$ & $1133(1505)$ & $<.001$ \\
\hline Haemoglobin $\mathrm{mmol} / \mathrm{l}$ mean (SD & $8.1(0.9)$ & $7.8(0.9)$ & 0.002 \\
\hline Creatinine $\mu \mathrm{mol} / \mathrm{l}$ mean (SD) & $82(45)$ & $100(64)$ & 0.001 \\
\hline \multicolumn{4}{|l|}{ Additional } \\
\hline BMI $\left(\mathrm{kg} / \mathrm{m}^{2}\right)$ mean $(\mathrm{SD})$ & $25(5)$ & $26(5)$ & 0.090 \\
\hline \multicolumn{4}{|l|}{ Electrocardiography } \\
\hline Abnormal & $217(73)$ & $132(91)$ & $<.001$ \\
\hline Left ventricular hypertrophy & $15(5)$ & $12(8)$ & 0.178 \\
\hline Pathological Q-wave & $87(29)$ & $55(38)$ & 0.061 \\
\hline Atrial fibrillation & $25(8)$ & $49(34)$ & $<.001$ \\
\hline Left bundle branch block & $11(4)$ & $18(12)$ & $<.001$ \\
\hline Sinustachycardia & $8(3)$ & $8(6)$ & 0.132 \\
\hline Sinusbradycardia & $37(12)$ & $9(6)$ & 0.046 \\
\hline \multicolumn{4}{|l|}{ Echocardiography } \\
\hline LVEDD n=309 mean (SD) & $43(8)$ & 45 (9) & 0.116 \\
\hline LVESD $n=284$ mean (SD) & $29(6)$ & $34(10)$ & $<.001$ \\
\hline LVEF n= 399 mean (SD) & 59 (9) & $49(14)$ & $<.001$ \\
\hline$E F>40 \% n=346$ & $255(85)$ & $91(63)$ & \\
\hline$E F<40 \% n=53$ & $11(4)$ & $42(29)$ & \\
\hline E/A ratio mean (range) & $0.74(0.27-3.25)$ & $1.22(0.31-4.45)$ & $<.001$ \\
\hline $\mathrm{E} / \mathrm{E}^{\prime}$ ratio mean (range) & $10.7(3.45-27.8)$ & $15.2(3.8-36.7)$ & $<.001$ \\
\hline Left atrial volume $n=254$ mean (SD) & $54(20)$ & $80(38)$ & $<.001$ \\
\hline \multicolumn{4}{|l|}{ Valvular function* } \\
\hline Aortic stenosis & $15(5)$ & $20(14)$ & 0.001 \\
\hline Aortic regurgitation & $18(6)$ & $18(12)$ & 0.019 \\
\hline Mitralic regurgitation & $17(6)$ & $26(18)$ & $<.001$ \\
\hline
\end{tabular}

Numbers indicate number of patients (\%) unless otherwise indicated.

NYHA New York Hear Association, bpm beats per minute, BP blood pressure, PND paroxysmal nocturnal dyspnea, JV jugular vein, COPD chronic obstructive pulmonary disease, CVA Cerebro-vascular accident, BMI body mass index, ACE angiotensine converting enzyme, ARB angiotensin receptor blocker, LVEDD left ventricular end diastolic diameter, LVESD left ventricular end systolic diameter, LVEF left ventricular ejection fraction, EF ejection fraction, E/A ratio of early to late diastolic mitral inflow waves E/e' ratio of the mitral inflow E wave to the tissue Doppler e' wave

* moderate to severe only 
Table 2. Diagnosis of HF by Nursing Home Physician (NHP) at three different stages comparison to expert team

Decision on the diagnosis of HF by the NHP at three different stages:

Stage 1 After cardiac history, anamnesis and physical examination

Stage 2 After additional information on ECG and NT-pro BNP measurement

Stage 3 After anamnesis, physical examination, ECG, NT-pro BNP measurement and additional information about comorbidity and medication.

\begin{tabular}{|c|c|c|c|c|}
\hline & \multicolumn{2}{|l|}{$\operatorname{NHP}(n)$} & \multicolumn{2}{|c|}{ Expert team $(n) *$} \\
\hline & & & HF present & HF absent \\
\hline \multirow[t]{4}{*}{ Stage 1} & HF present & 13 & 9 & 4 \\
\hline & HF absent & 204 & 32 & 172 \\
\hline & HF probably present & 40 & 27 & 13 \\
\hline & HF possible present & 187 & 77 & 110 \\
\hline \multirow[t]{4}{*}{ Stage 2} & HF present & 20 & 19 & 1 \\
\hline & HF absent & 213 & 17 & 196 \\
\hline & HF probably present & 51 & 39 & 12 \\
\hline & HF possible present & 160 & 70 & 90 \\
\hline \multirow[t]{2}{*}{ Stage 3} & HF present & 160 & 109 & 51 \\
\hline & HF absent & 284 & 36 & 248 \\
\hline
\end{tabular}

*the expert team diagnosed HF on the information at stage 3 and the echocardiography

\section{Predictors of heart failure}

To determine variables contributing to the diagnosis of HF the characteristics included in the multivariable logistic regression were: age, increased jugular venous pressure, oedema, rales, dyspnea, history of HF, CAD, valvular heart disease, arrhythmia, abnormal ECG, NT-proBNP value, haemoglobin, creatinine and cardiac medication. Odds ratios of variables that significantly differed between residents with and without $\mathrm{HF}$ in the univariate model are depicted in Table 3. The final model (Table 3) showed that characteristics with a high contribution in independently predicting HF were a history of HF, NT-proBNP levels, presence of rales, arrhythmia, dyspnoea, increased jugular vein pressure and using cardiac medication. 


\section{Chapter 5}

Table 3. Possible predictors for the presence of heart failure (HF) in nursing home residents

\begin{tabular}{|c|c|c|c|c|c|c|}
\hline \multirow[b]{2}{*}{ Variable } & \multicolumn{3}{|c|}{ Univariate model } & \multicolumn{3}{|c|}{ Final model } \\
\hline & OR & $95 \%-\mathrm{Cl}$ & $p$-value & $\overline{O R}$ & $95 \%-\mathrm{Cl}$ & p-value \\
\hline Age & 0.98 & $0.93-1.03$ & 0.37 & & & \\
\hline Rales & 2.38 & $\begin{array}{c}1.15-4.95 \\
1,07\end{array}$ & 0.02 & 2.32 & $1.15-4.65$ & 0.02 \\
\hline Increased JVP & 1.92 & $0.97-3.77$ & 0.06 & 2.01 & $1.05-3.84$ & 0.03 \\
\hline Dyspnoea & 0.46 & $0.23-0.92$ & 0.03 & 0.48 & $0.24-0.96$ & 0.04 \\
\hline Oedema & 1.47 & $\begin{array}{c}0.79-2.75 \\
3.05\end{array}$ & 0.23 & & & \\
\hline Arrhythmia & 2.23 & $1.14-4.35$ & 0.02 & 2.32 & $1.21-4.43$ & 0.01 \\
\hline CAD & 1.02 & $0.53-1.96$ & 0.95 & & & \\
\hline Valvular heart disease & 0.94 & $0.69-1.30$ & 0.72 & & & \\
\hline HF in history & 6.48 & $3.20-13.14$ & $<.001$ & 6.48 & $3.24-12.94$ & $<.001$ \\
\hline ECG & 1.67 & $0.67-4.14$ & 0.27 & & & \\
\hline Ln NT-proBNP & 5.06 & $3.36-7.62$ & $<.001$ & 4.87 & $3.34-7.10$ & $<.001$ \\
\hline Cardiac medication & 2.58 & $1.33-5.02$ & 0.01 & 2.61 & $1.39-4.91$ & 0.003 \\
\hline Haemoglobulin & 0.91 & $0.65-1.28$ & 0.60 & & & \\
\hline Creatinine & 1.00 & $0.99-1.00$ & 0.22 & & & \\
\hline
\end{tabular}

JVP jugular vein pressure, CAD coronary artery disease, HF heart failure, ECG electrocardiography.

\section{Accuracy of diagnosis of heart failure}

At stage 1 and 2 the NHP did not make a definite decision in 227 and 211 residents, respectively (HF probably or possible in Table 2). In order to determine the presence or absence of HF in these groups, the variables of the final model (Table 3) were used as predictors for the presence of HF. The probability value was used as a test variable in the ROC-curve analysis. Using the ROC-curve analysis, it appeared that a cut-off point of a probability of HF of 0.24 is the optimal choice in the sense that the sum of sensitivity and specificity was largest (using Youden criterion index).(16) Consequently, if the probability of HF was larger than 0.24 , the patient was classified as having HF. The accuracy of diagnosing HF by the NHP in combination with these predictors in case of uncertainty as compared to the expert team opinion for stage 1 and 2 is presented in Table 4. In case this model is used, the test characteristics (sensitivity, specificity, positive and negative predictive value) showed a slightly more favourable outcome as compared to the forced decision whether HF is present or not at the final stage (Table 4). For example, using the model in stage 2 for the group of residents classified as probably or possible HF leads to a sensitivity of $83 \%$ versus $75 \%$ at stage 3 (forced decision), a specificity of $85 \%$ versus $83 \%$ at stage 3 and an overall agreement of $84 \%$ (kappa 0.65 ) versus $80 \%$ (kappa 0.57 ). The performed tests for multi- 
collinearity showed no collinearity. Results after imputation of missing values were compared to the results of the original data and showed no significant changes.

Table 4. Agreement of the diagnosis of HF by the nursing home physician versus expert team using a model Decision on the diagnosis of HF by the NHP at three different stages:

Stage 1 After cardiac history, anamnesis and physical examination

Stage 2 After additional information on ECG and NT-pro BNP measurement

Stage 3 After anamnesis, physical examination, ECG, NT-pro BNP measurement and additional information about comorbidity and medication.

\begin{tabular}{|c|c|c|c|c|c|c|c|}
\hline \multirow{3}{*}{$\frac{\text { Stages }}{\text { Stage } 1}$} & \multirow{3}{*}{$\begin{array}{l}\text { NHP versus expert } \\
\text { team * }\end{array}$} & \multicolumn{4}{|c|}{ Cross-table } & \multirow[b]{3}{*}{ Sensitivity $74 \%$} & \multirow{3}{*}{$\begin{array}{l}95 \% \mathrm{Cl} \\
66-81\end{array}$} \\
\hline & & NHP & Exper & & & & \\
\hline & & & $\mathrm{HF}+$ & HF- & & & \\
\hline & & $\mathrm{HF}+$ & 107 & 43 & 150 & Specificity $86 \%$ & $82-90$ \\
\hline & & HF- & 38 & 256 & 294 & PPV $71 \%$ & $63-78$ \\
\hline & & & 145 & 299 & 444 & NPV $87 \%$ & $83-91$ \\
\hline \multirow[t]{5}{*}{ Stage 2} & NHP versus expert & NHP & \multicolumn{3}{|c|}{ Expert team } & & \\
\hline & team * & & $\mathrm{HF}+$ & HF - & & Sensitivity 83\% & $76-89$ \\
\hline & & $\mathrm{HF}+$ & 121 & 46 & 167 & Specificity $85 \%$ & $81-89$ \\
\hline & & HF- & 24 & 253 & 277 & $P P V_{72} \%$ & $65-79$ \\
\hline & & total & 145 & 299 & 444 & NPV 91\% & $87-94$ \\
\hline \multirow[t]{5}{*}{ Stage 3} & NHP versus expert & NHP & \multicolumn{3}{|c|}{ Expert team } & & \\
\hline & team & & $\mathrm{HF}+$ & HF - & & Sensitivity $75 \%$ & $67-82$ \\
\hline & & $\mathrm{HF}+$ & 109 & 51 & 160 & Specificity $83 \%$ & $78-87$ \\
\hline & & HF - & 36 & 248 & 284 & PPV 68\% & $60-75$ \\
\hline & & total & 145 & 299 & 444 & NPV $87 \%$ & $83-91$ \\
\hline
\end{tabular}

PPV positive predictive value, NPV negative predictive value

*using the final model (Table 3) for the group probably/possible HF (Table 2)

\section{DISCUSSION}

This study shows a concordance with the presence or absence of HF in $80 \%$ of patients as decided by the NHP with the available tools in the nursing home compared to an expert team of cardiologists and a geriatrician that also had the results of the echocardiography. In addition, there was a high contribution in independently predicting $\mathrm{HF}$ based on history of HF, NT-proBNP levels, presence of rales, arrhythmia and using cardiac medication.

Diagnosis of HF by NHPs based on anamnesis, physical examination, ECG and NTproBNP values results more often in overdiagnosis than underdiagnosis of HF. Nursing home residents may benefit from accurately diagnosed HF by the NHP, which saves them a burdensome visit to a cardiologist due to functional and cognitive limitations. On the other hand, unnecessary treatment as a result of false positive diagnosis is also 
not preferable because of the high risk of adverse drugs reaction.(17) Therefore, the question arises as to whether a 70\% correct diagnosis of HF (positive predictive value) is acceptable for nursing home residents. Unfortunately, to the best of our knowledge, there are no other studies on the diagnostic accuracy by NHPs or physicians attending nursing homes. Available studies in primary care show a correct diagnosis of HF between 26 and $50 \%$ only. $(12,13)$ Thus, a finding of almost $70 \%$ agreement in our study may be considered a positive result. However, this still means that almost one in three would not receive the correct treatment.

Hence, it is questionable whether it is possible to reduce the number of residents with a false positive or false negative diagnosis of HF made by an NHP. With the logistic regression model created to predict HF based on clinical characteristics, we could reduce the number of false positives to nearly one in four by employing the model when there is doubt about the diagnosis (HF probably or possible). The false negative diagnosis decreased from 13 to $9 \%$.

In the past, several scores in different patient groups to predict HF were developed. Mosterd et al.(1997) reviewed six HF scores for the detection of possible and definite HF and found a high sensitivity for the detection of definite HF, but a lower sensitivity for the detection of possible HF.(18) Unfortunately, most of these scores are not applicable for nursing homes residents because they require a chest $x$-ray and the patients included usually differed significantly from our population. However, none of these scores used the cardiac marker NT-proBNP to predict the presence of HF. A recent study by Oudejans et al.(2011) showed an improvement in the reliability to identify the presence or absence of HF when NT-proBNP levels were used.(19)They also found that loss of appetite, lower BMI and absence of wheezing were signs predicting the presence of HF. In our study, we could not confirm this, which may be related to the different population studied. In addition to differences in the occurrence of signs and symptoms, some questions are hard to answer in residents with cognitive impairments such as loss of appetite. Based on our data in a population of nursing home residents, it seems that the variables HF in history, NT-proBNP value, use of cardiac medication, arrhythmia, dyspnoea, rales and increased jugular venous pressure are best suited for more accurate detection of HF.

Furthermore, it may be discussed whether the need for echocardiography also applies to nursing home residents to avoid a false positive or a false negative diagnosis of HF. There is an overlap in pharmacological treatment concerning HF with reduced systolic function (HFrEF), hypertension and stable angina pectoris in which ACE- inhibitors and $\beta$-blockers are recommended.(20-22) Various factors such as older age, hypertension, diabetes mellitus (DM), obesity and coronary artery disease (CAD) have been described as risk factors for developing HF with preserved left systolic function (HFpEF) and were highly present in our study population.(23) Nearly two thirds of the residents in our study were diagnosed as HFpEF, which was similar to the results of Hancock.(2) Treatment of these risk factors and HFrEF may overlap to a significant 
extent. Therefore, in many instances, correct treatment can be installed even without knowing LVEF. Furthermore, echocardiography may help to determine underlying causes and distinguish between HF with preserved or reduced LVEF.(24) However, several underlying causes of HF such as hypertension (with LV hypertrophy) and atrial fibrillation can be diagnosed by physical examination and the use of an ECG only, which are available to NHPs. Nevertheless, there remains a group of nursing home residents in which performing echocardiography may be required, not in the context of diagnosis but as essential to treatment. These are residents who may benefit from therapeutic interventions other than pharmacological, as in the case of valvular disorders.(25) Moreover if cardiovascular comorbidities and/or risk factors do not require extensive treatment with ACE-inhibition (or angiotensin-II antagonist if intolerant), $\beta$ blockers and mineralocorticoid-antagonist, knowing LVEF is required to treat patients properly, but also to prevent patients from being exposed to unnecessary treatment in case of preserved LVEF. Also, it is important to notice that some medication is contraindicated in case of reduced LVEF (e.g. verapamil, diltiazem).(4) Again, if treatment would significantly change when knowing the diagnosis of HF, additional diagnostics should be considered.

The limitations in this study should be mentioned. Several NHPs were involved by performing anamnesis and physical examination in this study to diagnose HF in nursing home residents. Although the participating NHPs took a refresher course there is a possibility of inter-observer variation, which was not tested. Furthermore, there were missing echocardiographic values $(n=50)$ in the majority $(n=40)$ caused by poor image quality due to obesity, cachexia, or COPD. In a minority of cases $(n=10)$ in psychogeriatric residents, there was resistance to the echocardiography. There was no crossvalidation used for testing the logistic regression model, which may have resulted in a slightly over optimistic model, but if cross-validation had been used, the number of residents would have been smaller, leading to inaccurate results.

\section{CONCLUSION}

Our study showed that the physicians attending the nursing home were fairly capable of diagnosing HF in nursing home residents without the information of echocardiography. A visit to a cardiologist can be avoided. Echocardiography may be indicated in a group of residents if valvular disease is considered as a main cause and could be treated other than pharmacological or if treatment decisions are dependent on knowing LVEF. A model to predict HF when the NHP has doubt about the diagnosis of HF contributes to a more accurate diagnosis of HF in nursing home residents. 


\section{REFERENCES}

1. Bleumink GS, Knetsch AM, Sturkenboom MC et al. Quantifying the heart failure epidemic: prevalence, incidence rate, lifetime risk and prognosis of heart failure The Rotterdam Study. Eur Heart J. 2004 Sep;25(18):1614-9.

2. Hancock $\mathrm{HC}$, Close $\mathrm{H}$, Mason JM et al. High prevalence of undetected heart failure in long-term care residents: findings from the Heart Failure in Care Homes (HFinCH) study. Eur J Heart Fail. 2013 Feb;15(2):158-65.

3. Schols JM. Nursing home medicine in The Netherlands. Eur J Gen Pract. 2005 Sep-Dec;11(3-4):141-3.

4. McMurray JJ, Adamopoulos S, Anker SD et al. ESC Guidelines for the diagnosis and treatment of acute and chronic heart failure 2012: The Task Force for the Diagnosis and Treatment of Acute and Chronic Heart Failure 2012 of the European Society of Cardiology. Developed in collaboration with the Heart Failure Association (HFA) of the ESC. Eur Heart J. 2012 Jul;33(14):1787-847.

5. Lien $C T$, Gillespie ND, Struthers AD, McMurdo ME. Heart failure in frail elderly patients: diagnostic difficulties, co-morbidities, polypharmacy and treatment dilemmas. Eur J Heart Fail. 2002 Jan;4(1):91-8.

6. Heckman GA, Patterson CJ, Demers C et al. Heart failure and cognitive impairment: challenges and opportunities. Clin Interv Aging. 2007;2(2):209-18.

7. de Freitas EV, Batlouni M, Gamarsky R. Heart failure in the elderly. Journal of geriatric cardiology : JGC. 2012 Jun;9(2):101-7..

8. Butler J, Fonarow GC, Zile MR et al. Developing therapies for heart failure with preserved ejection fraction: current state and future directions. JACC Heart failure. 2014 Apr;2(2):97-112.

9. Clark MA, Arnold SV, Duhay FG et al. Five-year clinical and economic outcomes among patients with medically managed severe aortic stenosis: results from a Medicare claims analysis. Circulation Cardiovascular quality and outcomes. 2012 Sep 1;5(5):697-704.

10. Gaulden L. Diagnosis and management of heart failure in the long-term care setting. Director. 2003 Fall;11(4):177-81.

11. Hoek JF, Ribbe MW, Hertogh CMPM, van der Vleuten CPM. The Specialist Training Program for Nursing Home Physicians: A New Professional Challenge. Journal of the American Medical Directors Association.2(6):326-30.

12. Hobbs FD. Unmet need for diagnosis of heart failure: the view from primary care. Heart. 2002 Oct;88 Suppl 2:iig-11.

13. Wheeldon NM, MacDonald TM, Flucker CJ et al. Echocardiography in chronic heart failure in the community. The Quarterly journal of medicine. 1993 Jan;86(1):17-23.

14. Barents $M$, van der Horst IC, Voors AA et al. Prevalence and misdiagnosis of chronic heart failure in nursing home residents: the role of B-type natriuretic peptides. Neth Heart J. 2008 Apr;16(4):123-8.

15. Lang RM, Bierig M, Devereux RB et al. Recommendations for chamber quantification: a report from the American Society of Echocardiography's Guidelines and Standards Committee and the Chamber Quantification Writing Group, developed in conjunction with the European Association of Echocardiography, a branch of the European Society of Cardiology. J Am Soc Echocardiogr. 2005 Dec;18(12):1440-63.

16. Hajian-Tilaki K. Receiver Operating Characteristic (ROC) Curve Analysis for Medical Diagnostic Test Evaluation. Caspian Journal of Internal Medicine. 2013 Spring 4(2): 627-635

17. Sztramko R, Chau V, Wong R. Adverse drug events and associated factors in heart failure therapy among the very elderly. Canadian geriatrics journal : CGJ. 2011 Dec;14(4):79-92.

18. Mosterd A, Deckers JW, Hoes AW et al. Classification of heart failure in population based research: an assessment of six heart failure scores. Eur J Epidemiol. $1997 \mathrm{Jul} ; 13(5): 491-502$.

19. Oudejans I, Mosterd A, Bloemen JA et al. Clinical evaluation of geriatric outpatients with suspected heart failure: value of symptoms, signs, and additional tests. Eur J Heart Fail. May;13(5):518-27.

20. Mancia G, Fagard R, Narkiewicz K et al. 2013 ESH/ESC Guidelines for the management of arterial hypertension: the Task Force for the management of arterial hypertension of the European Society of 
Hypertension (ESH) and of the European Society of Cardiology (ESC). Journal of hypertension. 2013 Jul;31(7):1281-357.

21. Fox K, Garcia MAA, Ardissino D et al. Guidelines on the management of stable angina pectoris: executive summary. The Task Force on the Management of Stable Angina Pectoris of the European Society of Cardiology. 2006 Jun:00;27(11):1341-81.

22. Fihn SD, Gardin JM, Abrams J et al. 2012 ACCF/AHA/ACP/AATS/PCNA/SCAI/STS Guideline for the Diagnosis and Management of Patients With Stable Ischemic Heart DiseaseA Report of the American College of Cardiology Foundation/American Heart Association Task Force on Practice Guidelines, and the American College of Physicians, American Association for Thoracic Surgery, Preventive Cardiovascular Nurses Association, Society for Cardiovascular Angiography and Interventions, and Society of Thoracic Surgeons. Journal of the American College of Cardiology. 2012;6o(24):e44-e164.

23. Hogg K, Swedberg K, McMurray J. Heart failure with preserved left ventricular systolic function; epidemiology, clinical characteristics, and prognosis. J Am Coll Cardiol. 2004 Feb 4;43(3):317-27.

24. Mosterd A, Hoes AW, de Bruyne MC et al. Prevalence of heart failure and left ventricular dysfunction in the general population; The Rotterdam Study. Eur Heart J. 1999 Mar;20(6):447-55

25. Nishimura RA, Otto CM, Bonow RO et al. 2014 AHA/ACC Guideline for the Management of Patients With Valvular Heart Disease: A Report of the American College of Cardiology/American Heart Association Task Force on Practice Guidelines. Circulation. 2014 June 10, 2014;129(23):e521-e643. 



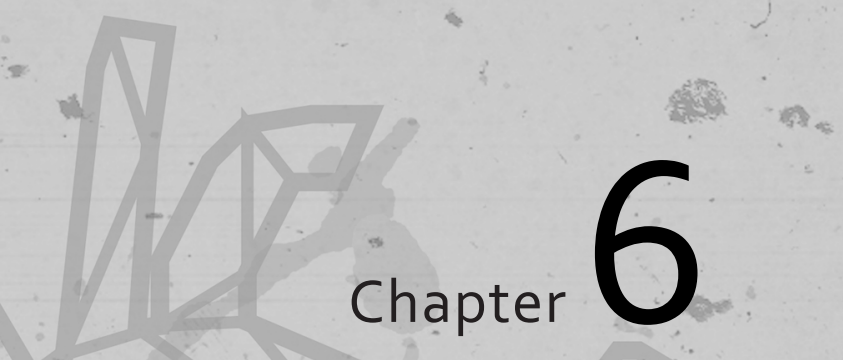

Treatment of heart failure in nursing home residents

Mariëlle AMJ Daamen, Jan PH Hamers, Anton PM Gorgels, Frans ES Tan, Jos MGA Schols, Hans-Peter Brunner-la Rocca

Published in Journal of Geriatric Cardiology. 2016;13:44-50 


\section{Chapter 6}

\section{ABSTRACT}

Objectives: For the treatment of chronic heart failure (HF), both pharmacological and non-pharmacological treatment should be employed in HF patients. Although HF is highly prevalent in nursing home residents, it is not clear whether the recommendations in the guidelines for pharmacological therapy also are followed in nursing home residents. The aim of this study is to investigate how HF is treated in nursing home residents and to determine to what extent the current treatment corresponds to the guidelines.

Methods: Nursing home residents of five large nursing home care organizations in the southern part of the Netherlands with a previous diagnosis of HF based on medical records irrespective of the left ventricle ejection fraction (LVEF) were included in this cross-sectional study. Data were gathered on the (medical) records, which included clinical characteristics and pharmacological- and non-pharmacological treatment. Echocardiography was used as part of the study to determine the LVEF.

Results: Out of 501 residents, 112 had a diagnosis of HF at inclusion. One third of them received an ACE-inhibitor and $40 \%$ used a beta-blocker. In $66 \%$, there was a prescription of diuretics with a preference of a loop diuretic. Focusing on the residents with a LVEF $<40$ only $46 \%$ of the 22 residents used an ACE-inhibitor and $64 \%$ a betablocker. The median daily doses of prescribed medication were lower than those that were recommended by the guidelines. Non-pharmacological interventions were recorded in almost none of the residents with HF.

Conclusion: The recommended medical therapy of HF was often not prescribed; if prescribed, the dosage was usually far below what was recommended. In addition, non-pharmacological interventions were mostly not used at all. 


\section{INTRODUCTION}

Heart failure (HF) is a common disease in older persons and, as a consequence, also highly prevalent in nursing home residents. $(1,2)$ Adequate treatment of HF may not only lead to reduced mortality and hospital admissions, but it may also relieve symptoms, lead to improvement in quality of life and increase functional capacity. $(3,4)$ According to the current guidelines of the European Society of Cardiology and the American College of Cardiology/American Heart Association, both pharmacological and non-pharmacological therapies should be employed in HF patients. $(5,6)$ The pharmacological treatment depends on the type of HF. Pharmacological treatment of $\mathrm{HF}$ in patients with reduced ejection fraction is clearly described, whereas, for HF with preserved ejection fraction, there is no evidenced pharmacological therapy available. $(5,6)$ Every HF patient with reduced ejection fraction should receive an angiotensin converting enzyme (ACE)-inhibitor and, thereafter, also a beta-blocker as soon as possible. A diuretic could be necessary to control fluid overload. For HF with preserved ejection fraction, adequate treatment of underlying diseases and symptoms, such as hypertension, myocardial ischaemia and oedema, is recommended. Nonpharmacological interventions consist of life style changes such as fluid- and sodiumrestriction, daily weighing, adjustment of activity, vaccination against influenza, smoking cessation and limitation of the amount of alcohol ingested.(7)

Nursing home residents are frail, disabled, older persons with high levels of care dependency, who are mostly excluded from clinical and epidemiological studies.(8) Despite that, recommendations regarding diagnostics and therapeutic interventions do not differ depending on age.(5) Therefore, nursing home residents should be treated similarly to other patients, but previous studies conclude that this is often not the case. In a review of Litaker, 13 studies (published between 1991 and 2002) concerning the pharmacological treatment of $\mathrm{HF}$ in elderly nursing home residents were analysed with an overall conclusion that nursing home residents with HF did not receive pharmacological treatment according to the guidelines.(9) In addition, more recent studies in Sweden, Poland and the United States have demonstrated that the treatment of patients with HF in nursing homes and long-term care facilities is still not in accordance with current guidelines.(10-12) Unfortunately, it has not been properly investigated whether the recommendations for non-pharmacological HF treatment as described in the guidelines are also applied to nursing home residents. However, nonpharmacological treatment can have a positive impact on symptoms, functional capacity, well-being, morbidity and prognosis.(13) The aim of this study was to investigate how nursing home residents with HF are treated pharmacologically and nonpharmacologically in Dutch nursing homes. In particular, we determined to what extent the actual treatment corresponded with current international HF guidelines. $(5,6)$ 


\section{Chapter 6}

\section{METHODS}

This study followed a multi-center cross-sectional design and was nested in a larger study on HF in nursing home residents described in a previously published study protocol.(14) The study complied with the Declaration of Helsinki and has been granted approval from the Medical Ethics Committee of Maastricht University/Academic Hospital Maastricht (NL33281.068.10/MEC10-3-074).The study is registered in the Dutch trial register (NTR2663).

\section{Setting and sample}

Nursing home residents in the southern part of the Netherlands allocated to five large long-term care organizations were recruited to participate. In the Netherlands, nursing homes provide a high-level of nursing, medical and paramedical care to frail elderly people with chronic diseases and disabilities that are either physical or mental in nature (mainly dementia), or both.(15) Five hundred and one residents over 65 years of age, who received long-term care on somatic or psychogeriatric wards, were eligible for participating in the larger study. Only residents with a diagnosis of HF in the medical record were included in this study, irrespective of how the diagnosis was made or who made it. In most patients, this meant that left-ventricular ejection fraction (LVEF) was not known. Patients with the diagnosis of HF were compared with those not having a diagnosis of HF. Data were gathered within a specified time period (January 2011 to June 2013). Informed consent for participating was obtained from the residents themselves or from their legal representatives in the case of psychogeriatric residents, or residents with aphasia.

\section{MEASUREMENTS AND MATERIALS}

Patients' characteristics were collected in all participating residents including age, gender, receiving psychogeriatric or somatic nursing home care, symptoms, cardiac history, comorbidities, and cardiovascular risk factors. These predetermined variables of demographic data, cardiac history, comorbidities and cardiovascular risk factors were obtained from medical records and registered on a case record file (CRF) by a research nurse. A nursing home physician, who had received a refresher course in diagnosing HF, was responsible for assessment of symptoms of HF on the CRF.

Regarding the pharmacological treatment, cardiac medications (diuretics, ACEinhibitors, beta-blockers and angiotensin receptor blocker (ARB) antagonists) as prescribed and processed by the pharmacist on the medication list, including the dosages, were registered. Regarding non-pharmacological interventions, fluid restriction $(<1.5 \mathrm{~L} /$ day), sodium restriction ( $\max 2.5 \mathrm{gram} /$ day), physiotherapy residents them- 
selves or the nursing staff (in case of dementia or aphasia) were questioned about whether interventions were applied. After inclusion all participating residents underwent an echocardiography. A LVEF of $<40$ as was considered as reduced ejection fraction. $(5,6)$

\section{STATISTICAL ANALYSIS}

Statistical analyses were performed using IBM SPSS statistics software version 22. Data are presented as frequencies or means (standard deviations) as appropriate. Differences between groups were tested using Student's $t$-tests for continuous (dependent) variables and Chi-square tests (cross-table analysis) for discrete variables.

\section{RESULTS}

Of the 501 residents included in the main study, 112 were previously diagnosed with HF based on their medical records. The characteristics of the patients with and without the diagnosis of HF are shown in Table 1. In 15 residents there were missing echocardiography results caused by poor image quality due to e.g. obesity or chronic obstructive pulmonary disease (COPD) and/or resistance to the echocardiography mainly by psychogeriatric residents. Of the remaining residents $(n=97)$ with a diagnosis of HF 22 residents (20\%) had a LVEF $<40 \%$. When comparing the two groups of residents with and without HF, residents with HF had more complaints of dyspnoea shown by the percentages of the New York Heart Association classes. Peripheral oedema was highly prevalent in both groups. There was a significantly higher prevalence of cardiovascular diseases, except for hypertension, in residents with HF. COPD was more prevalent in residents with HF compared to those without HF. The mean blood pressure (systolic and diastolic) was lower in residents with HF as compared to those without. 


\section{Chapter 6}

Table 1. Clinical Characteristics of the Study Population

\begin{tabular}{|c|c|c|c|}
\hline Variables & $\begin{array}{l}\text { No heart failure recorded } \\
\qquad N=389\end{array}$ & $\begin{array}{l}\text { HF recorded in medical record } \\
\qquad \mathrm{N}=112\end{array}$ & p-value \\
\hline Age (years) mean (SD) & $82(7)$ & $83(7)$ & 0.114 \\
\hline Gender, male n(\%) & $131(34)$ & $48(43)$ & 0.074 \\
\hline psychogeriatric n(\%) & $259(67)$ & $67(60)$ & 0.186 \\
\hline \multicolumn{4}{|l|}{ NYHA-class } \\
\hline NYHA class 1 n(\%) & $260(67)$ & $47(41)$ & $<0.001$ \\
\hline NYHA class 2 n(\%) & $74(19)$ & $34(31)$ & 0.023 \\
\hline NYHA class 3 n(\%) & $36(9)$ & $21(29)$ & 0.014 \\
\hline NYHA class 4 n(\%) & $19(5)$ & $9(8)$ & 0.336 \\
\hline \multicolumn{4}{|l|}{ Symptoms } \\
\hline Edema n(\%) & $203(52)$ & $72(64)$ & 0.018 \\
\hline Orthopnoea n (\%) & $38(10)$ & $24(21)$ & $<0.001$ \\
\hline \multicolumn{4}{|l|}{ Cardial history } \\
\hline Hypertension n(\%) & $181(47)$ & $55(49)$ & 0.63 \\
\hline Myocardial infarction n(\%) & $51(13)$ & $30(27)$ & 0.001 \\
\hline Arrhythmia n(\%) & $60(15)$ & $39(35)$ & $<0.001$ \\
\hline Coronary ischaemia n(\%) & 73 (19) & $40(36)$ & 0.001 \\
\hline Valvular heart disease $\mathrm{n}(\%)$ & $20(5)$ & $18(16)$ & 0.001 \\
\hline Coronary Bypass graft n(\%) & $27(7)$ & $13(12)$ & 0.275 \\
\hline Pace maker n(\%) & $13(3)$ & $6(5)$ & 0.603 \\
\hline \multicolumn{4}{|l|}{ Comorbidity } \\
\hline Diabetes mellitus n(\%) & $79(20)$ & $28(25)$ & 0.286 \\
\hline COPD n(\%) & $51(13)$ & $32(29)$ & $<0.001$ \\
\hline CVA n(\%) & $162(42)$ & $45(40)$ & 0.781 \\
\hline Renal insufficiency eGFR*<6o n(\%) & $106(27)$ & $56(50)$ & $<0.001$ \\
\hline Anemia n (\%) & $114(29)$ & $43(38)$ & 0,058 \\
\hline \multicolumn{4}{|l|}{ Cardiac risc factors } \\
\hline BMI mean (SD) & $25(5)$ & $26(5)$ & 0.224 \\
\hline Hypercholesteroliemia n(\%) & $105(27)$ & $25(22)$ & 0.520 \\
\hline Smoking n(\%) & $54(14)$ & $14(13)$ & 0.931 \\
\hline Heart rate mean (SD) & $73(13)$ & $73(15)$ & 0.921 \\
\hline Systolic blood pressure mean (SD) & $142(24)$ & $132(29)$ & $<0.001$ \\
\hline Diastolic blood pressure mean (SD) & $76(14)$ & $72(15)$ & 0.026 \\
\hline Creatinine $\mu \mathrm{mol} / \mathrm{l}(\mathrm{SD})$ & $83(45)$ & $102(66)$ & 0.001 \\
\hline \multicolumn{4}{|l|}{ Echocardiography } \\
\hline LVEF mean (SD) $n=405$ & $56(11)$ & $52(14)$ & 0.001 \\
\hline$>40 \%$ & $276(90)$ & $75(77)$ & 0.002 \\
\hline$<40 \%$ & $32(10)$ & $22(23)$ & \\
\hline
\end{tabular}

NYHA :new York Heart Association, COPD: chronic obstructive pulmonary disease, CVA: cerebrovascular accidents BMI: Body Mass Index, eGFR: glomular filtration rate $\mathrm{ml} / \mathrm{min} / 1,73 \mathrm{~m}^{2}$, LVEF left venrtricular ejection fraction 


\section{PHARMACOLOGICAL AND NON- PHARMACOLOGICAL TREATMENT OF HF}

An overview of the pharmacological and non-pharmacological treatment is presented in Table 2. $46 \%$ of the residents with an LVEF $<40 \%$ used an ACE-inhibitor and $64 \%$ a beta-blocker. Diuretics were prescribed in two thirds of the residents diagnosed with $\mathrm{HF}$. Only one third of residents with a reduced ejection fraction received a combination of an ACE-inhibitor/ARB-antagonist and a beta-blocker.Spironolacton was prescribed in only a minority of patients, irrespective of LVEF.

Non-pharmacological treatment, such as fluid-restriction, sodium-restriction or physiotherapy, was recorded in $5 \%$ or less of the residents. Many more patients without the diagnosis of HF received physiotherapy as compared to nearly none with HF.

Table 2. Pharmacological and Non- Pharmacological Treatment of HF in Nursing Home Residents

\begin{tabular}{|c|c|c|c|c|c|}
\hline & No HF & \multicolumn{4}{|c|}{ Diagnosed with HF } \\
\hline & $\begin{array}{l}\text { Total } \\
\mathrm{n}=389\end{array}$ & $\begin{array}{c}\text { Total } \\
\mathrm{n}=112\end{array}$ & $\begin{array}{l}\text { LVEF }^{b} \\
<40 \% \\
n=22\end{array}$ & $\begin{array}{l}\text { LVEF } \\
>40 \% \\
n=75\end{array}$ & $\begin{array}{c}\text { No } \\
\text { echocardiography } \\
n=15\end{array}$ \\
\hline \multicolumn{6}{|l|}{ Pharmacological Treatment } \\
\hline \multicolumn{6}{|l|}{ Medication } \\
\hline Diuretics (\%) & $117(30)$ & $74(66)$ & $18(82)$ & $45(60)$ & $11(73)$ \\
\hline Beta-blocker (\%) & $112(29)$ & 44 (39) & $14(64)$ & $24(32)$ & $6(40)$ \\
\hline ACE-inhibitor (\%) & $59(15)$ & $33(30)$ & $10(46)$ & $20(27)$ & $3(20)$ \\
\hline ARB-antagonist (\%) & $46(12)$ & $7(6)$ & $2(9)$ & $3(4)$ & $2(13)$ \\
\hline Spironolacton (\%) & $7(2)$ & $18(16)$ & $3(14)$ & $11(15)$ & $4(27)$ \\
\hline ACE-inhibitor and ARB antagonist (\%) & & 1 & 1 & & \\
\hline $\begin{array}{l}\text { ACE-inhibitor/ARB antagonist and } \\
\text { betablocker (\%) }\end{array}$ & $43(11)$ & $19(17)$ & $8(36)$ & $8(11)$ & $1(7)$ \\
\hline Betablocker and Diuretics(\%) & $47(12)$ & $32(29)$ & $12(55)$ & $16(21)$ & $5(33)$ \\
\hline $\begin{array}{l}\text { Ace-inhibitor/ARB antagonist and } \\
\text { Diuretics (\%) }\end{array}$ & $45(12)$ & $34(30)$ & $8(36)$ & $17(23)$ & $5(33)$ \\
\hline Trias $^{\mathrm{a}}$ medication (\%) & $16(4)$ & $17(15)$ & $8(36)$ & $8(11)$ & $1(7)$ \\
\hline \multicolumn{6}{|l|}{ Non-Pharmacological Treatment } \\
\hline Fluid-restriction (until 1,5l/day) & $4(1)$ & $6(5)$ & & & \\
\hline Sodium- restriction (until 2,5gr/day) & $3(1)$ & $4(4)$ & & & \\
\hline Physiotherapy/activity training & $171(44)$ & $1(1)$ & & & \\
\hline
\end{tabular}

$\mathrm{ACE}=$ angiotensin converting enzym, $\mathrm{ARB}=$ angiotensin receptor blocker

${ }^{\mathrm{a}}$ Trias medication $=\mathrm{ACE}$-inhibitor/ARB- antagonist and betablocker and diuretics

${ }^{b}$ Information of echocardiography available in $n=97$ residents 
Chapter 6

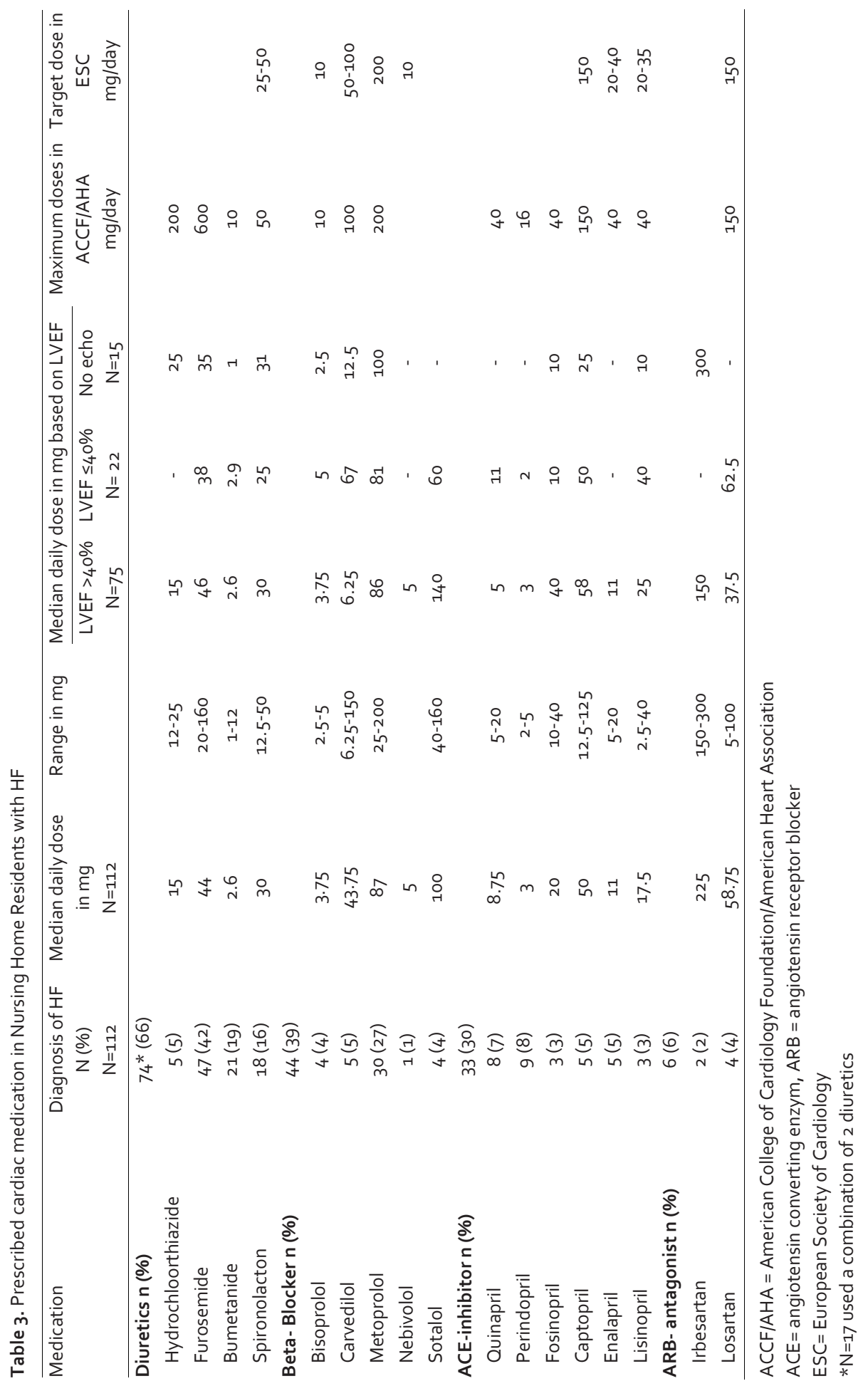




\section{PRESCRIBED CARDIAC MEDICATION}

As shown in Table 3, there was no preference for the use of a specific ACE-inhibitor in our patient population with HF. The median daily doses of ACE-inhibitors and ARBs were lower than those recommended by the guidelines.

For the beta-blockers, metoprolol was the drug of preference with a median dose of $87 \mathrm{mg}$, which is $<50 \%$ of the target dose stated in the guidelines. Loop diuretics were the medication of choice if patients received diuretic therapy. The median daily dose varies per drug in both LVEF $\leq 40 \%$ as LVEF $\geq 40 \%$.

\section{DISCUSSION}

In our group of nursing home residents with the previous diagnosis of heart failure, the recommended medical therapy for HF was often not prescribed and, if prescribed, dosage was usually far below what was recommended by the guidelines, whereas non-pharmacological interventions were rarely used.

The prescription of an ACE-inhibitor in 30\% of the residents with HF irrespective of the LVEF was in line with the results presented in the review by Litaker, where the prevalence of ACE-inhibitor use ranged from 21-35\%.(9) A more recent publication by Hancock showed a use of $44 \%$ in residents with a reduced left ventricular ejection fraction (LVEF) and $26 \%$ in residents with a preserved LVEF.(1) This was also seen in the study of Foreman, where all participating residents had a LVEF $\leq 40 \%$, and $35 \%$ of the residents used an ACE-inhibitor.(16) These findings are similar to our findings, showing an underuse of ACE-inhibitors in our nursing home residents. Although there is only an evidence based treatment of HF with a reduced EF, previous studies did not find major differences in the prescription rate of cardiac medication in patients with reduced LVEF as compared to preserved LVEF. $(17,18)$ This is also demonstrated in this study.

A possible reason for the underuse might be that residents were at a greater risk for adverse drug reactions, such as renal dysfunction and hypotension due to polypharmacy and comorbidity. $(18,19)$ However, we do not have any information to what extent this might have explained the underuse seen in our study. In addition, average renal function was not severely reduced. Another explanation for the underuse of treatment with ACE-inhibitors could be that the time of onset of HF is not always obvious and, as a result, no medication adjustment as recommended by the guidelines occurs.

Although beta-blocker use was $64 \%$ in residents with HF and LVEF $<40$, only $36 \%$ of these residents received a combination of a beta-blocker with an ACE-inhibitor or ARB-antagonist. In the studies by Bolmsjo and Hancock, $59 \%$ and $30 \%$, respectively, of the residents used a beta- blocker. $(1,10)$ Compared to the early 2000 s this seems to 
be a positive development in the use of beta-blockers. As in the studies by Ruths and Lien, only $3 \quad(n=1552)$ and $5 \quad(n=116)$ residents, respectively, used a betablocker. $(20,21)$ However, it might be that this increase in the use of beta-blockers is not only a consequence of a better compliance with the guidelines to treat HF, but also the result of prescribing a beta-blocker due to another indication. These other indications, such as hypertension, CAD or arrhythmia are also very prevalent in our nursing home population. In addition, focusing on morbidity and mortality, the SENIORS study investigated the effect of nebivolol, and found that it was well tolerated and effective in reducing mortality and morbidity in patients $>70$ years old, regardless of the ejection fraction.(22) It is remarkable that, in our study, only one resident used nebivolol. Studies on other beta-blockers in HF, such as the drug of preference, metoprolol, included much younger patient populations.(23)

In our study, loop diuretics were the most frequently used therapeutics for residents with $\mathrm{HF}$, as seen in many other cohort studies, particularly in elderly patients. (24) A relatively high rate of diuretic use is expected because diuretics are recommended for symptomatic treatment of fluid overload irrespective of LVEF. Still, it is noteworthy that a significant proportion of patients without the diagnosis of HF also received diuretics and had peripheral oedema.

This study showed that, in almost none of the residents, the recommended daily target dose of cardiac medication was achieved. Comparing the median daily dose by LVEF, a higher median daily dose in residents with LVEF $\leq 40 \%$ might be expected. However on average, this was not the case. Given the low rate of HF specific treatment, this may be seen as not surprising knowing that nursing home residents are at a greater risk for adverse drug reactions due to polypharmacy and comorbidities.(11) Older patients on beta-blocker medication have a higher risk of side effects when compared to younger persons, and diuretics could have a negative effect such as the development of the cardio-renal syndrome.(25)

An overall reason for not prescribing and/or prescribing cardiac medication in a low dosage could be due to the fact that reducing mortality may be seen as unimportant in nursing home residents, but relieving symptoms and improving quality of life may be seen as even more crucial. It is, however, important to note that the treatment with ACE-inhibitors was not only found to reduce mortality in HF, but also to reduce symptoms and significantly improve quality of life. Although there seems to be no benefit regarding the quality of life by adding a beta-blocker or spironolactone, there is still the need for appropriate diagnostics and therapy of HF given the effects on reducing hospitalisations, taking age into account and the fact that a patient is living in a nursing home.(26)

The use of non-pharmacological interventions was nearly absent in our residents. We are not aware of any other studies that described the non-pharmacological treatment in nursing home residents with HF. Non-pharmacological therapy, including exercise training and dietary and life-style advice, showed beneficial effects in reliev- 
ing symptoms and improving both quality of life and prognosis.(7) Several studies showed benefits of exercise in older persons on tiredness and breathlessness that limited daily activities. $(27,28)$ Unfortunately, it appears that there is insufficient attention on the benefits of non-pharmacological interventions of HF in nursing home residents, which is an important area of attention for improving HF care in nursing homes. The possible reasons for this discrepancy remain speculative. One could be that nursing home physicians do not have enough knowledge regarding the benefits of nonpharmacological interventions.

There are several limitations of this study. First, the diagnosis of HF was retrieved out of medical records; however in many patients, as is often the case in clinical practice, original records of cardiologic examinations were not available. Thus, LVEF related to the previous diagnosis of HF was not known and we could separate patient groups based on LVEF after inclusion in the study only. Moreover, in some patients, LVEF could not be determined. Furthermore, there was no information available about possible adverse drugs reactions. Thus, we do not understand precise indications of medication in individual patients.

Guidelines assume that elderly should be treated the same way as younger patients with HF. However, the guideline treatment of hypertension has demonstrated adjustments of the target values of systolic blood pressure and the TIME-CHF study showed that there were no differences in outcomes for the elderly when HF was treated more intensively, in contrast to the younger patients. $(29,30)$ This suggests that it might be necessary to adjust the guidelines to optimize HF treatment in the elderly and more specific in nursing home residents, but this should be tested prospectively in appropriate clinical trials.

In conclusion, this study demonstrated that the current pharmacological treatment of nursing home residents with HF was not according to the guidelines specified, and that non-pharmacological treatment was almost absent in nursing residents with HF. The clinical consequences are unknown and require specific studies on this frail population. 


\section{REFERENCES}

1 Hancock HC, Close $\mathrm{H}$, Mason JM, et al. High prevalence of undetected heart failure in long-term care residents: findings from the Heart Failure in Care Homes (HFinCH) study. Eur J Heart Fail 2013;15:158-65.

2 Daamen MA, Schols JM, Jaarsma T, et al. Prevalence of heart failure in nursing homes: a systematic literature review. Scand J Caring Sci 2010;24:202-8.

3 Fonarow GC. Heart failure: recent advances in prevention and treatment. Rev Cardiovasc Med 2000;1:25-33, 54.

4 Ekman I, Swedberg K. Patients' persistence of evidence-based treatment of chronic heart failure: a treatment paradox. Circulation 2007;116:693-5.

5 McMurray JJ, Adamopoulos S, Anker SD, et al. ESC Guidelines for the diagnosis and treatment of acute and chronic heart failure 2012: The Task Force for the Diagnosis and Treatment of Acute and Chronic Heart Failure 2012 of the European Society of Cardiology. Developed in collaboration with the Heart Failure Association (HFA) of the ESC. Eur Heart J 2012;33:1787-847.

6 Yancy CW, Jessup M, Bozkurt B et al. 2013 ACCF/AHA guideline for the management of heart failure: a report of the American College of Cardiology Foundation/American Heart Association Task Force on practice guidelines. Circulation 2013;128:e240-327.

7 Coats AJ. Advances in the non-drug, non-surgical, non-device management of chronic heart failure. Int $J$ Cardiol 2005;100:1-4.

8 Schols JM, Crebolder HF, van Weel C. Nursing home and nursing home physician: the Dutch experience. J Am Med Dir Assoc 2004;5:207-12.

9 Litaker JR CJ. Patterns of pharmacologic treatment of congestive heart failure in elderly nursing home residents and related issues: a rview of the literature. Clin Ther 2003;25:1918-35.

10 Bolmsjo BB, Molstad S, Ostgren CJ, et al. Prevalence and treatment of heart failure in Swedish nursing homes. BMC Geriatr 2013;13:118.

11 Michalik C, Matusik P, Nowak J, et al. Heart failure, comorbidities, and polypharmacy among elderly nursing home residents. Pol Arch Med Wewn 2013;123:170-5.

12 Sloane PD, Gruber-Baldini AL, Zimmerman S, et al. Medication undertreatment in assisted living settings. Arch Intern Med 2004;164:2031-7.

13 van der Wal $\mathrm{MH}$, Jaarsma T, van Veldhuisen DJ. Non-compliance in patients with heart failure; how can we manage it? Eur J Heart Fail 2005;7:5-17.

14 Daamen MA, Hamers JP, Gorgels AP, et al. The prevalence and management of heart failure in Dutch nursing homes; design of a multi-centre cross-sectional study. BMC Geriatr 2012;12:29.

15 Ribbe MW, Ljunggren G, Steel K, et al. Nursing homes in 10 nations: a comparison between countries and settings. Age Ageing 1997;26 Suppl 2:3-12.

16 Forman $\mathrm{DE}$, Chander RB, Lapane $\mathrm{KL}$, et al. Evaluating the use of angiotensin-converting enzyme inhibitors for older nursing home residents with chronic heart failure. J Am Geriatr Soc 1998;46:1550-4.

17 Alagiakrishnan K, Banach M, Jones LG, et al. Update on diastolic heart failure or heart failure with preserved ejection fraction in the older adults. Ann Med 2013;45:37-50.

18 Cheng JW, Nayar M. A review of heart failure management in the elderly population. Am J Geriatr Pharmacother 2009;7:233-49.

19 Sztramko R, Chau V, Wong R. Adverse drug events and associated factors in heart failure therapy among the very elderly. Can Geriatr J 2011;14:79-92.

20 Ruths S, Straand J, Nygaard HA, et al. Drug treatment of heart failure--do nursing-home residents deserve better? Scand J Prim Health Care 2000;18:226-31.

21 Lien CT, Gillespie ND, Struthers AD, et al. Heart failure in frail elderly patients: diagnostic difficulties, co-morbidities, polypharmacy and treatment dilemmas. Eur J Heart Fail 2002;4:91-8.

22 Flather MD, Shibata MC, Coats AJ, et al. Randomized trial to determine the effect of nebivolol on mortality and cardiovascular hospital admission in elderly patients with heart failure (SENIORS). Eur Heart J 2005;26:215-25. 
23 Poole-Wilson PA, Swedberg K, Cleland JG, et al. Comparison of carvedilol and metoprolol on clinical outcomes in patients with chronic heart failure in the Carvedilol Or Metoprolol European Trial (COMET): randomised controlled trial. Lancet 2003;362:7-13.

24 Crawford T, Segars LW, Rasu RS. Prescribing trends for management of congestive heart failure from 2002 to 2004. Res Social Adm Pharm 2013;9:482-9.

25 lacoviello M, Antoncecchi V. Heart failure in elderly: progress in clinical evaluation and therapeutic approach. J Geriatr Cardiol 2013;10:165-77.

26 Dobre D, van Jaarsveld $\mathrm{CH}$, Ranchor AV, et al. Evidence-based treatment and quality of life in heart failure. J Eval Clin Pract 2006;12:334-40.

27 Yu DS, Lee DT, Woo J, et al. Non-pharmacological interventions in older people with heart failure: effects of exercise training and relaxation therapy. Gerontology 2007;53:74-81.

28 Witham MD, Struthers AD, McMurdo ME. Exercise training as a therapy for chronic heart failure: can older people benefit? J Am Geriatr Soc 2003;51:699-709.

29 Mancia G, Fagard R, Narkiewicz K, et al. 2013 ESH/ESC Guidelines for the management of arterial hypertension: the Task Force for the management of arterial hypertension of the European Society of Hypertension (ESH) and of the European Society of Cardiology (ESC). J Hypertens 2013;31:1281-357.

30 Troughton RW, Frampton CM, Brunner-La Rocca HP, et al. Effect of B-type natriuretic peptide-guided treatment of chronic heart failure on total mortality and hospitalization: an individual patient metaanalysis. Eur Heart J 2014;35:1559-67. 



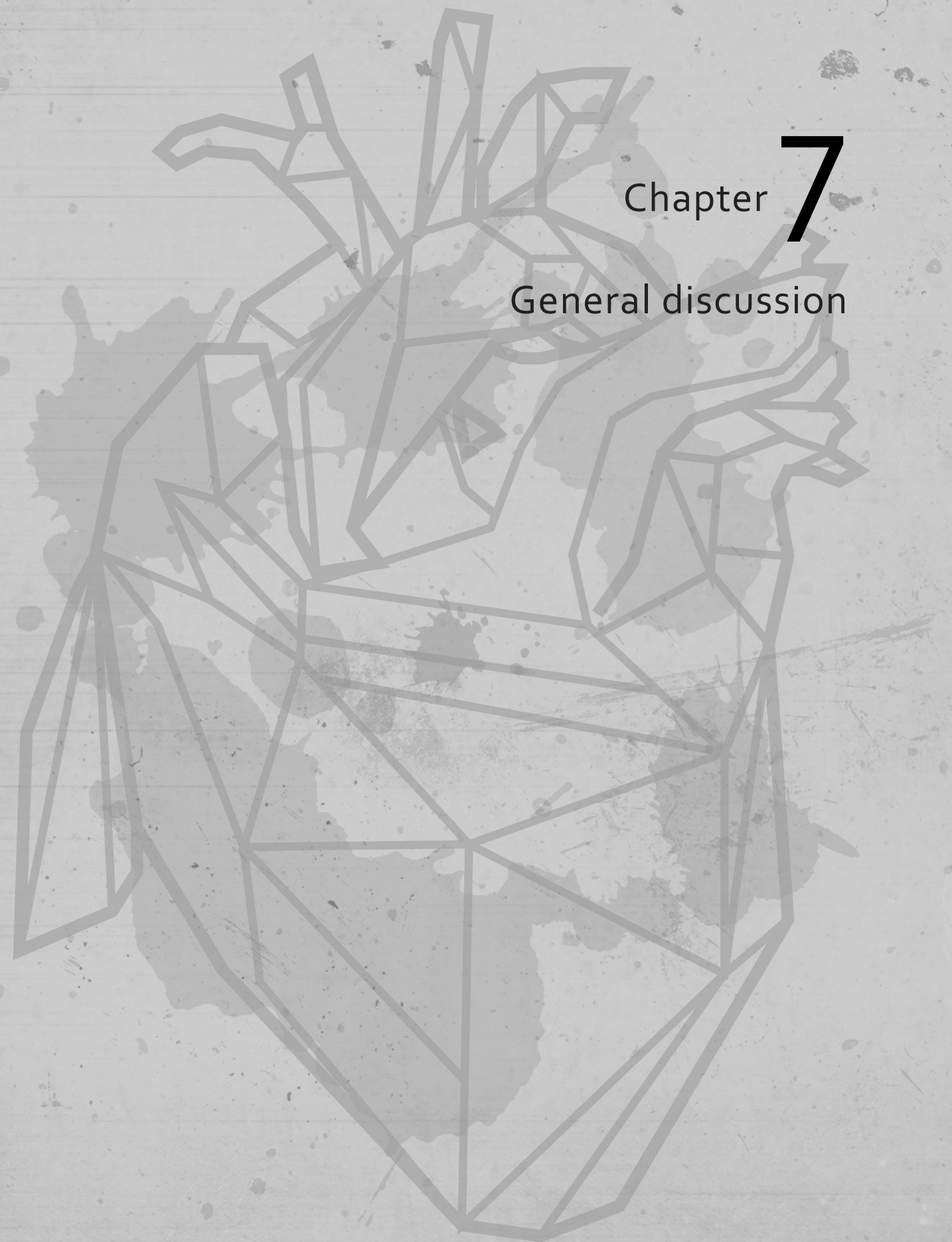



The studies of this thesis about heart failure (HF) in nursing home residents have given us more insights into the state of HF in this specific group of frail and disabled older persons, specifically regarding prevalence, characteristics, accuracy of diagnosing and treatment. The specific aims of this thesis were:

1. To determine the prevalence of HF and the clinical characteristics of nursing home residents with HF.

2. To investigate to what extent it is possible to diagnose HF by the nursing home physicians (NHPs) in the nursing home setting without the use of echocardiography.

3. To investigate how HF is currently treated pharmacologically and non-pharmacologically in nursing home residents.

This chapter provides an overview of the main findings described in the previous chapters of this thesis. Thereafter, theoretical and methodological considerations will be discussed. Finally, recommendations for daily practice and further research will be presented.

\section{MAIN FINDINGS}

The studies in this thesis showed that HF is a major problem in nursing home residents.

The main findings are as follows:

- Heart failure is highly prevalent in nursing home residents, in both somatic and psychogeriatric residents, including many unknown or falsely diagnosed with HF. The numbers of HF patients with reduced and preserved left ventricular ejection fraction are about equal.

- Nursing home residents with HF are older, more likely to have typical signs and symptoms of HF and have more often a history of cardiac diseases. Diabetes and COPD are disorders commonly associated with HF.

- Trained NHPs are fairly capable of diagnosing HF in nursing home residents without information from an echocardiography. The latter is mainly indicated if results have an impact on treatment.

- A model to predict HF contributes to a more accurate diagnosis of HF in nursing home residents.

- The current pharmacological treatment does not follow guidelines and nonpharmacological treatment is almost absent in nursing home residents. 


\section{THEORETICAL CONSIDERATIONS}

The main aim of our studies was to gain more insight into the current status of $\mathrm{HF}$ in nursing home residents. In fact it is rather surprising that knowledge about such a highly prevalent chronic disease as HF in nursing home residents is so limited. This is probably related to the perception that nursing home residents are mostly frail and very disabled older persons at the end of their lives and treatment to improve prognosis may be seen as less relevant. Furthermore, nursing home residents are often excluded from clinical and epidemiological studies. Fortunately, medical professionals all over the world have become increasingly convinced that scientific research is essential in nursing home residents to improve (medical) care for this highly vulnerable group of patients. Examples include the Nursing Home International Working Group and the emerging Academic Collaborative Centers on Care for Older people also focusing on nursing homes in the Netherlands. $(1,2)$

The question arises why there is an important need to increase knowledge on HF in nursing home residents knowing that quality of life is more important than their length of life. The answer to this question is rather simple as improving knowledge may increase the ability to apply the required proper care which suits the needs of these frail nursing home residents regarding their quality of life. Proper care, in this respect, is perceived as recognizing $\mathrm{HF}$ in time, diagnosing $\mathrm{HF}$ without burdensome investigations and administering tailored pharmacological and non-pharmacological treatment. In this context prevalence, diagnosis, assessment and treatment of HF will be discussed sequentially.

\section{Prevalence of heart failure}

Heart failure was expected and indeed demonstrated to be highly prevalent (chapter 4). Our finding of an overall prevalence of $\mathrm{HF}$ of $33 \%$ is generally higher compared to other studies. In our review study (chapter 2) we found a prevalence of HF with a range of $15-45 \%$. However, the diagnosis of $\mathrm{HF}$ was based on information derived from medical records only in all but one.(3-7) In the study by Butler et al. the diagnosis of $\mathrm{HF}$ was made after a clinical examination by a geriatrician resulting in a prevalence of $45 \%$.(6) Echocardiography was not performed which may have resulted in an overestimation of the prevalence of HF.

Moreover, two recently published studies on the prevalence of $\mathrm{HF}$ in nursing home residents with a rather similar HF assessment found a prevalence of $23 \% .(8,9)$ In one study (Barents 2010), a much lower number of residents was included, 103 residents versus 501 residents in our study and only residents living on a somatic ward. The second study (Hancock 2012) included 405 residents but, care facility managers decided on participation based on concerns about the balance of risks and benefits in ad- 
vance resulting in 30\% ineligible residents which may have caused selection bias resulting in a lower prevalence of HF.

There may be several reasons to endorse a higher prevalence of $\mathrm{HF}$ in nursing home residents. The prevalence of HF in older persons is expected to be high due to an ageing population and higher survival rates after cardiovascular events.(10)

In addition, HF was traditionally seen as a result of impairment of the heart to pump sufficient amounts of blood into the circulation during systole, the so called systolic left ventricular dysfunction.(11) Thus prevalence figures were primarily related to HF with reduced ejection fraction (HFrEF). In recent years, insight into the pathophysiology of HF has shown that also an impaired filling of the left ventricle, but normal systolic function (i.e. HF with preserved ejection fraction (HFpEF)) may lead to signs and symptoms of HF consequently leading to a higher prevalence of HF.

Finally in our study on prevalence of HF, half of the residents with HF had not been diagnosed prior to inclusion in the study. This may imply that HF was not recognized when they were still living at home or HF developed during their stay in the nursing home. Assuming some missed diagnoses, this finding indicates that the true prevalence of $\mathrm{HF}$ in the general population may be underestimated.

Given the high prevalence of HF, it may be interesting to determine whether there is any possibility to reduce this prevalence. The multidisciplinary guideline on cardiovascular risk management aims to encourage adequate treatment of patients with an increased risk of cardiovascular events to prevent (new) events resulting also in a decrease of HF.(12) However, it is uncertain to what extent this guideline is also applicable in frail and disabled elderly. For example, the risk table does not include figures for persons over 70 years and a treatment period for the use of, for instance statins of 1-2 years to obtain an effect on mortality is often not realistic in nursing home residents.(13)

In addition, it is important to know, how the prevalence of HF is related to other common diseases in nursing home residents. Unfortunately, to our knowledge, there are no recent overviews available about the most common diseases in nursing home residents. These data were collected by SIVIS (nursing home information system) up to 2004 and by LZR (national care registration nursing homes) up to 2005. After the law was abolished, the registration was no longer compulsory and therefore ceased. Consequently, we are lacking relevant information about medical diagnoses in nursing home residents.

However, PublicHealthCare.info2016 presents a ranking list of the most common diseases in the overall Dutch population $>65$ years of age. HF occupies the tenth position, whereas coronary heart diseases, chronic obstructive pulmonary diseases (COPD) and diabetes mellitus (DM) are more prevalent. Prevalence numbers are displayed as point prevalence with absolute numbers of patients.(14) For our study population, we also collected data for the comorbidities of coronary heart diseases (CAD), DM and COPD and found a prevalence of 30\%, 21\% and $17 \%$ respectively (chapter 4 ). 
These prevalence figures of comorbidities have also been reported in other studies of nursing home residents (chapter 3), i.e. DM (11-38\%) COPD (12-36\%) and CAD (13$59 \%) .(3-7,15-19)$ Cerebrovascular accidents (CVAs) had a prevalence of $41 \%$. The diagnosis of CVA, due to its remaining disabilities is the most frequent diagnosis at admission for residents on somatic wards and therefore expected to be highly prevalent. Regarding the prevalence figures of comorbidities in nursing home residents it might imply that HF in nursing home residents may have a higher ranking compared with other diseases.

\section{Diagnosing heart failure by nursing home physicians}

As early diagnosis and treatment of HF may prevent progression and can lead to improvement of quality of life, it is essential that HF is diagnosed adequately in nursing home residents.(20) In our prevalence study, it appeared that in one third of the residents with a previous presumed diagnosis of $\mathrm{HF}$, this diagnosis was rejected and in half of the residents with HF the diagnosis had not been made before. These are remarkable figures, but they confirm previous findings in similar studies on the prevalence of HF in nursing home residents. $(8,9)$

Nevertheless, considering the high prevalence of HF in nursing home residents, it might be expected that the NHP possesses sufficient knowledge and skills to diagnose and treat HF. Still, the numbers of residents with unknown or falsely diagnosed HF may suggest the opposite. It seemed that a previous diagnosis of HF was not critically evaluated by the NHP at admission and there was inadequate attention to the potential presence of HF. Reasons for this are not clear. It is possible that NHPs have insufficient knowledge about HF. NHPs acquire their knowledge and skills regarding HF above all during their bachelor's and master's programme in regular medical study. Postgraduate training for elderly care physicians (formerly nursing home physicians) focuses on different areas of competence, but assumes the presence of basic medical knowledge. In the most recent education programme, learning occurs by describing issues and considerations of professional situations and by following educational programmes on chronic diseases.(21) Education about HF is included in the curriculum. In the first year there is a 3 hour lecture about HF. Additionally, the reader at the start of year 1 and 2 contains a summary of the disease HF and learning objectives about HF may be formulated if there is common ground in other programmes such as polypharmacy and palliative care.

Another reason could be a lack of time to conduct a proper and critical clinical assessment in nursing home residents after admission to the nursing home. This would be an undesirable condition. The ability to diagnose diseases based on history, physical examination and available diagnostics in the nursing home such as laboratory testing, is actually the strength of the Dutch NHP providing medical care in nursing home 
residents. This has been confirmed in our study on diagnosing HF by the NHP (chapter 5) which showed that a trained NHP is fairly well capable of diagnosing HF without the use of an echocardiography. However, the better performance of NHPs in our study as compared to diagnosis prior to the study was seen after additional training on HF. In addition their participation in a study on HF may have led to a higher awareness of the possible presence of HF.

Moreover, diagnosis of HF may be accepted as true if residents visited a cardiologist previously or it might be seen as less relevant to evaluate the diagnosis if residents are already being treated with cardiac medication such as ACE-inhibitors and beta-blockers.

In our study on diagnosing HF by NHPs, we asked the NHP to decide (stepwise) on the diagnosis of HF. At step two, with information from anamnesis, physical examination, ECG and NT-proBNP, NHPs were still in doubt in about half of the cases. We then forced them at step 3 (= step 2 + information about medication and comorbidities, except echocardiography) to make a final decision on the presence or absence of HF. Interestingly, the number of both wrong diagnoses and undetected HF could be reduced by applying a multivariable model of independent characteristics if there was still doubt about the diagnosis of HF at step two. At present there is no 'user friendly software' to predict the presence of HF in daily practice. After it is adapted for this purpose and validated in another cohort, our model may contribute to a more proper diagnosis of HF in nursing home residents. In addition, it might also be suitable in the general population of elderly persons not residing in a nursing home.

\section{Heart failure assessment}

Following current guidelines, a structured diagnostic workup including medical history, physical examination, electrocardiography (ECG), assessment of cardiac biomarkers (natriuretic peptides) and echocardiography should be employed for each patient to diagnose HF.(22) Echocardiography is used to get objective evidence of a structural and/or functional abnormality of the heart.(22) At present however, it is unusual to perform echocardiography in nursing homes due to the unavailability of echocardiography on location. Thus, the question arises as to whether we cause harm to nursing home residents if HF is diagnosed without echocardiography? Indeed, there may be arguments to support such an assumption. Thus, Barents et al. who studied the role of B-type natriuretic peptides in diagnosing HF and stated that natriuretic peptides can only be used to rule out HF, but is not sufficient to diagnose HF. Based on this finding they concluded that echocardiography is necessary to diagnose HF in residential elderly. However, several diseases that cause structural or functional abnormalities of the heart such as hypertension (with LV hypertrophy) and atrial fibrillation can be diagnosed by physical examination and the use of an ECG only, which are regularly available to NHPs. As described above, we found that a trained NHP using 
available diagnostic means in the nursing home is indeed fairly capable of diagnosing HF without echocardiography which is in line with other studies. Oudejans et al.(2012) determined the ability of general practitioners and geriatricians to diagnose HF without echocardiography and concluded that they could establish the diagnosis in two third of the elderly patients.(23) In a study to assess the diagnostic values of symptoms, signs and additional tests (natriuretic peptides, ECG and chest X-ray) Oudejans et al.(2011) demonstrated that in the vast majority of geriatric outpatients with suspected HF no echocardiography was needed to diagnose HF. Echocardiography was recommended when there was doubt about the diagnosis or to determine the cause of HF.(24)

Obviously, it might be disputable if the accuracy found in these studies and ours is sufficient. Thus, the need for echocardiography might be seen differently if the focus is on the treatment of $\mathrm{HF}$, as the distinction between HFrEF and HFpEF may have important therapeutic consequences.(25) We found that the risk factors for developing HFpEF were highly present. Treatment of these risk factors and HFrEF overlap to a significant extent. Therefore, in many instances, correct treatment can be initiated without knowing left ventricular ejection fraction (LVEF).

Still, in our opinion, echocardiography is advisable if treatment may be different based on the knowledge of the distinction between HFrEF and HFpEF and potentially treatable underlying causes such as valvular heart disease, which are considered a main cause of HF. In such patients, it is highly advisable to conduct an echocardiography.

Until now, residents have had to visit the hospital or a specialized unit to undergo an echocardiography. However, in our study, the complete HF assessment was conducted in the residents' own environment and if required in the presence of a familiar person. This also included echocardiography in the nursing homes. Only a few residents refused echocardiography, but in the majority it was possible to perform the echocardiography using a mobile echo device. Thus, we strongly recommend the performance of echocardiography in the nursing homes themselves. In our study a (fellow) cardiologist performed the echocardiography. It may be questioned whether a NHP might be able to conduct this. To answer this question several elements are of interest. First in order to acquire the necessary skills, the possibility of a training course for NHPs on basic echocardiography should be explored. Second, to ensure a proper assessment of the data an echo device with storage capacity should be used. Subsequently the results should be transferred and evaluated in close cooperation with a cardiologist, guaranteeing better care for residents with HF.

Finally, it should be considered if the number of echocardiographies performed in nursing homes would be sufficient to maintain the achieved skills. We assume that the high prevalence of HF in nursing home residents together with the high turnover of residents, due to the high mortality rate, will ensure sufficient indications to consider the performing of echocardiographies by NHPs. 


\section{Treatment of heart failure}

Pharmacological and non-pharmacological treatments of HF in nursing home residents did not follow the ESC- guidelines.(22) Regarding pharmacological treatment, this is not an unexpected outcome, because Heckman (2004) also found that pharmacological treatment in Canadian long-term care facilities was not according to the guidelines.(4) There are two possible reasons for incompliance with the guidelines attributed to the prescriber, in our study the NHP. On the one hand, it could be due to a lack of knowledge of the guidelines, on the other hand, it could be conscious noncompliance with the guidelines for the benefit of the resident. In our study, it was unknown how well the NHPs were familiar with the guidelines on treatment of HF. The pharmacotherapy protocol which is most commonly used in nursing homes is usually drafted within the nursing home but closely derived from available evidence based guidelines. Since the NHPs mainly take care of the treatment of HF in nursing home residents, we assume that to a greater of lesser extent they are familiar with the guidelines. This may suggest that incompliance with the guidelines was a conscious decision. In general, it might be difficult to apply guidelines that are not aligned with the target group. More specifically, the current guidelines on treatment of HF may not be applicable to very frail older persons. Some possible explanations can be identified supporting this opinion. First, nursing home residents have a higher risk of adverse drug reactions.(26) Adverse drug reactions may include hypotension, possibly leading to falls and decrease in renal function which in turn may worsen heart failure. NHPs want to protect their residents from these side effects knowing that this would decrease their quality of life. However, there is some evidence that these side effects may not be attributed to the prescription of cardiac medication. An additional study on data of the TIME-CHF study demonstrated that worsening of renal function was not caused by ACE- inhibitors or beta blockers in the very elderly.(27) Although we have no specific data regarding blood pressure and cardiac medication we found no statistically significant differences in mean systolic and diastolic blood pressure in residents with and without $\mathrm{HF}$, being $136 / 74$ versus $140 / 75 \mathrm{mmHg}$ (chapter 4 ), which cannot be considered as hypotensive with a higher risk of falls. This could suggest that NHPs might be too cautious in prescribing medication with the rationale to prevent adverse drug reactions or side effects.

Secondly, the presence of comorbidities often implies the presence of polypharmacy leading to adverse drug reactions. It is not clear in what way the presence of comorbidities is responsible for incompliance with the guidelines.

Thirdly, evidence based treatment is based on outcomes of large HF trials to reduce mortality and hospital readmissions.(28) Reducing mortality may be seen as unimportant in nursing home residents, where relieving symptoms and improving quality of life are more crucial, possibly resulting in modified treatment decisions, such as lower dosage, that may not fit the guidelines. 


\section{Chapter 7}

Finally, it is important to note that all treatment trials that form the basis for the guidelines were performed in patients that are not representative of nursing home residents. Therefore, it is uncertain as to whether the guidelines are really applicable to the study population of this study, which may have contributed to fewer prescriptions.

The use of non-pharmacological interventions was nearly absent in residents with HF in our study. Non-pharmacological therapy can have a positive impact on symptoms, functional capacity, well-being, morbidity and prognosis as stated by van der Wal (2005).(29) It might be expected that these interventions, which are also well applicable in nursing home residents, would be applied more often. Possible reasons for this discrepancy remain speculative. It could be that NHPs do not have enough knowledge regarding the benefits of non-pharmacological interventions. However, a recent study of a small group of nursing home residents, who received a twice weekly one hour moderate to high-intensity exercise training programme during 16 weeks, showed no effect in reducing symptoms of HF.(30) To gain more insight in the effect of non-pharmacological interventions in HF treatment, further research is necessary.

\section{METHODOLOGICAL CONSIDERATIONS RELATED TO THE STUDIES IN THIS THESIS}

\section{Study design}

Our assumption at the basis of this thesis was that HF in nursing home residents is a major problem, and that knowledge about HF in this specific group is lacking. The main objective was to gain more insight into $\mathrm{HF}$ in this frail population. To achieve this, two observational methods were used: 1. a systematic literature review and 2. a cross-sectional study. A systematic literature review is the most appropriate method to obtain an overview, because it provides a summary of the current literature relevant to a related research question. We identified that there were only five studies about the prevalence of HF. In most studies the diagnosis of HF was retrieved from the medical records only.

In addition, some concerns about previous studies on the prevalence of can be raised. The prevalence of HF seems to have changed over the past decades. In prevalence studies before 1995, as described in a review of Cowie (1997,) there was a lack of a uniform definition of HF and there were differences in the assessment to diagnose HF.(31) At that time, the diagnosis of HF was made on clinical criteria (signs and symptoms) by physical examination or on review of medical records only, and/or based on questionnaires and interviews or self-reports with verification by use of cardiac medication. These differences in diagnosing HF may explain the variation in prevalence (range $3-13 \%$ ). Mosterd (2007) stated in a review of the clinical epidemiology of HF 
that physical examinations and objective methods (echocardiography, electrocardiography and cardiac markers) should be used to determine the prevalence of HF.(32)

Therefore, to answer the research question about the prevalence, but also about the diagnosis and treatment of HF in Dutch nursing homes, we used the recommended approach to collecting data by a concrete and complete HF assessment (including history, physical examination, additional investigations (ECG, cardiac markers, echocardiography) and additional information from medical records and questionnaires as described in the study protocol (chapter 3 ).

\section{Study population and sample}

Nursing home residents from 28 locations allocated to five health care organizations providing long-term care participated in this study. The residents living in the larger facilities (with the highest number of residents) were recruited first. In order to prevent selection bias, we decided to include as many residents as possible. Of the 1,819 residents eligible to participate in the study, only $27 \%$ agreed to participate. Reasons for not participating were that residents considered themselves too old or believed that the investigations were too burdensome. In particular, we encountered difficulties, when asking legal representatives to make decisions regarding participations on behalf of (demented) residents. These findings are in line with a study by Barnes et al. (2005) who also focused on the recruitment of older people in a HF study, in which only $30 \%$ of the initially identified participants agreed to participate.(33)

To reveal a possible selection bias, we compared the demographic characteristics of age, gender and ward type for both participants and non- participants and found no clinically significant differences. We believe this is a common problem among studies of nursing home residents, as potential participants do not see advantages in research participation or consider the examinations too burdensome.

\section{Data collection and analysis.}

For each resident, trained nursing home physicians at each healthcare organization collected data using an on-site integral examination. After receiving a refresher course on a structured physical examination for HF, the NHPs performed the anamnesis and physical examination of nursing home residents for which they were not the primary medical care provider. To minimize variability in the clinical examinations, a brief description of how to investigate and interpret the finding of each variable was given.

In general, to determine the relationship between the outcome and other independent characteristics by estimating probabilities, a (multivariable) logistic regression model is most commonly used. Variables used in the logistic regression model depend on the research question mostly involving statistical significant characteristics $(P$-value $<0.05)$ and variables based on literature and expert opinion. To avoid circular 
reasoning when determining the independent predictors of prevalent HF (chapter 4), variables used to diagnose HF (dyspnoea, signs of right-sided HF and NT-proBNP), although statistically significant, were not added to the model.

The final model of characteristics with a high contribution in independently predicting HF (chapter 5) was not cross-validated. For cross-validation, we need to randomly select a subset of the data to be treated as a learning set. The prediction model would then be based on this much smaller (e.g. half of the observed data) learning set. Validating the model by applying the remaining subset on the obtained prediction model, may lead to less reliable results due to the small sample size of the two groups. Thus, we have decided not to cross-validate the model and accept that the current results might be slightly too optimistic.

\section{RECOMMENDATIONS FOR DAILY PRACTICE}

$\mathrm{HF}$ is predominantly present in nursing home residents and all physicians (NHPs) and nurse practitioners responsible for the medical care of nursing home residents should be aware of this. To diagnose HF accurately, they need to ensure that their knowledge of HF and more generally of all prevalent diseases in nursing home residents, remains up to date. In the basic medical curriculum, education on chronic diseases such as HF, especially in the older population, should be adequately covered. In postgraduate training for elderly care physicians, the focus might be more towards bedside teaching because the strength of the NHP compromises tailored physical examination. For the NHP, there are several options for postgraduate professional development. Usually, refresher courses are accessible to a large audience and based on theoretical knowledge. Our refresher course was given by very experienced cardiologists and included a review of signs and symptoms of HF followed by bedside teaching and a training on ECG findings in relation to HF. Supported by the findings of our study we would recommend our training formula with the advantage of personal feedback due to small groups (5-6 persons), face to face contact with the trainer, and the formula of bedside teaching.

Furthermore, NHPs are used to perform a comprehensive geriatric assessment of residents at admission to the nursing home. A well conducted examination is relevant for each nursing home resident, with specific attention to the high prevalence of chronic diseases and should include a thorough physical examination, an ECG and laboratory testing. Linking abnormalities found on the assessment to pathological processes of possible underlying diseases, could possibly reduce the need for additional investigations. Subsequently, the results of the assessment should be discussed with the resident and/or their representatives, followed by a proposal on whether or not to treat considering the quality of life (shared decision making). 
This assessment should also include a critical evaluation of the presence or absence of HF and if indicated, in case of doubt or direct consequences for treatment decisions, appropriate to the treatment proposal, an echocardiography should be arranged. Our study showed that it is quite possible to perform echocardiography in the nursing homes themselves if indicated. In order to achieve this, a partnership between nursing homes and hospital cardiology departments or cardiology units should be considered, depending on the healthcare organization in different countries.

In addition, focusing on the pharmacological treatment of HF, it is important to review the prescribed cardiac medication and the doses used. Depending on the treatment goals, it can be necessary to modify treatment. This might be primarily symptom relief while following the guidelines less strictly, but on the other hand, adequate treatment in other cases may require stricter adherence to the guidelines. To identify adverse drug reactions, decrease in renal function or other problems in prescribing medications due to co-morbidities in nursing home residents, it is recommended to precisely document the rationale of prescriptions and evaluations in the medical records. Furthermore, there should be more attention on improving HF care by implementing the use of non-pharmacological interventions in a feasible way.

Finally, if our prediction model was implemented in a user-friendly software for use in daily practice it could be used to reduce the number of false positive and false negative diagnoses of HF in nursing home residents. However, it should first be validated in another cohort of nursing home residents.

\section{RECOMMENDATIONS FOR FURTHER RESEARCH}

Based on our study findings some recommendations for further research on HF in nursing home residents can be made. First, we encourage the continued monitoring of the prevalence of HF both in the general population and in specific elderly populations such as nursing home residents. In particular, this is because it is expected that the incidence and prevalence will further increase due to ageing of the population and higher survival rates after cardiovascular events.

Second, further research on appropriate pharmacological treatment in nursing home residents should be employed. However, it may be difficult to establish good research in this vulnerable group of frail older persons, due to the possibly low participation rates, common comorbidities and high dropouts. Still, participation rate might be higher than in our study which was purely observational, if interventions that may result in some benefit are tested. More research is needed on adverse drug reactions and the effects of non-pharmacological interventions on HF in this specific group of nursing home residents. Ultimately, it is essential to achieve and incorporate more customized recommendations for very frail older persons in renewed guidelines on $\mathrm{HF}$ that fit their prognostic profile better. 


\section{Chapter 7}

Finally, it would be interesting to know more about the experienced quality of life of nursing home residents with HF, care dependency in relation to HF and the burden experienced by nursing home residents when they undergo additional investigations. 


\section{REFERENCES}

1. Available from: www.nursing-home-research.com.

2. Available from: http://academischeouderenzorg.nl/.

3. Shibata MC, Soneff CM, Tsuyuki RT. Utilization of evidence-based therapies for heart failure in the institutionalized elderly. Eur J Heart Fail. 2005 Dec;7(7):1122-5.

4. Heckman GA, Misiaszek B, Merali F, Turpie ID, Patterson CJ, Flett N, et al. Management of heart failure in Canadian long-term care facilities. Can J Cardiol. 2004 Aug;20(10):963-9.

5. Gambassi G, Forman DE, Lapane KL, Mor V, Sgadari A, Lipsitz LA, et al. Management of heart failure among very old persons living in long-term care: has the voice of trials spread? The SAGE Study Group. Am Heart J. 2000 Jan;139(1 Pt 1):85-93.

6. Butler R, Fonseka S, Barclay L, Sembhi S, Wells S. The health of elderly residents in long term care institutions in New Zealand. N Z Med J. 1999 Nov 12;112(1099):427-9.

7. Ranz TT, Blumenschein K, Clifton GD. Prevalence and treatment of heart failure in elderly long-termcare patients. Am J Health Syst Pharm. 1999 Jul 1;56(13):1334-8.

8. Hancock HC, Close H, Mason JM, Murphy JJ, Fuat A, Singh R, et al. High prevalence of undetected heart failure in long-term care residents: findings from the Heart Failure in Care Homes (HFinCH) study. Eur J Heart Fail. 2013 Feb;15(2):158-65.

9. Barents $M$, van der Horst IC, Voors AA, Hillege $J$, Muskiet FA, de Jongste MJ. Prevalence and misdiagnosis of chronic heart failure in nursing home residents: the role of B-type natriuretic peptides. Neth Heart J. 2008 Apr;16(4):123-8.

10. Kannel WB. Incidence and epidemiology of heart failure. Heart Fail Rev. 2000 Jun;5(2):167-73.

11. Kemp CD, Conte JV. The pathophysiology of heart failure. Cardiovascular Pathology. 2012 $9 / / ; 21(5): 365-71$.

12. Banga JD, Dijk van JL, Dis van I, Giepmans L, Goudswaard AN, Grobbee DE, et al. multidisciplinary guideline cardiovascular risk management, revision. 2011.

13. Shepherd J, Blauw GJ, Murphy MB, Bollen EL, Buckley BM, Cobbe SM, et al. Pravastatin in elderly individuals at risk of vascular disease (PROSPER): a randomised controlled trial. Lancet. 2002 Nov 23;360(9346):1623-30.

14. National Health and Care 2016a Bilthoven: RIVM; 2015. Available from: https://www.volksgezondheid enzorg.info/ranglijst/ranglijst-ziekten-op-basis-van-prevalentie/leeftijd\#node-top-tien-65-plussers.

15. Ahmed A, Allman RM, DeLong JF. Predictors of nursing home admission for older adults hospitalized with heart failure. Arch Gerontol Geriatr. 2003 Mar-Apr;36(2):117-26.

16. Hutt E, Frederickson E, Ecord M, Kramer AM. Associations among processes and outcomes of care for Medicare nursing home residents with acute heart failure. J Am Med Dir Assoc. 2003 Jul-Aug;4(4):195-9.

17. Ahmed A. Clinical characteristics of nursing home residents hospitalized with heart failure. J Am Med Dir Assoc. 2002 Sep-Oct;3(5):310-3.

18. Havranek EP, Masoudi FA, Westfall KA, Wolfe P, Ordin DL, Krumholz HM. Spectrum of heart failure in older patients: results from the National Heart Failure project. Am Heart J. 2002 Mar;143(3):412-7.

19. Wang R, Mouliswar M, Denman S, Kleban M. Mortality of the institutionalized old-old hospitalized with congestive heart failure. Arch Intern Med. 1998 Dec 7-21;158(22):2464-8.

20. Gaulden L. Diagnosis and management of heart failure in the long-term care setting. Director. 2003 Fall;11(4):177-81.

21. Smalbrugge $M$, Geer van der $E$, Kleine Schaars I, Kromhout M, LindenberghA, Mak R, et al. National training programme for elderly care physicians. 2016.

22. McMurray JJ, Adamopoulos S, Anker SD, Auricchio A, Bohm M, Dickstein K, et al. ESC Guidelines for the diagnosis and treatment of acute and chronic heart failure 2012: The Task Force for the Diagnosis and Treatment of Acute and Chronic Heart Failure 2012 of the European Society of Cardiology. Developed in collaboration with the Heart Failure Association (HFA) of the ESC. Eur Heart J. 2012 Jul;33(14):1787-847. 


\section{Chapter 7}

23. Oudejans I. Heart failure in geriatric outpatients. Diagnosis, prognosis and treatment.: Utrecht University; 2012.

24. Oudejans I, Mosterd A, Bloemen JA, Valk MJ, van Velzen E, Wielders JP, et al. Clinical evaluation of geriatric outpatients with suspected heart failure: value of symptoms, signs, and additional tests. Eur J Heart Fail. May;13(5):518-27.

25. Butler J, Fonarow GC, Zile MR, Lam CS, Roessig L, Schelbert EB, et al. Developing therapies for heart failure with preserved ejection fraction: current state and future directions. JACC Heart failure. 2014 Apr;2(2):97-112.

26. Sztramko R, Chau V, Wong R. Adverse drug events and associated factors in heart failure therapy among the very elderly. Canadian geriatrics journal : CGJ. 2011 Dec;14(4):79-92.

27. Brunner-La Rocca H-P, Knackstedt C, Eurlings L, Rolny V, Krause F, Pfisterer ME, et al. Impact of worsening renal function related to medication in heart failure. European Journal of Heart Failure. 2015;17(2):159-68.

28. Fonarow GC. Heart failure: recent advances in prevention and treatment. Reviews in cardiovascular medicine. 2000 Summer;1(1):25-33, 54.

29. van der Wal MH, Jaarsma T, van Veldhuisen DJ. Non-compliance in patients with heart failure; how can we manage it? Eur J Heart Fail. 2005 Jan;7(1):5-17.

30. Barents M. Chronic heart failure diagnostics and application of neuropeptides in residential elderly: University of Groningen; 2015.

31. Cowie MR, Mosterd A, Wood DA, Deckers JW, Poole-Wilson PA, Sutton GC, et al. The epidemiology of heart failure. Eur Heart J. 1997 Feb;18(2):208-25.

32. Mosterd A, Hoes AW. Clinical epidemiology of heart failure. Heart. 2007 Sep;93(9):1137-46

33. Barnes S, Gott M, Payne S, Parker C, Seamark D, Gariballa S, et al. Recruiting older people into a large, community-based study of heart failure. Chronic Illn. 2005 Dec;1(4):321-9. 


\section{Summary}

\section{Samenvatting}

Valorization addendum

Dankwoord

About the author

Publications 



\section{Summary}

Heart failure (HF) is an important health care problem in Western countries. The prevalence of HF increases with age. It is a growing problem as the population ages and survival rates after cardiovascular events increase. This thesis reports on a study of HF in nursing home residents. Research questions covered the prevalence, diagnosis and management of HF in nursing home residents.

The introduction (first chapter) provides general background information about HF and more specific about HF in nursing home residents. HF is a major problem in older persons and may lead to reduced quality of life. Knowledge regarding HF in nursing home residents, characterized by multimorbidity and polypharmacy, is therefore particularly relevant. Prior to our study, this knowledge was largely lacking. Guidelines of the European Society of Cardiology and the American College of Cardiology/American Heart Association present recommendations how HF, should be diagnosed and treated in general, but specific recommendations for vulnerable older persons with multiple comorbidities, such as nursing home residents are lacking. Thus, the primary aim of this thesis is to provide novel information to fill this gap.

In chapter $\mathbf{2}$ the results of a systematic literature review are presented. The focus was on the prevalence of HF in nursing homes and the presence of comorbidities. The search procedure and evaluation of the methodological quality are briefly described. We found only five studies about the prevalence of HF. The diagnosis of HF was retrieved from the medical records only in all of these studies but one, in which HF was diagnosed after a concrete physical examination performed by a geriatrician. Still even in this study, no additional examinations were performed to prove the diagnosis. Findings indicate that the mean prevalence of heart failure is 20\% (range 15-45\%) and that there is a significant level of comorbidity, such as dementia, diabetes mellitus and COPD, in nursing home residents with HF.

Chapter 3 presents the design of the main study. The aim of this study was to retrieve data to answer research questions about the prevalence, diagnosis and management of HF in nursing home residents and to explore the association between HF, care dependency and quality of life. The study population comprised nursing home residents of five health care organizations, in the Southern part of the Netherlands, more specific Zuid-Limburg (Parkstad, Westelijke mijnstreek en Heuvelland). A thorough HF- assessment was performed to obtain information for diagnosing HF. Trained nursing home physicians, not being the treating physicians of the residents, performed the assessment to collect stepwise information to decide on the diagnosis of HF. The participating nursing home physicians took the anamnesis and performed the physical examination; two research assistants made an electrocardiography, took a 
blood sample to determine the NT-proBNP value, filled in the questionnaires about quality of life and care dependency and retrieved data from the medical records. Standard echocardiographies were performed by (fellow) cardiologists.

Based on all results, except echocardiography, the nursing home physicians decided stepwise on the diagnosis HF; first after medical history (including cardiac history) and physical examination; second after the additional information on NT-proBNP and ECG and finally, the NHP received additional information about medication and known comorbidities.

An expert team of two cardiologists and a geriatrician judged on the final diagnosis of HF, based on all the data collected including echocardiography.

In chapter 4, the prevalence of HF and their clinical characteristics are described. As expected the results show that HF is very prevalent in nursing home residents. HF was divided into the two types of $\mathrm{HF}$; i.e.HF with preserved ejection fraction (LVEF $\geq 50 \%$; HFpEF) and HF with reduced ejection fraction (LVEF<50\%; HFrEF). Equal numbers of HF patients had HFpEF and HFrEF.

A former diagnosis of HF described in the medical record was not confirmed by the expert team in $31 \%$ of the residents, while in $54 \%$ of the residents with HF, the diagnosis of HF was not known before. The clinical characteristics were displayed for both groups of nursing home residents, with and without HF. The symptoms dyspnoea and oedema and a cardiac history were more common in residents with HF. Diabetes mellitus, chronic obstructive pulmonary disease (COPD) were also more prevalent in those with HF. Residents with HF had a higher score on the Mini Mental State Examination, thus they have a better cognitive performance.

In chapter 5 the agreement on the diagnosis of heart failure by the nursing home physician versus the expert team is discussed. In the nursing home, HF is usually diagnosed by the nursing home physician based on history, clinical examination, electrocardiography and measured NT-proBNP value only. It was found that the nursing home physicians were fairly well capable of diagnosing heart failure without echocardiography. Nursing home physicians diagnosed HF in 160 nursing home residents. The NHP correctly identified 109 residents with HF compared to the expert team (sensitivity $75 \%$ ) and excluded HF correctly in 248 residents (specificity 83\%) Additionally, characteristics with a high contribution in predicting $\mathrm{HF}$ were a history of $\mathrm{HF}$, a high NT-proBNP level, the presence of rales, arrhythmias and use of cardiac medication.

Chapter 6 focuses on the treatment of HF. Both the prescribed pharmacological therapies as well as the non-pharmacological therapy of HF in nursing home residents were examined. As there is only evidence based medical therapy for HF with reduced ejection fraction, this group was analyzed separately. The results show that the recommended medical therapy of HF by the guidelines ${ }^{1,2}$ was often not prescribed and if prescribed, the dosage was usually far below the recommended dosage. This may be seen as not surprising knowing that nursing home residents are at a greater risk for adverse drug reactions due to polypharmacy and comorbidities. Besides, an overall 
reason for not prescribing and/or prescribing cardiac medication in a low dosage could be due to the fact that reducing mortality may be seen as less important in nursing home residents, but relieving symptoms and improving quality of life as more crucial. In addition, non-pharmacological interventions, such as fluid-restriction, sodiumrestriction or physiotherapy were mostly not used at all. It appears that there is insufficient attention on the benefits of non-pharmacological interventions of HF in nursing home residents, which is an important area of attention for improving HF care in nursing homes.

The final chapter (chapter 7) concerns the general discussion and contains an overview of the main findings presented in the previous chapters of the thesis. Theoretical and methodological considerations of the conducted studies are addressed and finally several implications for daily practice and further research are presented.

\section{REFERENCES}

1. McMurray JJ, Adamopoulos S, Anker SD, et al. ESC Guidelines for the diagnosis and treatment of acute and chronic heart failure 2012: The Task Force for the Diagnosis and Treatment of Acute and Chronic Heart Failure 2012 of the European Society of Cardiology. Developed in collaboration with the Heart Failure Association (HFA) of the ESC. Eur Heart J 2012;33:1787-847.

2. Yancy CW, Jessup M, Bozkurt B et al. 2013 ACCF/AHA guideline for the management of heart failure: a report of the American College of Cardiology Foundation/American Heart Association Task Force on practice guidelines. Circulation 2013;128:e240-327. 



\section{Samenvatting}

Hartfalen is een belangrijk gezondheidsprobleem in de westerse wereld. De prevalentie van hartfalen neemt toe met het stijgen van de leeftijd en is daarmee een relevant en groeiend probleem geworden ten gevolge van de toenemende vergrijzing en betere overlevingskansen bij cardiovasculaire aandoeningen. Dit proefschrift gaat over een onderzoek omtrent hartfalen bij een specifieke doelgroep, namelijk de verpleeghuisbewoners. Onderzoeksonderwerpen waren de prevalentie, diagnostiek en behandeling van hartfalen bij deze doelgroep.

De introductie (hoofdstuk 1) geeft algemene achtergrondinformatie over hartfalen en meer specifiek over hartfalen bij verpleeghuisbewoners. hartfalen is een belangrijk probleem bij ouderen en kan leiden tot afname van de kwaliteit van leven. Kennis over hartfalen bij verpleeghuisbewoners die gekenmerkt worden door multimorbiditeit, zorgafhankelijkheid en polyfarmacie is daarom juist ook relevant. Echter tot nu toe is hierover nog niet veel bekend. Richtlijnen van de European Society of Cardiology en de American College of Cardiology/ American Heart Association geven aanbevelingen over hoe hartfalen gediagnosticeerd en behandeld moet worden, maar specifieke aanbevelingen voor kwetsbare ouderen met bijkomende aandoeningen, zoals verpleeghuisbewoners ontbreken. Het primaire doel van dit proefschrift is om nieuwe informatie te verzamelen om bij te dragen aan de oplossing van dit hiaat.

In hoofdstuk 2 worden de resultaten van een systematische literatuurstudie gepresenteerd. De focus lag op de prevalentie van hartfalen bij verpleeghuisbewoners en de aanwezigheid van bijkomende aandoeningen. De zoekstrategie en de evaluatie van de methodologische kwaliteit van de gevonden artikelen worden beknopt beschreven. Slechts vijf studies over de prevalentie van hartfalen bij verpleeghuisbewoners werden gevonden. In de meeste studies werd de diagnose hartfalen overgenomen uit de medische dossiers met uitzondering van één studie, waarin hartfalen werd gediagnosticeerd na een concreet lichamelijk onderzoek door een geriater. Ook in deze studie werden geen aanvullende onderzoeken uitgevoerd om de diagnose te bevestigen. De resultaten laten zien dat de gemiddelde prevalentie van hartfalen $20 \%$ bedraagt (range 15-45\%) en dat er een significant aantal relevante bijkomende aandoeningen, zoals dementie, diabetes mellitus en COPD, aanwezig is bij verpleeghuisbewoners met hartfalen.

Hoofdstuk 3 presenteert het design van de hoofdstudie. Het doel van deze studie was om data te verzamelen waarmee de onderzoeksvragen betreffende de prevalentie, diagnostiek en behandeling van hartfalen bij verpleeghuisbewoners beantwoord konden worden en om een eventuele samenhang tussen hartfalen, zorgafhankelijkheid en kwaliteit van leven na te gaan. 
De studiepopulatie bestond uit verpleeghuisbewoners van vijf zorgorganisaties uit Zuid-Limburg (Parkstad, Westelijke mijnstreek en Heuvelland). In het onderzoek werd door aanvullend geschoolde specialisten ouderengeneeskunde (voorheen verpleeghuisartsen), niet zijnde de behandelende artsen van de bewoners, een grondig hartfalen onderzoek vitgevoerd om stapsgewijs informatie te verzamelen waarmee de diagnose hartfalen gesteld kon worden. De participerende specialisten ouderengeneeskunde namen de anamnese af en voerden het lichamelijk onderzoek uit; onderzoeksassistenten maakten een ECG, namen bloed af voor een NT-pro BNP bepaling, vulden vragenlijsten in m.b.t de kwaliteit van leven en zorgafhankelijkheid en verzamelden gegevens uit het medisch dossier. Standaard echocardiogrammen werden gemaakt door een cardioloog of een arts-assistent cardiologie geschoold in echocardiografie.

Op basis van de uitkomsten met uitzondering van de echocardiografie uitslag konden de specialisten ouderengeneeskunde stapsgewijs de diagnose hartfalen stellen. Eerst na de gegevens verkregen door anamnese en lichamelijk onderzoek, daarna aangevuld met ECG en NT- pro BNP waarde en tot slot op basis van alle uitkomsten, met uitzondering van de echo vitslag. Een expertteam bestaande uit 2 cardiologen en een internist ouderengeneeskunde besliste op basis van alle verzamelde gegevens, inclusief de echocardiografie uitslag over de definitieve diagnose hartfalen.

In hoofdstuk 4 worden de prevalentie van hartfalen bij verpleeghuisbewoners en ook hun klinische kenmerken beschreven. Zoals verwacht laten de resultaten zien dat hartfalen vaak voorkomt bij verpleeghuisbewoners. Hartfalen wordt onderverdeeld in 2 typen hartfalen; hartfalen met behouden ejectiefractie (LVEF $\geq 50 \%$; HFpEF) en hartfalen met verminderde ejectiefractie (LVEF <50\%; HFrEF). De verdeling tussen beiden typen HFpEF en HFrEF was nagenoeg gelijk. Een eerdere diagnose van hartfalen in het medisch dossier werd bij 31\% van de betreffende bewoners niet bevestigd door het expertteam, terwijl bij 54\% van de bewoners met hartfalen de diagnose nog niet eerder gesteld was. De klinische kenmerken worden beschreven voor verpleeghuisbewoners met en zonder hartfalen. De symptomen dyspneu, oedeem en een cardiovasculaire voorgeschiedenis waren meer aanwezig bij bewoners met hartfalen. Ook diabetes mellitus en COPD waren meer aanwezig bij bewoners met hartfalen. Daarnaast hadden bewoners met hartfalen een hogere score op de Mini Mental State Examination, dus waren ze cognitief beter.

In hoofdstuk $\mathbf{5}$ wordt de overeenstemming tussen de diagnose hartfalen zoals gesteld door de specialist ouderengeneeskunde vergeleken met het oordeel van het expertteam. In het verpleeghuis, wordt hartfalen meestal vastgesteld door de specialist ouderengeneeskunde gebaseerd op anamnese, lichamelijk onderzoek, elektrocardiografie en de gemeten NT-proBNP waarde. In dit onderzoek blijkt dat de specialist ouderengeneeskunde redelijk goed in staat is om de diagnose hartfalen te stellen zonder gebruik te maken van een echocardiogram. De diagnose hartfalen werd door de specialist ouderengeneeskunde bij 160 bewoners gesteld. Bij 109 bewoners kwam deze diagnose overeen met de diagnose gesteld door het expertteam (sensitiviteit 
$75 \%$ ), terwijl 248 bewoners correct geëxcludeerd werden als hartfalen patiënten (specificiteit $83 \%$ ). Kenmerken die in hoge mate ondersteunend zijn om de aanwezigheid van hartfalen te voorspellen betreffen: een voorgeschiedenis van hartfalen, een hoge NT-proBNP waarde, de aanwezigheid van crepitaties, hartritmestoornissen en het gebruik van cardiale medicatie.

Hoofdstuk 6 focust op de behandeling van hartfalen bij verpleeghuisbewoners. Zowel de voorgeschreven medicamenteuze behandeling als de niet- medicamenteuze behandeling van hartfalen bij verpleeghuisbewoners werden onderzocht. Daar er alleen een evidence-based medicamenteuze behandeling voor hartfalen met een verminderde ejectiefractie bestaat, werd deze groep apart geanalyseerd. De resultaten laten zien dat de door de richtlijnen ${ }^{1,2}$ aanbevolen medicamenteuze behandeling van hartfalen vaak niet wordt voorgeschreven en als deze wel wordt voorgeschreven is de dosis van de medicatie meestal ver beneden de geadviseerde dosis. Mogelijke verklaringen hiervoor zijn enerzijds het grotere risico voor verpleeghuisbewoners op nadelige medicatie effecten door polyfarmacie en bijkomende aandoeningen en anderzijds wordt afname van de mortaliteit als minder belangrijk beschouwd. Het verminderen van klachten veroorzaakt door hartfalen en het verbeteren van de kwaliteit van leven worden meer van belang geacht en deze doelen worden mogelijk al met een lagere dosering bereikt.

Daarnaast worden niet-medicamenteuze interventies, zoals vocht-, zoutbeperking en oefentherapie bijna helemaal niet ingezet. De voordelen van niet-medicamenteuze interventies zijn mogelijk onvoldoende onder de aandacht bij specialisten ouderengeneeskunde.

Het laatste hoofdstuk (hoofdstuk 7) betreft de algemene discussie en bevat een overzicht van de belangrijkste bevindingen zoals gepresenteerd in de voorgaande hoofdstukken van het proefschrift. Theoretische en methodologische beschouwingen aangaande de verrichte onderzoeken worden neergezet en tenslotte worden er aanbevelingen gegeven voor de dagelijkse praktijk en voor toekomstig onderzoek.

\section{REFERENTIES}

1. McMurray JJ, Adamopoulos S, Anker SD, et al. ESC Guidelines for the diagnosis and treatment of acute and chronic heart failure 2012: The Task Force for the Diagnosis and Treatment of Acute and Chronic Heart Failure 2012 of the European Society of Cardiology. Developed in collaboration with the Heart Failure Association (HFA) of the ESC. Eur Heart J 2012;33:1787-847.

2. Yancy CW, Jessup M, Bozkurt B et al. 2013 ACCF/AHA guideline for the management of heart failure: a report of the American College of Cardiology Foundation/American Heart Association Task Force on practice guidelines. Circulation 2013;128:e240-327. 



\section{Valorization Addendum}

In this chapter, the findings of this thesis on heart failure (HF) in nursing home residents and their societal value are addressed. Consecutively, the relevance of the problem of HF in nursing homes, the diagnosis of HF in nursing home residents and the findings regarding the treatment of HF in nursing home residents, respectively, are briefly described. Attention will also be paid to the significance of the participation of nursing home residents in research. This chapter ends with the description of the dissemination of results.

Currently, $17 \%$ of all inhabitants in the Netherlands are above the age of 65 . It is expected that this number will rise up to $26 \%$ in 2040 , due to the 'baby boom generation' of 1945-1970 and the higher survival rates due to developments in medical care and technology. The Dutch government encourages a policy of "aging in place", meaning that people live at home as long as possible, even if they get frail and disabled. However by aging, the risk of onset of diseases and limitations in performing activities of daily living is increasing.

When the need of care services is beyond the range of informal and formal regular home care services, admission to a nursing home is inevitable. Thereby, nursing home residents represent a specific group of older persons. These residents can be described as old and considerably disabled persons, with either progressive chronic somatic or psychogeriatric diseases, resulting in multimorbidity and polypharmacy.

The main focus of the care for these residents is not on the healing of these diseases, which often is not possible anymore, but on providing adequate care and symptom relief to add to the quality of the rest of their life.

Because of their heterogeneous clinical profile, they are often excluded from clinical and epidemiological studies, which makes it difficult to determine clear diagnostic and treatment strategies. That's why it is very important to get more insight in the presentation and course of chronic diseases in this target group of multimorbid nursing home residents, to derive adequate indications for diagnosis and treatment.

One of the main findings of this thesis is that research in nursing home residents is possible, if prepared very well and if adequate attention is paid to the aspect of communication with the residents themselves and/or their legal representatives. This even applies to residents with dementia, who nearly always are excluded from scientific studies by using the easy motive of "why bothering them....?" In the media and also in daily practice however, there are often discussions about the insufficiency of knowledge and the quality of care provided in nursing homes. Tailoring high quality care for both somatic and psychogeriatric nursing home residents, therefore, can bene- 
fit largely from studies done in the target group itself and this should be taken into account when developing future research programs in frail and disabled older persons.

We found that HF is very prevalent in nursing home residents and therefore a relevant problem in daily practice of nursing home care. Thereby, this thesis supports the assertation that improving knowledge and skills of the nursing home team, especially the nursing home physicians may contribute in offering proper care to residents with $\mathrm{HF}$, fitting in their needs and improving their quality of life. This study clearly reveals that it is important that nursing home physicians are trained well to adequately recognize, diagnose and treat HF in nursing home residents. This study showed that trained nursing home physicians are fairly capable to diagnose HF in nursing home residents by using available tools such as anamnesis, physical examination, laboratorial testing and electrocardiography. The training program used in this study can easily be incorporated in the postgraduate training program to become a nursing home physician.

For the nursing staff of the nursing home it is important to be trained in recognizing relevant signs and symptoms at an early stage and to subsequently inform the nursing home physician about their observations. The knowledge of relevant signs and symptoms of HF acquired in this study can be taken up in regular educational nursing programs.

In diagnosing HF, echocardiography must be recommended when there is doubt about the diagnosis or to determine the underlying cause of HF. Moreover, knowing left-ventricular ejection fraction may be relevant to apply proper treatment. Normally, residents have to visit the hospital or a specialized unit to undergo an echocardiography but in this study it appeared that echocardiography can be done easily in the nursing home itself by using a hand-held device. Because of the logistic problems and inconvenience that often are associated with ambulatory visits or admissions of nursing home residents to hospitals it can be advised strongly for nursing homes to arrange adequate collaboration with a neighboring hospital department of cardiology, to achieve a situation in which the total diagnostic process of HF including echocardiography can be performed in the nursing home itself. The residents will clearly benefit from this, as also will the collaborative approach of this relevant disease.

Looking to the treatment of $\mathrm{HF}$, the results of this thesis showed that there is incompliance to the current guidelines on $\mathrm{HF}$, regarding both the pharmacological and non-pharmacological treatment. As suggested this incompliance with the guidelines may be a conscious decision because the profile of nursing home residents is challenging to cope with in the traditional health care model which is mainly single disease oriented and based on disease specific guidelines, strongly promoting an evidence based approach that is based on large randomised controlled trials. This approach often causes fragmentation of care because it asks for homogeneous patient groups and not for multimorbid heterogeneous ones such as nursing home residents, who therefore are mostly excluded from these trials. 
It might be difficult, therefore, to apply guidelines that are not aligned with a target group, which is far beyond the single disease status. In addition, the currently available guidelines on treatment of HF may not be well applicable to very frail and disabled older persons with a profile of polypharmacy, due to the high chance of adverse drug reactions, side effects and significant interactions. This study stresses the need and necessity of specific guidelines for this target group of multimorbid patients. Therefore, future research on appropriate (non)-pharmacological treatment of HF in nursing home residents should get high priority to get more customized and tailored guidelines for very frail and disabled older persons, contributing to patient's safety and quality of life.

\section{DISSEMINATION}

Next to the scientific value of this thesis, of which all chapters have been published in international scientific journals, the results of this thesis also have concrete societal value. In addition to relevant aspects already mentioned above, they may be used to raise awareness of the problem of HF in nursing homes; e.g. the manuscript about the prevalence of HF has been published also in a Dutch journal (Nederlands Tijdschrift voor Geneeskunde) entitled as Heart failure in nursing home residents; a difficult diagnosis?, to reach the largest part of the target group of Dutch nursing home physicians and hospital geriatricians. This awareness will be further raised by presentations on congresses.

Second, the results of this thesis can and will be used in the development and provision of educational training programs for nursing home physicians and nursing staff.

Third, the results of this thesis will actually be used during the updating of the current Dutch guideline on HF.

Finally, the approach used in this thesis can be applied also to do more in-depth research on other relevant diseases in nursing home residents, but also on other HF populations not yet well studied. 



\section{Dankwoord}

\section{Het was een missie en de missie is voltooid.}

Dit had ik nooit kunnen bereiken zonder de hulp van velen.

Allereerst dank aan de bewoners van de verpleeghuizen die bereid waren om deel te nemen aan het onderzoek. Zonder hen was dit proefschrift nooit tot stand gekomen.

Dank ook aan alle medewerkers van de betrokken zorgorganisaties (Envida, Sevagram, MeanderGroep, Zuyderland en Cicero Zorggroep) voor jullie medewerking, behulpzaamheid en gastvrijheid.

Het begon ooit tijdens de introductiedagen van de opleiding tot specialist ouderengeneeskunde. In september 1998 tekende ik op mijn schild de wens om ooit een proefschrift af te leveren. In 2006 was de eerste afspraak met Jos Schols.....

Een woord van dank gaat uit naar mijn begeleiders gedurende de afgelopen jaren voor de begeleiding en misschien nog wel meer voor het vertrouwen dat ze in mij gesteld hebben om dit resultaat te kunnen bereiken.

Beste Jos, jij was gedurende al die jaren steeds gedreven en altijd bereid om me weer op weg te helpen. Als ik niet binnen 1 dag een antwoord kreeg op mijn mail, dan wist ik dat er iets mis gegaan was met het verzenden.

Beste Jan, jij volgde altijd trouw de stappen die nodig waren om goed onderzoek af te leveren en leerde me dat kijken als onderzoeker iets anders is dan kijken als dokter.

Beste Ton, als eerste cardioloog betrokken bij het onderzoek. Ik zal je enthousiasme voor mijn onderzoek niet gauw vergeten. Ondanks je drukke werkzaamheden, was je op de momenten waar dat nodig was zeer betrokken bij het onderzoek. Later zorgde jij ervoor dat Hans- Peter betrokken werd bij het onderzoek.

Beste Hans -Peter wat heb ik nog veel van je kunnen leren over hartfalen. Jij was naast een bron van inspiratie ook iemand die heel pragmatisch kon meedenken bij beslissingen die genomen moesten worden.

Beste Frans, als statisticus betrokken bij de begeleidingsgroep. Wat had jij een geduld om een dokter met een zeer beperkte statistische achtergrond steeds opnieuw uit te leggen waarom er vanuit de statistiek gezien andere waarheden gelden dan in het dagelijks werk van de specialist ouderengeneeskunde.

Beste Marja, je was korte tijd betrokken bij het onderzoek, maar je bereidheid om je steentje bij te dragen was hartverwarmend. 
Graag wil ik de leden van de beoordelingscommissie, Prof. dr. MGA oude Egbrink, Prof. dr. J Gussekloo, Prof. dr. CMPM Hertogh, Dr. BL Kietselaer en Dr. SMG Zwakhalen hartelijk danken voor het lezen en beoordelen van dit proefschrift.

Elles en Miriam: Eén ding weet ik zeker. Dit was zeker niet gelukt zonder jullie hulp. Jullie waren twee enthousiaste onderzoeksassistenten. Samen vormden we een geweldig team en hebben we een leuke tijd gehad. Dank hiervoor.

De collega's van de vakgroep HSR wil ik graag bedanken voor de fijne contacten en de bereidheid om me te helpen als ik het even niet meer wist.

Ook dank aan al mijn directe collega's, eerst bij Meander en later bij Cicero, die altijd met interesse mijn vorderingen gevolgd hebben. Ik ben dankbaar voor de ruimte die ik binnen Cicero Zorggroep kreeg om mijn promotieonderzoek te kunnen voltooien.

Gelukkig had ik, de afgelopen jaren veel lieve vrienden om me heen die er voor zorgden dat ik naast werk en promoveren nog tijd vrij kon maken voor sociale activiteiten.

Mijn "kookclubje" zorgde ervoor dat ik regelmatig even kon "afschakelen".

Raymond en Ingrid, wat heb ik genoten van onze zondagse wandelingen de afgelopen jaren met onze viervoeters Chica en Trix. Ik hoop dat er nog vele zullen volgen. Ingrid, jij zorgde er mede voor dat mijn lichamelijke conditie goed op peil bleef. Behalve onze beenspieren, werden ook onze kaakspieren goed getraind tijdens het hardlopen.

Marlie, Jenny†, Stella en Yvonne. Onze "nichtenuitjes" waren altijd heel bijzonder. We hebben heel wat afgelachen en na een dagje met jullie was ik weer volledig op de hoogte van alle nieuwtjes. Jenny wat was het fijn geweest als jij er nog bij had kunnen zijn.

Hans, Stella, Maartje, Chantal en Janneke, onze hechte familieband is bijzonder en me zeer dierbaar. Ik hoop dan ook dat we nog vele gezellige momenten samen kunnen delen. Stella, je bent een schoonzus uit duizenden. Doordat je zelf op latere leeftijd je studie psychologie afgerond hebt en daarna in de functie van onderzoeksassistente veel promovendi naast je hebt gehad, wist jij als geen ander wat een promotieonderzoek betekent en steunde je me op de juiste momenten.

Pap en mamt, op jullie manier waren jullie trots op wat ik deed. Mam, helaas ben je vandaag niet meer bij de verdediging van mijn proefschrift. Ik heb je gelukkig wel nog kunnen vertellen dat het manuscript goed gekeurd was.

Tot slot dank aan mijn gezin. Jullie zijn het zwaarst getroffen door mijn missie. Ruben en Thom, ik weet dat jullie me enorm gestoord vinden, omdat ik zoveel van mijn vrije 
tijd besteedde aan een promotieonderzoek naast mijn baan. Ik ben benieuwd hoe jullie toekomst eruit gaat zien.

Rachel, als student geneeskunde, treed jij langzaam in mijn voetsporen. Je hebt de ECG data opnieuw in kaart gebracht en mijn wens zou dan ook zijn om samen met jou nog een artikel te schrijven.

Anton, jij staat het dichtst bij me. Je gaf me de ruimte en floot me terug. Je begreep het, maar soms ook niet. En viteindelijk is het goed gekomen en is het proefschrift af. Niet alleen door mijn inzet, maar ook jij hebt ervoor gezorgd dat ik deze missie kon voltooien. Dank je wel! 



\section{About the author}

Mariëlle Daamen was born in Brunssum, the Netherlands, on the $7^{\text {th }}$ of April 1967. After graduating from secondary school (atheneum) at St. Janscollege in Hoensbroek, she started her medical study at Maastricht University. Mariëlle obtained her medical degree in 1991. From 1991 to 1993 she worked on an emergency ward and as physician of cardiology at Zuyderland Hospital (former Hospital Gregorius de Grote in Brunssum and De Wever hospital in Heerlen). In 1993 she began working as a physician in the MeanderGroep a nursing home organization in Kerkrade. From 1998 to 2000 she specialized in elderly care medicine at Leiden University Medical Center. In 2006 she took the initial steps to start her PhD traject at Maastricht University. Her $\mathrm{PhD}$ study focused on heart failure in nursing home residents and was performed at the Research school CAPHRI, in the department of Health Services Research, in collaboration with the Department of cardiology and the Department of Clinical Chemistry of Maastricht University Medical Center.

Since 2009 she works as an elderly care physician (former nursing home physician) at Cicero Zorggroep in Brunssum and is responsible for the daily medical care of nursing home residents. In Cicero Zorggroep, together with two colleagues, she acts as a representative of the internal department of elderly care medicine.

Mariëlle lives in Merkelbeek together with her husband Anton van der Velden and they have one daughter (Rachel 1995) and two sons (Ruben 1999 and Thom 2001). 



\section{Publications}

- Daamen AMJ, Brunner-la Rocca HP, Tan FES, Hamers JPH, Schols JMGA. Diagnosis of heart failure in nursing home residents: Do we need a cardiologist? Submitted

- Mariëlle A.M.J. Daamen, Jan P.H. Hamers, Hans-Peter Brunner-la Rocca, Jos M.G.A. Schols. Hartfalen bij verpleeghuisbewoners; Een moeilijke diagnose. Ned Tijdschr Geneeskd. 2016;160:D390

- Daamen MA, Hamers JP, Gorgels AP, Tan FE, Schols JM, Brunner-la Rocca HP. Treatment of heart failure in nursing home residents. J Geriatr Cardiol. 2016 Jan;13(1):44-50

- Daamen MA, Hamers JP, Gorgels AP, Brunner-La Rocca HP, Tan FE, van Dieijen-Visser MP, Schols JM. Heart failure in nursing home residents; a crosssectional study to determine the prevalence and clinical characteristics. BMC Geriatr. 2015 Dec 16;15:167

- Cardinaels EP, Daamen MA, Bekers O, ten Kate J, Niens M, van Suijlen JD, van Dieijen-Visser MP, Brunner-La Rocca HP, Schols JM, Mingels AM. Clinical Interpretation of Elevated Concentrations of Cardiac Troponin T, but Not Troponin I, in Nursing Home Residents. J Am Med Dir Assoc. 2015 Oct 1;16(10):884-91

- Daamen MA, Hamers JP, Gorgels AP, Brunner-la Rocca HP, Tan FE, van Dieijen-Visser MP, Schols JM. The prevalence and management of heart failure in Dutch nursing homes; design of a multi-centre cross-sectional study. BMC Geriatr. 2012 Jun 11;12:29.

- Mariëlle A.M.J. Daamen, Jos M.G.A. Schols, Tiny Jaarsma, Jan P.H. Hamers. De prevalentie van hartfalen in verpleeghuizen; een systematisch literatuuronderzoek. Tijdschrift voor ouderengeneeskunde 2010(4):131-36

- Daamen MA, Schols JM, Jaarsma T, Hamers JP. Prevalence of heart failure in nursing homes: a systematic literature review. Scand J Caring Sci. 2010 Mar;24(1):202-8. 